\title{
PROPRIEDADES ELÉTRICAS DE DISPOSITIVOS EMISSORES DE LUZ UTILIZANDO ÓXIDO DE ZINCO COMO ELETRODO TRANSPARENTE
}

Edivaldo Leal Queiróz

Dissertação apresentada ao Instituto de Física de São Carlos, da Universidade de São Paulo, para a obtenção do título de Mestre em Ciências: Física Aplicada

ORIENTADOR: Prof. Dr. Roberto Mendonça Faria

São Carlos - 2004 
Queiróz, Edivaldo Leal

"Propriedades elétricas de dispositivos emissores de luz utilizando óxido de zinco como eletrodo transparente"

Edivaldo Leal Queiróz - São Carlos, 2004

Dissertação (Mestrado) - Instituto de Física de São Carlos, 2004Paginas: 84

Orientador: Prof. Dr. Roberto Mendonça Faria

1.Dispositivos poliméricos.; Condutividade; Eficiência

I. Título 
Dedico esta dissertação aos meus pais, a minha irmã, a minha esposa Rosiela e ao meu filho Gabriel, pois, sem estas pessoas nada teria sentido. 


\section{Agradecimentos}

- Ao prof. Dr. Roberto Mendonça Faria pela orientação e apoio.

- Aos meus pais Antonia e Faustino e a minha irmã Meire pelo amor e carinho.

- A minha esposa Rosiela e ao meu filho Gabriel pelo amor, carinho e paciência nos momentos difíceis.

- Aos técnicos Níbio, Berto e Ademir e a secretaria Rosângela pelos serviços prestados

- Ao prof. Dr. Rodrigo Fernando Bianchi pelo apoio, amizade e pelas inúmeras discussões e ensinamentos, que foram fundamentais para o desenvolvimento desse trabalho.

- Aos professores do departamento de física da UFPI, em especial aos professores Helder e Pimentel pelo enorme incentivo.

- Aos amigos Mauricio e Milene, Rodrigo (Guidoval), Letícia, Vicente e Deuzuita, Carla Eiras, Fábio, Miguel e Lu, Rafael, Silmar, Xuxa, Felipe (tubinho), Thiago Cazati, Célio Borges e Raquel, Fernando Castro, Clarissa pela ótima convivência dentro e fora do ambiente de trabalho.

- Ao Lucas pela ajuda no laboratório de medidas elétricas.

- A todos os professores do Grupo de Polímeros.

- A capes pelo apoio financeiro. 


\section{SUMÁRIO}

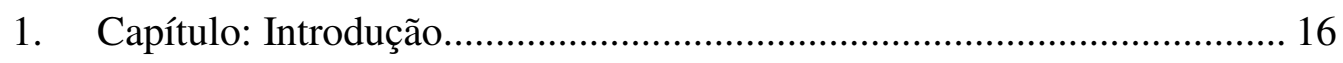

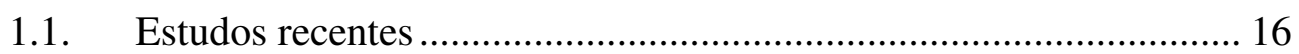

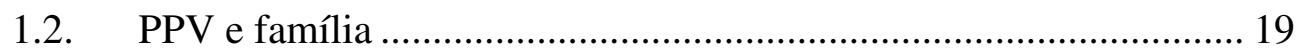

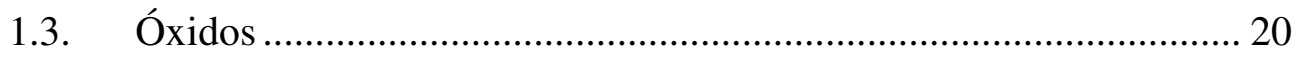

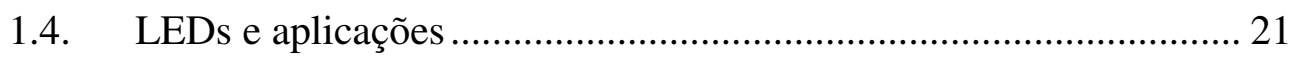

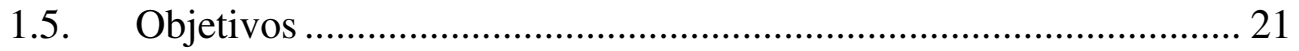

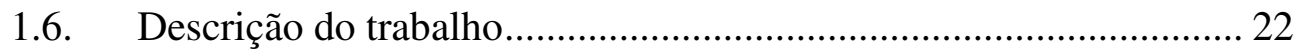

2. Capítulo: Polímeros conjugados .......................................................... 23

2.1. Poliacetileno - protótipo de polímeros condutores......................... 23

2.2. Propriedades eletrônicas de polímeros conjugados.......................... 25

3. Capítulo: Preparação de dispositivos emissores de luz poliméricos........ 28

3.1. Construção de um PLED .............................................................. 28

3.2. Confecção dos eletrodos transparentes ............................................. 30

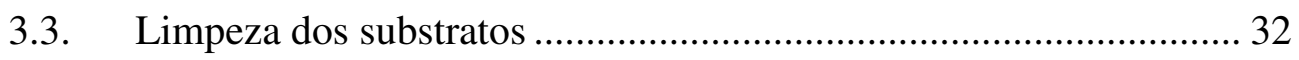

3.4. Preparação dos filmes ............................................................... 33

3.5. Obtenção de filmes de MEH-PPV ................................................. 35

3.6. Preparação dos eletrodos metálicos .............................................. 36

4. Capítulo:Equipamentos e Métodos de medidas ..................................... 39

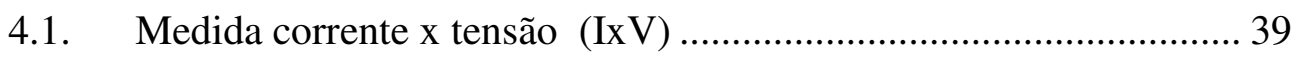

4.2. Medida de condutividade em campo alternado (AC) ..................... 39

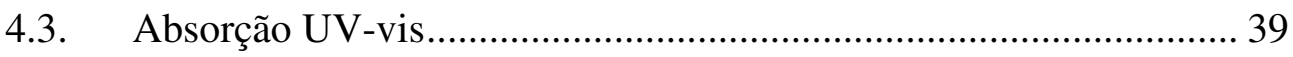

4.4. Medida com temperatura................................................................. 40

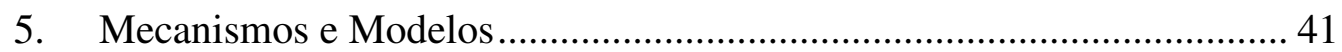


5.1. Injeção - Schottky e Fowler-Nordeheim ......................................... 41

5.2. Modelo de circuitos equivalentes ............................................. 42

5.3. Modelo de Dyre.............................................................................. 44

6. Capítulo:Resultados e discussões....................................................... 48

6.1. Caracterização do óxido de zinco $(\mathrm{ZnO})$...................................... 48

6.2. Medidas elétricas com filme de óxido de zinco $(\mathrm{ZnO})$................... 49

6.3. Medidas de corrente vs. tensão (I vs.V) de PLEDs com I-ZnO....... 54

6.4. Medidas Complexas do dispositivo I-ZnO/MEH-PPV/Al............... 57

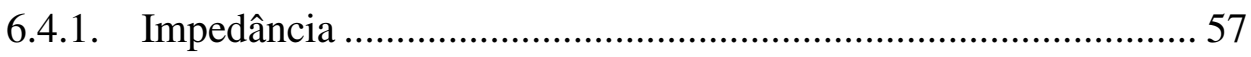

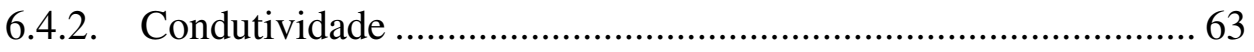

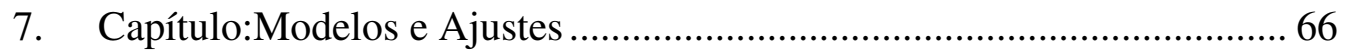

7.1. Modelo para análise das curvas obtidas do PLED .......................... 66

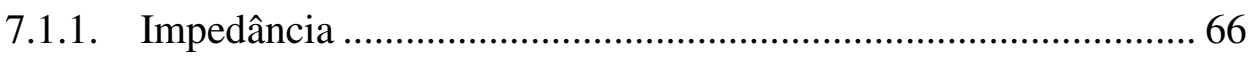

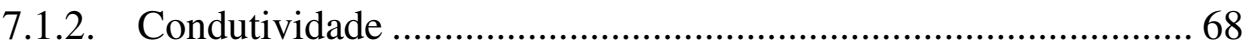

7.2. Modelo para análise das curvas obtidas do filme de $\mathrm{ZnO}$.............. 69

8. Discussões dos parâmetros..................................................................... 71

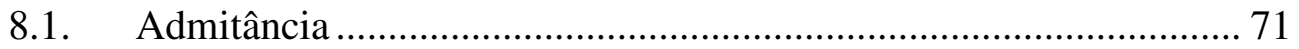

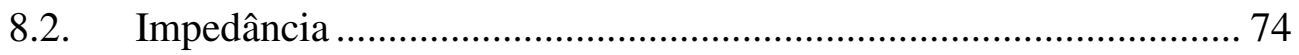

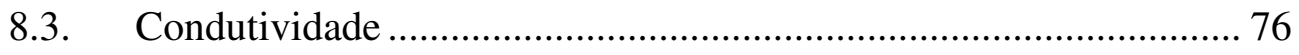

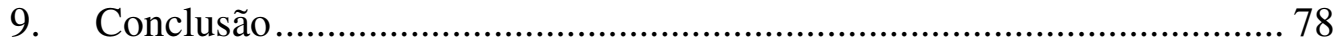

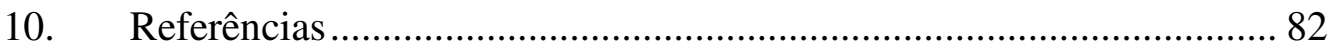




\section{LISTA DE FIGURAS}

Figura 1.1: Estrutura química do poli(2-metoxi-5-(2'-etil-hexiloxi)-1,4-fenileno vinileno) MEH-PPV

Figura 1.2: Circuito integrado e display policromático à base de polímeros. Fontes Phillips e Cambridge Display Technology.

Figura 2.1 a) Estrutura do trans-poliacetileno; b) Estrutura degenerada do transpoliacetileno. As seqüências de ligações A e B possuem a mesma energia.

Figura 2.2: Representação de um sóliton no trans-poliacetileno; $\mathrm{S}^{0}$ sóliton neutro, $\mathrm{S}^{+}$ sóliton positivamente carregado e $\mathrm{S}^{-}$sóliton negativamente carregado.

Figura 2.3: Representação dos orbitais $\pi$ (em vermelho) e orbitais $\sigma$ (em azul)........ 25

Figura 2.4: Estrutura não degenerada do cis-poliacetileno ${ }^{25}$. 26

Figura 2.5: Pólaron, bipólaron e éxciton singleto para polímeros com estado fundamental não-degenerado. 26

Figura 2.6: Espectro de emissão e absorção entre estados eletrônicos $\mathbf{S}_{\mathbf{0}}$ e $\mathbf{S}_{\mathbf{1}}$.

Figura 3.1: Estrutura típica de um dispositivo emissor de luz polimérico. A figura ilustra a camada polimérica entre os eletrodos metálicos e o eletrodo transparente depositados sobre um substrato de vidro. 28

Figura 3.2: Diagrama de energias (função trabalho, HOMO - highest occupied molecular orbital e LUMO - lowest unoccupied molecular orbital) entre o ITO, ZnO, MEH-PPV e alumínio como eletrodo metálico ${ }^{7}$.

Figura 3.3: Óxido de zinco sobre substrato de quartzo ou vidro e eletrodos de alumino.(a) visão frontal (b) visão lateral

Figura 3.4: Etapas do processo de decapagem. Etapa 1: proteção das regiões de óxido com geometria desejada, no caso, trilhas. Etapa 2: retirada das regiões não protegidas com suspensão de zinco e ácido clorídrico. Etapa 3: remoção da tinta protetora com acetona em ebulição.

Figura 3.5: Equipamentos usados para a obtenção de filmes poliméricos pelos métodos casting e spin coating. (a) Casting (b-1) Aparato giratório (b-2) Substrato onde será depositado o polímero (b-3) Deposição do polímero (b-4) Solução polimérica sobre o substrato (b-5) Aparato girando para expelir o excesso de solução (b-6) filme fino. . 35

Figura 3.6: (a) Etapas do processo de construção das máscaras utilizadas na metalização. Etapa 1: impressão das trilhas em papel tipo Glossy Etapa 2: transferência para a placa de cobre. Etapa 3: corrosão e retirada da tinta com acetona. 
Figura 3.7: Dessecador à vácuo adaptado para a realização de medidas elétricas com controle de umidade e pressão.

Figura 5.1: Representação do modelo de circuitos equivalentes e a representação em termos de impedância.

Figura 5.2: Comportamento da componente real da condutividade complexa no modelo de barreiras de energias livres aleatórias (RFEB).

Figura 6.1: Medidas de absorção óptica em filmes de $\mathrm{IZnO}$ e $\mathrm{ZnO}$ não dopado. Para comparação, uma medida com ITO é apresentada..

Figura 6.2: Variação da condutividade em filmes de óxido de zinco não dopado 50

Figura 6.3: Medidas de impedância ac de um filme de $\mathrm{ZnO}$ em diferentes temperaturas (a) Filme menos condutivo e (b) Filme mais condutivo.

Figura 6.4 Componentes real e imaginária de medidas de impedância.(a)Antes de iluminar e (b) Após iluminar durante 20 minutos. As linhas contínuas representam os ajustes teóricos.

Figura 6.5: Gráficos Z" vs. Z' das medidas apresentadas na figura 6.3.(a) Antes de iluminar e (b) Após iluminar durante 20 minutos e (c) Após expor a amostra durante 8 horas em atmosfera de ozônio

Figura 6.6: Curva densidade de corrente vs. tensão para dispositivos I-ZnO/MEHPPV/Al. A espessura do polímero é $\sim 400 \mathrm{~nm}$ e área dos eletrodos $\sim 4 \mathrm{~mm}^{2}$. Medida realizada em temperatura ambiente sob vácuo e no escuro.

Figura 6.7: Curva IxV de um dispositivo I-ZnO/MEH-PPV/Al em diferentes temperaturas. (a) Em escala linear e (b) Em escala mono-logaritmica. 56

Figura 6.8: Componente real $Z^{\prime}(\boldsymbol{\square})$ e imaginaria $Z^{\prime \prime}(\bullet)$ em função da freqüência do campo elétrico oscilante do dispositivo $\mathrm{ZnO} / \mathrm{MEH}-\mathrm{PPV} / \mathrm{Al}$. 58

Figura 6.9: Medidas de Impedância Complexa em dispositivo ZnO/MEH-PPV/Al realizadas num intervalo de temperatura de 175 a $300 \mathrm{~K}$ de 25 em $25 \mathrm{~K}$

Figura 6.10 (a) Componente real (Z') e (b) Componente imaginária (Z”) de medidas de impedância complexa em um dispositivo $\mathrm{ZnO/MEH-PPV/A1.}$

Figura 6.11: (a) Gráficos Z" vs Z'. das medidas de impedância em diferentes temperaturas. (b) e (c) Ampliação da parte circulada para melhor visualização. As linhas contínuas são os ajustes teóricos.

Figura 6.12: Medidas de impedância realizadas variando a tensão de polarização e mantendo a temperatura fixa em $300 \mathrm{~K}$ : (a) $\mathrm{V}_{\text {bias }}=15 \mathrm{~V}$; (b) $\mathrm{V}_{\text {bias }}=30 \mathrm{~V}$; (c) $\mathrm{V}_{\text {bias }}=40$ V; (d) Componente real da impedância em diversas tensões.

Figura 6.13: Componentes real, $\sigma$ '(f), e imaginária, $\sigma$ '(f), obtidas de amostras ZnO/MEH-PPV/Al nas temperaturas (a) $300 \mathrm{~K}$, (b) $275 \mathrm{~K}$, (c) $250 \mathrm{~K}$, (d) $225 \mathrm{~K}$, (e) 
$200 \mathrm{~K}$ e (f) $175 \mathrm{~K}$ (g) Componente real nas diversas temperaturas. As linhas continuas (-) são os ajustes obtidos com a equação 5 do item 7.3. .

Figura 7.1: Representação do circuito equivalente utilizado para representar o sistema $\mathrm{ZnO} / \mathrm{MEH}-\mathrm{PPV} / \mathrm{Al} .$. 66

Figura 7.2: Resistência de contato do eletrodo transparente $\mathrm{ZnO}$ associada em série com o modelo microscópico de condução RFEB. 68

Figura 7.3: Associação em serie do modelo microscópico de condução RFEB representando o volume dos grãos e a interface entre grãos.

Figura 8.1: Modelo esquemático da microestrutura e correspondente bandas de energia de um óxido semicondutor.

Figura 8.2: Curvas de admitância apresentando os ajustes teóricos através da equação (6) do item 7.2. 72

Figura 8.3: Processos ativados por Arrhenius $\sigma_{d c}=\sigma_{0} e^{-E_{a} / k T} \mathrm{e} \gamma_{\min }=\gamma_{0} \mathrm{e}^{-\mathrm{E}_{\mathrm{a}} / \mathrm{kT}} \cdot \mathrm{E}_{\mathrm{a}} \mathrm{e}$ a energia de ativação térmica. 


\section{Lista de Tabelas}

Tabela 8.I: Valores obtidos dos ajustes das curvas de medidas do filme de $\mathrm{ZnO}$ não dopado através da equação (6) do item 7.2.

Tabela 8.II: Parâmetros obtidos com os ajustes teórico-experimentais variando temperatura e mantendo bias fixa em $15 \mathrm{~V}$ de medidas realizadas em amostra I$\mathrm{ZnO/MEH-PPV/Al} \mathrm{através} \mathrm{da} \mathrm{equação} \mathrm{(7.4)}$

Tabela 8.III: Parâmetros obtidos com os ajustes teórico-experimentais variando bias e mantendo temperatura fixa.

Tabela 8.IV: Parâmetros obtidos com os ajustes teórico-experimentais, variando-se temperatura e mantendo-se tensão offset igual a $15 \mathrm{~V}$ e AC $1 \mathrm{~V}$. 


\section{Lista de Abreviaturas}

MEH-PPV

$\mathrm{ZnO}$

$\mathrm{I}-\mathrm{ZnO}$

$\mathrm{ZnO} / \mathrm{MEH}-\mathrm{PPVAl}$

PPV

ITO

PLED

UV-VIS

RFEB

aleatórias)

EL

FN

RS

SCLC poli(2-metoxi-5-(2'-etil-hexiloxi)-1,4-fenileno vinileno)

Óxido de Zinco

Óxido de Zinco dopado com índio

Dispositivo com filme de MEH-PPV entre eletrodos de $\mathrm{ZnO}$ e Al

Poli(p-fenilenovinileno)

Indium-tin oxide (óxido de estenho e índio)

Polymer light-emitting diode (diodo emissor de luz polimérico)

Ultraviolet-Visible

Random free energy barrier model (modelo de energias livres

Eletroluminescência

Fowler-Nordheim

Richardson-Schottky

Space Charge Limit Current (corrente limitada por carga espacial) 


\section{Lista de Símbolos}

\begin{tabular}{|c|c|}
\hline $\mathrm{S}^{0}$ & Sóliton neutro \\
\hline $\mathrm{S}^{+}, \mathrm{S}^{-}$ & Sóliton positiva e negativamente carregado \\
\hline $\mathrm{P}^{+}, \mathrm{P}^{-}$ & Pólaron positivo e negativo \\
\hline $\mathrm{BP}^{+}, \mathrm{BP}^{-}$ & BiPolaron positivo e negativo \\
\hline $\mathrm{IxV}$ & Curva corrente versus tensão \\
\hline $\mathrm{V}_{0}$ & Tensão de operação \\
\hline $\mathrm{Z}^{*}$ & Impedância complexa ( $Z^{*}=Z^{\prime}+$ iZ”) \\
\hline $\mathrm{V}_{\mathrm{ac}}$ & Amplitude da tensão oscilante \\
\hline$V_{\text {bias }}$ & Tensão de polarização \\
\hline $\mathrm{R}_{\mathrm{MEH}}$ & Resistência do filme de MEH-PPV \\
\hline $\mathrm{R}_{\mathrm{ZnO}}$ & Resistência do $\mathrm{ZnO}$ \\
\hline $\mathrm{C}_{\mathrm{MEH}}$ & Capacitância do filme de MEH-PPV \\
\hline $\mathrm{Z}_{\mathrm{R}}$ & Impedância do contato \\
\hline $\mathrm{Z}_{\mathrm{RC}}$ & Impedância do circuito RC \\
\hline$\varepsilon, \rho_{\mathrm{MEH}}$ & Constante dielétrica e resistividade da camada polimérica \\
\hline $\begin{array}{l}\text { A } \\
\text { paralelas }\end{array}$ & Área efetiva dos eletrodos de uma amostra de placas planas \\
\hline$\ell_{\mathrm{MEH}}$ & Espessura do filme polimérico \\
\hline$\sigma^{*}$ & Condutividade complexa $\left(\sigma^{*}=\sigma^{\prime}+i \sigma^{\prime \prime}\right)$ \\
\hline$\sigma_{\mathrm{dc}}$ & Condutividade dc \\
\hline $\mathrm{f}$ & Freqüência \\
\hline$f_{c}$ & Freqüência crítica \\
\hline
\end{tabular}


E

$\mathrm{E}_{\text {máx }}$

$\mathrm{E}_{\text {min }}$

$\gamma_{\text {máx }}$

$\gamma_{\text {mín }}$

$\mathrm{T}$
Energia

Energia de salto máxima

Energia de salto mínima

Freqüência de salto máxima

Freqüência de salto mínima

Temperatura 


\section{RESUMO}

Neste trabalho medidas de condutividade alternada e de corrente versus tensão foram realizadas em dispositivos emissores de luz baseados em poli(2-metoxi-5-(2'etil-hexiloxi)-1,4-fenileno vinileno)-MEH-PPV com óxido de zinco ( $\mathrm{ZnO}$ ) como eletrodo transparente e injetor de buracos e alumínio (Al) como eletrodo metálico e injetor de elétrons. MEH-PPV é um derivado do PPV que emite no vermelho. O ZnO tem função trabalho similar à do ITO, mas é menos agressivo ao polímero, menos caro e mais fácil de ser processado. A curva I vs. V retificada mostrou que a corrente direta depende da temperatura. As componentes real e imaginária da condutividade (ac) apresentam comportamento típico de alguns materiais desordenados: a componente imaginária aumenta como função da freqüência e a componente real mostrou-se independente da freqüência para baixas frequiências e varia como uma lei de potência no domínio de frequiências mais altas $\mathrm{O}$ modelo de barreira de energias livres aleatórias-RFEB e uma resistência em série para o fenômeno de interface foram desenvolvidos e ajustados para os resultados ac. Com base neste ajuste teóricoexperimental, obtemos importantes parâmetros do dispositivo, bem como informações quantitativas sobre o fenômeno de transporte no MEH-PPV 


\begin{abstract}
In this work current $v s$. voltage (I vs. V) and alternating conductivity (ac) measurements were carried out in poly[(2-methoxy- 5-hexyloxy)-pphenylenevinilene] - MEH-PPV light-emitting diodes having zinc oxide $(\mathrm{ZnO})$ as transparent anode and $\mathrm{Al}$ as metallic cathode. MEH-PPV is a PPV derivative, which emits in the red spectral region; $\mathrm{ZnO}$ has a work function similar to that of ITO, but it is less aggressive to the polymer, less expensive and easily processed. The retificated I vs. V curves shows that the direct current depends on the temperature. Moreover, the real and imaginary components of alternating conductivity (ac) present typical behavior of somewhat disordered material: the imaginary component grows as a function of the frequency and the real component was observed to be frequencyindependent for lower frequencies, and follows a power-law above a certain frequency. The Random Energy Free Barrier model approaches and a resistance in series for the interface phenomenon were developed and adjusted for the ac results. From this experimental-theoretical fitting we obtained important parameters of the devices as well as, quantitative informations about the MEH-PPV transport phenomenon.
\end{abstract}




\section{Capítulo: Introdução}

Até fins dos anos 60, as aplicações dos materiais poliméricos na área elétrica e eletrônica se resumia ao papel coadjuvante de isoladores. Este quadro começou a mudar após a descoberta ${ }^{1}$ de que a condutividade elétrica de polímeros conjugados poderia ser variada, partindo de um bom isolante e atingindo condutividade metálica. Desde então a ciência de polímeros eletricamente condutivos tem se desenvolvido rapidamente e alcançado notório destaque na área de dispositivos eletrônicos, principalmente em diodos, transistores e células fotovoltaicas. ${ }^{2}$ Em 1990, o leque de aplicações desses materiais se estendeu aos dispositivos emissores de luz, a partir da descoberta da eletroluminescência do poli( $p$-fenilenovinileno) - $\mathrm{PPV}^{3}$. Desde então, foram intensificados os interesses na pesquisa de materiais poliméricos que apresentassem propriedades isolantes, semicondutoras ou metálicas.

\subsection{Estudos recentes}

Visando otimizar o desempenho óptico e elétrico dos diversos dispositivos poliméricos emissores de luz atualmente existentes, muitas pesquisas vêm sendo realizadas procurando compreender os mecanismos responsáveis pela eficiência e pelo tempo de vida dos mesmos ${ }^{4}$. Dentro deste contexto, os fenômenos relacionados à injeção de portadores de carga nas interfaces eletrodo-polímero e o transporte destes portadores nas camadas poliméricas têm sido objeto de grande interesse, pois estes mecanismos determinam não somente as propriedades elétricas dos dispositivos ${ }^{5,6}$, tais como os níveis de corrente, mas também a sua eficiência luminosa e/ou seu comportamento com a tensão aplicada ${ }^{5,6,7}$. Devido à importância destes mecanismos 
para a otimização do desempenho destes sistemas, há na literatura um número muito grande de artigos focados no estudo do comportamento das propriedades elétricas dos dispositivos poliméricos, sobretudo dos dispositivos eletroluminescentes. Entretanto, no decorrer das pesquisas realizadas, há ainda vários pontos a serem destacados e mencionados, pois há inúmeras controvérsias que ainda persistem. Um breve histórico sobre a evolução da pesquisa científica nesta área é apresentado a seguir.

O estudo e a investigação das propriedades elétricas de dispositivos emissores de luz poliméricos deu-se logo após as descobertas da eletroluminescência do PPV em $1990^{3}$. O primeiro artigo a explorar tal tema foi publicado em 1991, por D. Braun e A. J. Heeger ${ }^{8}$, sobre a correlação entre as propriedades de emissão de diodos emissores de luz de poli(2-metoxi-5-(2'-etil-hexiloxi)-1,4-fenileno vinileno) - MEH-PPV, em estruturas simples do tipo ITO/MEH-PPV/Al, com os mecanismos de injeção de portadores de carga nas interfaces MEH-PPV/Al e MEH-PPV/ITO (ITO: indium tin oxide). Como resultado dos seus estudos eles observaram que o comportamento e os valores da corrente elétrica dos dispositivos como função da tensão aplicada não dependia da temperatura, deixando claro que a corrente era controlada, principalmente, por mecanismos de injeção por tunelamento nas interfaces polímeroAl obedecendo ao modelo de Fowler-Nordheim ${ }^{9}$. A afirmação de Braun e Heeger foi fortalecido através dos resultados de Parker ${ }^{9}$ em 1994. Porém, em 1995, Bässler e coautores $^{10}$, rebateram as afirmações levantadas por Heeger, Braun e Parker, mostrando que a corrente elétrica destes dispositivos era, na verdade, controlada pelo mecanismo de injeção Fowler-Nordheim apenas em regimes de altos campos, sendo, para baixos campos, controlada pelo mecanismo de emissão termiônica de Richardson-Schottky $(\mathrm{RS})^{11,12}$ onde haveria uma forte dependência da corrente com a temperatura. Ainda em 1995 Abkowitz ${ }^{13}$ contraria todas estas idéias atribuindo o comportamento da 
curva I vs. V à um mecanismos de injeção típico de saltos (hopping) de portadores na interface eletrodo-polímero. Um ano mais tarde, uma nova suposição é levantada. Blom e colaboradores ${ }^{14}$ observaram que a corrente era determinada pelas propriedades do volume do polímero e não pelas propriedades de injeção, como era amplamente divulgado pelos outros autores ${ }^{9,10,11}$. Segundo eles, a dependência quadrática da densidade de corrente com a voltagem aplicada, revelava que a corrente era limitada pelo mecanismo de corrente limitada por carga espacial (SCLC-Space Charge Limit Current ${ }^{15}$. Para corroborar esta afirmação, os autores mostram que a corrente predita pela teoria de Fowler-Nordheim excederia em muitas ordens de grandeza o valor da corrente observada experimentalmente, o que não estaria de acordo com os modelos propostos até o momento. Tal suposição de que a aplicação da teoria de FowlerNordheim deveria ser revista para o caso dos polímeros, foi levada adiante pelos estudos de E. Cowell ${ }^{16}$, que indicou a discrepância da teoria de Fowler-Nordheim usada por Heeger (1993) e por Parker (1994), pois ela não se aplicaria aos polímeros conjugados devido ao pequeno comprimento de conjugação das suas cadeias poliméricas e, que a curva $\mathrm{IxV}$ concordaria bem com o efeito de corrente limitada por carga especial. Em contrapartida, no mesmo ano, Blom ${ }^{17}$ observando a dependência com a espessura do dispositivo da curva de corrente vs. tensão no regime de baixos campos, afirma que os efeitos de carga espacial produzem uma boa descrição, porém um desvio apresentado em altas voltagens foi associado à mobilidade dependente do campo

Em 1998, usando modelos baseados nas características desordenadas dos sistemas poliméricos, Arkhipov e colaboradores ${ }^{18}$ apresentam um modelo para a injeção baseada em saltos aleatórios para sítios energeticamente distribuídos numa gaussiana próximos à interface eletrodo/polímero. Nesse caso, depois de injetado em 
um desses sítios, os portadores podem retornar ao eletrodo (potencial imagem) ou escapar (saltar) para sítios mais distantes da interface (difusão). O modelo de tunelamento FN, segundo os autores, não é adequado, pois, as correntes obtidas são ordens de grandeza menores que a prevista por Fowler-Nordheim. Scott e Malliaras ${ }^{19}$, em 1999, encontraram uma expressão para a corrente total injetada, levando-se em conta o efeito de carga-imagem e a diminuição da barreira Schottky tanto pelo potencial imagem quanto pelo campo elétrico aplicado. Em seus resultados obtiveram um valor para a corrente que é inferior ao valor predito. Isso ocorre devido à não inclusão da desordem e do efeito de carga espacial, ou seja, não considera os efeitos da condução no volume do material. Toda esta controvérsia é, em parte, alimentada pela corrida tecnológica na perspectiva de aplicações desses polímeros em produtos eletrônicos e optoeletrônicos, como corroboram os investimentos de empresas como Philips, Sony, Pioneer, Du Pont e a Kodak ${ }^{7}$

\subsection{PPV e família}

Associado ao intenso estudo das propriedades dos PLEDs está a escolha do material utilizado como camada emissiva. O uso do poli(2-metoxi-5-(2'-etil-hexiloxi)1,4-fenileno vinileno) MEH-PPV vem do fato de este ser um polímero solúvel em solventes orgânicos comuns, permitindo assim seu fácil processamento, e por apresentar baixa voltagem de operação para a emissão de luz ${ }^{9}$. Por ser um material bastante atrativo na construção dos PLEDs, A Figura 1.1 mostra a estrutura química do MEH-PPV. 


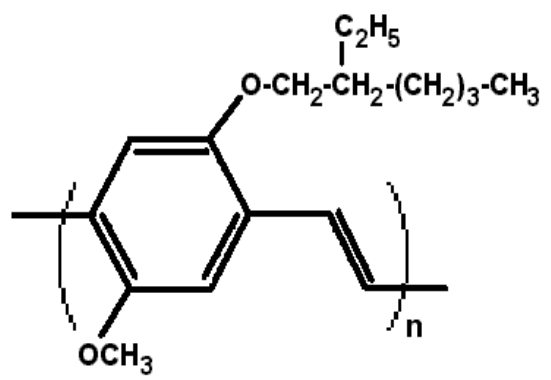

PPV

Figura 1.1: Estrutura química do poli(2-metoxi-5-(2'-etil-hexiloxi)-1,4-fenileno vinileno) MEH-

\section{3. Óxidos}

A escolha dos eletrodos é outro importante fator na otimização das propriedades ópticas e elétricas dos dispositivos emissores de luz, pois deles depende a injeção de portadores na camada polimérica. O óxido de estanho e índio (ITO) é o eletrodo mais comumente usado como injetor de buracos em dispositivos emissores de luz. O ITO é um semicondutor tipo-n, transparente na região visível do espectro e apresenta alta condutividade $\left(10 \text { a } 10^{3} \mathrm{~S} / \mathrm{cm}\right)^{20}$, entretanto o Óxido de Zinco $(\mathrm{ZnO})$, tem se tornado um material bastante estudado como eletrodo transparente por ser um material promissor e por permitir a passagem de luz na região do espectro em que os polímeros comumente utilizados emitem. $\mathrm{O}$ valor da função trabalho desses materiais é próximo ao valor da afinidade eletrônica dos derivados do PPV, em torno de $5,2 \mathrm{eV}^{21}$, o que contribui para o aumento da eficiência dos dispositivos. Em nosso trabalho, o $\mathrm{ZnO}$ foi obtido através de uma colaboração com o Departamento de Ciências dos Materiais da Universidade Nova de Lisboa, Portugal e as propriedades elétricas de dispositivos construídos com estes materiais serão estudadas. 


\subsection{LEDs e aplicações}

Como já mencionado no início deste capítulo a descoberta da eletroluminescência do PPV em $1990^{3}$ consolidou os materiais poliméricos como materiais ativos em dispositivos emissores de luz e outros vários dispositivos, acirrando a corrida tecnológica na perspectiva de aplicações desses polímeros em produtos eletrônicos e optoeletrônicos, como corroboram os investimentos de inúmeras empresas ${ }^{7}$.

A título de ilustração, a Figura 1.2 mostra dois dispositivos eletrônicos à base de materiais poliméricos. São apresentadas a foto de um circuito integrado, com trilhas, transistores e diodos inteiramente poliméricos ${ }^{22}$, e a foto de um relógio-TV com display luminoso policromático utilizando polímero como material eletroluminescente ${ }^{23}$. Ambos sistemas apresentam como principal inovação o baixo custo de produção e a facilidade de processamento, que são as principais características dos dispositivos eletrônicos poliméricos.
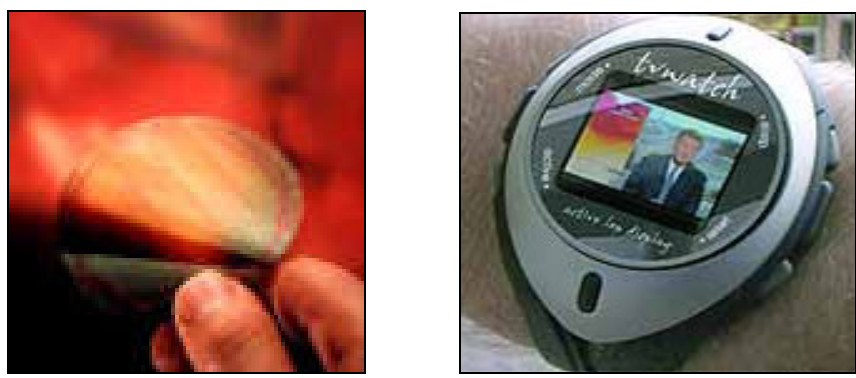

Figura 1.2: Circuito integrado e display policromático à base de polímeros. Fontes Phillips e Cambridge Display Technology.

\subsection{Objetivos}

Este trabalho tem como objetivo o estudo das propriedades elétricas de dispositivos emissores de luz tendo o poli(2-metoxi-5-(2'-etil-hexiloxi)-1,4-fenileno 
vinileno)-MEH-PPV como polímero emissor, o óxido de zinco ( $\mathrm{ZnO})$ como eletrodo transparente e injetor de buracos e alumínio (Al) como eletrodo metálico e injetor de elétrons. Foram desenvolvidas todas as etapas de construção de um dispositivo desde a preparação do eletrodo transparente até a realização de medidas elétricas de corrente vs. tensão e condutividade em campo alternado.

\subsection{Descrição do trabalho}

No CAPÍTULO 2, apresentamos as características eletrônicas de polímeros conjugados. No CAPÍTULO 3, descrevemos as etapas de preparação dos dispositivos inclusive o processo de obtenção dos filmes e o encapsulamento das amostras. No CAPÍTULO 4 apresentamos o aparato experimental utilizado para a realização de medidas elétricas e de absorção na região UV-vis. No CAPÍTULO 5 apresentamos os principais mecanismos e modelos utilizados neste trabalho. No CAPÍTULO 6 apresentamos a caracterização elétrica dos dispositivos através de medidas de corrente $v s$. tensão em diferentes temperaturas, condutividade em campo alternado variando-se a temperatura e medidas elétricas realizadas com luz em substratos contendo óxido de zinco. No CAPÍTULO 7 apresentamos os resultados dos ajustes teóricos das medidas realizadas. No CAPÍTULO 8 apresentamos as discussões dos parâmetros obtidos. No CAPÍTULO 9 apresentamos as principais conclusões deste trabalho e perspectivas para futuros trabalhos. 


\section{Capítulo: Polímeros conjugados}

Polímeros são macromoléculas consistindo de um grande número de unidades repetidas que são acopladas umas as outras formando uma longa cadeia, tipo -A-A-AA-A-A-A-, onde -A- é a unidade monomérica. Por exemplo, a fórmula estrutural do polietileno é $\mathrm{CH}_{3}-\left(\mathrm{CH}_{2}\right)_{n}-\mathrm{CH}_{3}$, onde $-\mathrm{CH}_{2}$ - é a unidade monomérica e $\mathrm{n}$ o grau de polimerização.Tipicamente $\mathrm{n}$ vai de $10^{3}$ a $10^{4}$. Apesar de originalmente serem isolantes, hoje há uma gama de materiais poliméricos semicondutores e até condutores. Eles são os polímeros da família dos conjugados, que apresentam propriedades interessantes para dispositivos optoeletrônicos por serem caracterizados pela alternância de ligações simples e duplas dos átomos de carbono ao longo da cadeia. Neste capítulo apresentamos uma breve descrição da origem destas propriedades.

\subsection{Poliacetileno - protótipo de polímeros condutores}

$\mathrm{O}$ trans-poliacetileno $(\mathrm{CH})_{\mathrm{x}}$ é o polímero comumente usado como protótipo no estudo dos polímeros conjugados devido a sua simplicidade estrutural e por possuir estrutura degenerada no estado fundamental, ou seja, seqüências de alternância entre ligações simples e duplas com a mesma energia através da introdução de um defeito. A Figura 2.1 mostra um esquema da cadeia estrutura do trans-poliacetileno e de sua estrutura degenerada devido a um defeito. 
a)

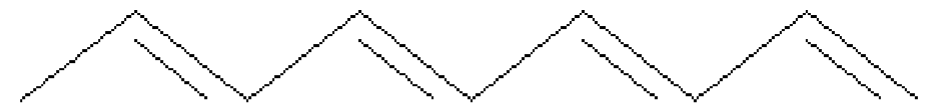

b)

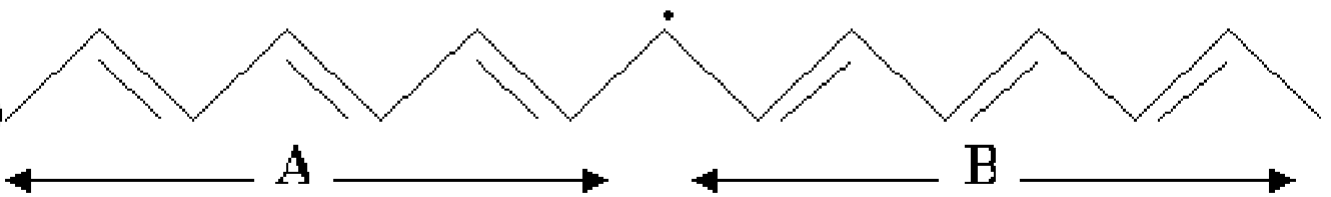

Figura 2.1 a) Estrutura do trans-poliacetileno; b) Estrutura degenerada do trans-poliacetileno. As seqüências de ligações A e B possuem a mesma energia.

O defeito mostrado na Figura $2.1 b$ recebe o nome de sóliton e está associado a um nível de energia situado no meio do gap. O sóliton mostrado na figura é um sóliton neutro $\left(S^{0}\right)$ com spin eletrônico $1 / 2$, onde existe um elétron ocupando o nível energético no meio do gap, mas este defeito pode existir em dois outros estados, ou com este elétron removido, onde temos um sóliton positivamente carregado $\left(\mathrm{S}^{+}\right)$ou com um outro elétron adicionado, resultando num sóliton negativamente carregado $\left(\mathrm{S}^{-}\right)$; ambos os defeitos possuem spin eletrônico nulo ${ }^{24,25,7}$. A Figura 2.2 mostra a representação de um sóliton no trans-poliacetileno.
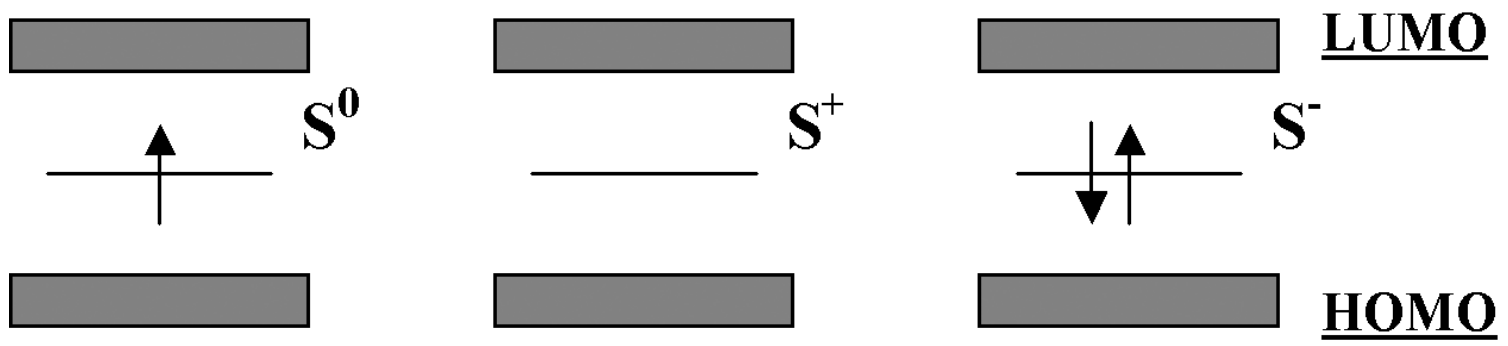

Figura 2.2: Representação de um sóliton no trans-poliacetileno; $\mathrm{S}^{0}$ sóliton neutro, $\mathrm{S}^{+}$sóliton positivamente carregado e $\mathrm{S}^{-}$sóliton negativamente carregado 


\subsection{Propriedades eletrônicas de polímeros conjugados}

A estrutura eletrônica dos polímeros conjugados é descrita pelas ligações $\sigma$, formadas pela sobreposição dos orbitais híbridos $\mathrm{sp}^{2}$ ao longo do plano da cadeia e ligações $\pi$, formadas pela sobreposição dos orbitais $\mathrm{p}_{\mathrm{z}}{ }^{24}$ situadas num plano perpendicular ao plano da cadeia. Os elétrons da ligação $\pi$, ao contrário dos elétrons da ligação $\sigma$, são mais deslocalizados, com mobilidade maior para se mover ao longo da cadeia conjugada. As ligações $\sigma$ são responsáveis pelas propriedades mecânicas da cadeia polimérica, enquanto as ligações $\pi$ determinam as propriedades elétricas e ópticas do polímero. A Figura 2.3 mostra a representação dos orbitais atômicos das ligações $\pi$.
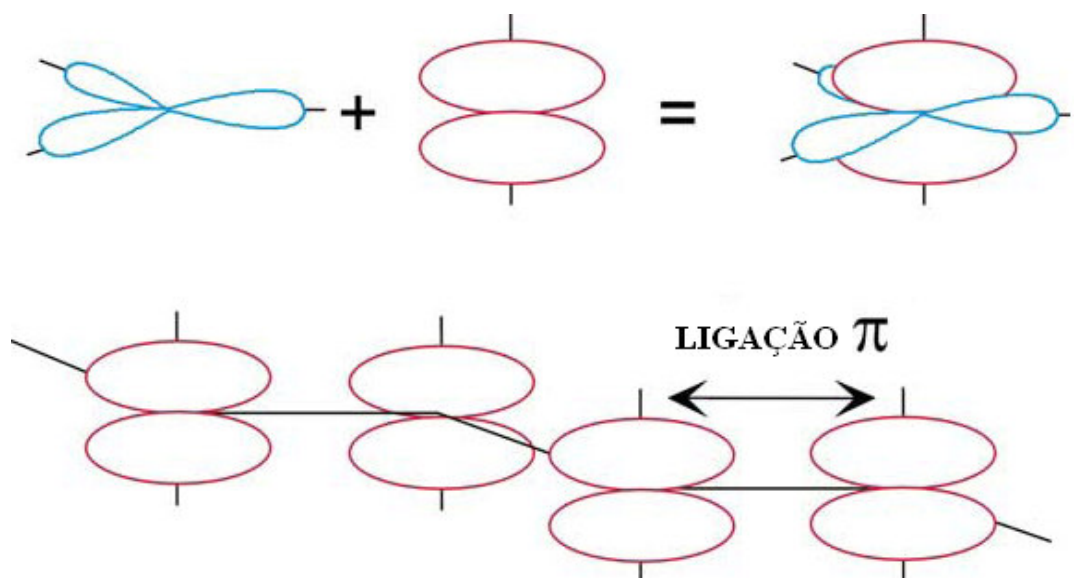

Figura 2.3: Representação dos orbitais $\pi$ (em vermelho) e orbitais $\sigma$ (em azul) ${ }^{26}$.

Numa cadeia trans-PA perfeita, que é unidimensional, a sobreposição dos orbitais $\pi$ obedece a instabilidade de Peierls, que nesse caso está relacionado ao fato de ligações simples serem mais longas que ligações duplas. Portanto, os elétrons $\pi$ não são totalmente deslocalizados, e no diagrama de estrutura eletrônica há um gap de energia (gap $\pi-\pi^{*}$ ), de aproximadamente $1,6 \mathrm{eV}$, que determina as propriedades elétricas intrínsecas do material. Esse gap é análogo ao gap entre as bandas de valência 
e condução em semicondutores inorgânicos, e nos polímeros são entre o HOMO (highest occupied molecular orbital) e o LUMO (lowest unoccupied molecular orbital).

Na estrutura Cis-PA, Figura 2.4, um sóliton seria instável pois estaria entre duas estruturas de energias distintas. Para se obter a estabilização ocorre a existência de um anti-defeito (ou anti-sóliton). Este par (defeito e anti-defeito) recebe o nome de pólaron e está diretamente ligado a formação de estados ligantes e anti-ligantes simetricamente deslocados em relação ao meio do gap.

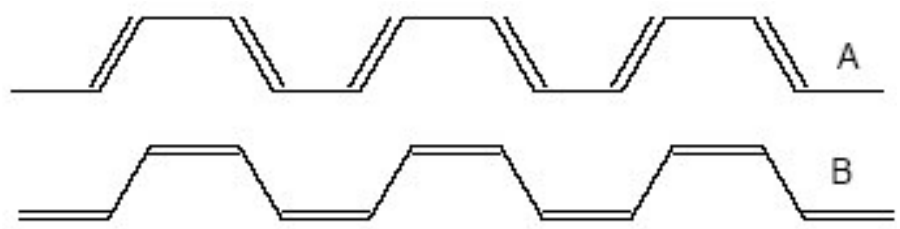

Figura 2.4: Estrutura não degenerada do $c i s$-poliacetileno ${ }^{25}$.

Quando estes níveis são ocupados por um elétron formam um pólaron positivo $\left(\mathbf{p}^{+}\right)$, por dois elétrons formam um éxciton pólaron, que pode decair radiativamente emitindo luz, por três elétrons um pólaron negativo $\left(\mathbf{p}^{-}\right)$, por quatro elétrons temos um bipólaron negativo ( $\mathbf{b p}^{2-}$ ) e quando estes níveis estão desocupados formam um bipólaron positivo $\left(\mathbf{b p}^{2+}\right)^{24}$. A Figura 2.5 mostra a representação do pólaron, bipólaron e do éxciton singleto para polímeros com estado fundamental não-degenerado.

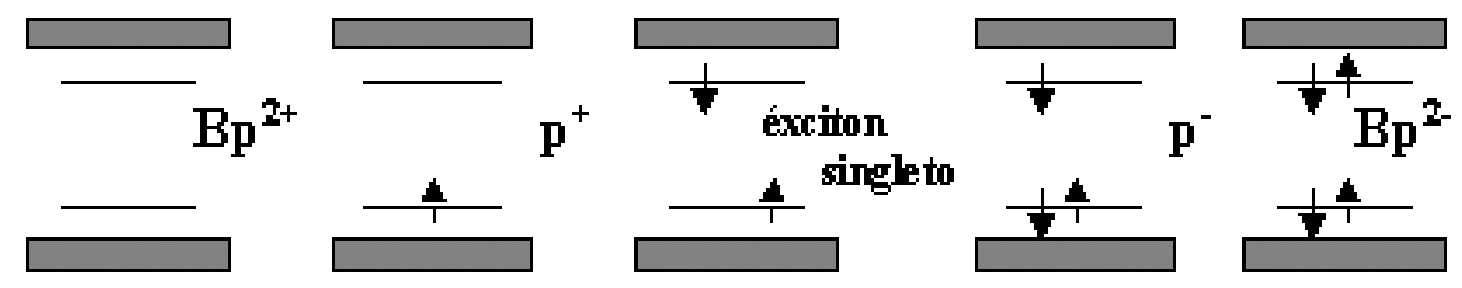

Figura 2.5: Pólaron, bipólaron e éxciton singleto para polímeros com estado fundamental nãodegenerado. 
A promoção de elétrons do estado fundamental para estados excitados em moléculas orgânicas, ocorre através da injeção de carga ou excitação através de luz. O espectro de absorção fornece as energias características de transições do subnível de energia mais baixo do estado fundamental $\left(\mathbf{S}_{\mathbf{0}}\right)$ para diferentes subníveis do estado eletrônico excitado $\left(\mathbf{S}_{\mathbf{1}}\right)$, enquanto o espectro de emissão fornece transições do subnível eletrônico mais baixo do estado excitado $\left(\mathbf{S}_{\mathbf{1}}\right)$ para diferentes subníveis do estado fundamental $\left(\mathbf{S}_{\mathbf{0}}\right)$. A Figura 2.6 mostra os espectros de emissão e absorção entre estados eletrônicos excitados $\left(\mathbf{S}_{\mathbf{1}}\right)$ e estado fundamental $\left(\mathbf{S}_{\mathbf{0}}\right)$, onde podemos observar uma diferença entre os máximos de emissão e absorção devido à transições nãoradiativas. Esta diferença é conhecida como deslocamento de Stokes ${ }^{24}$

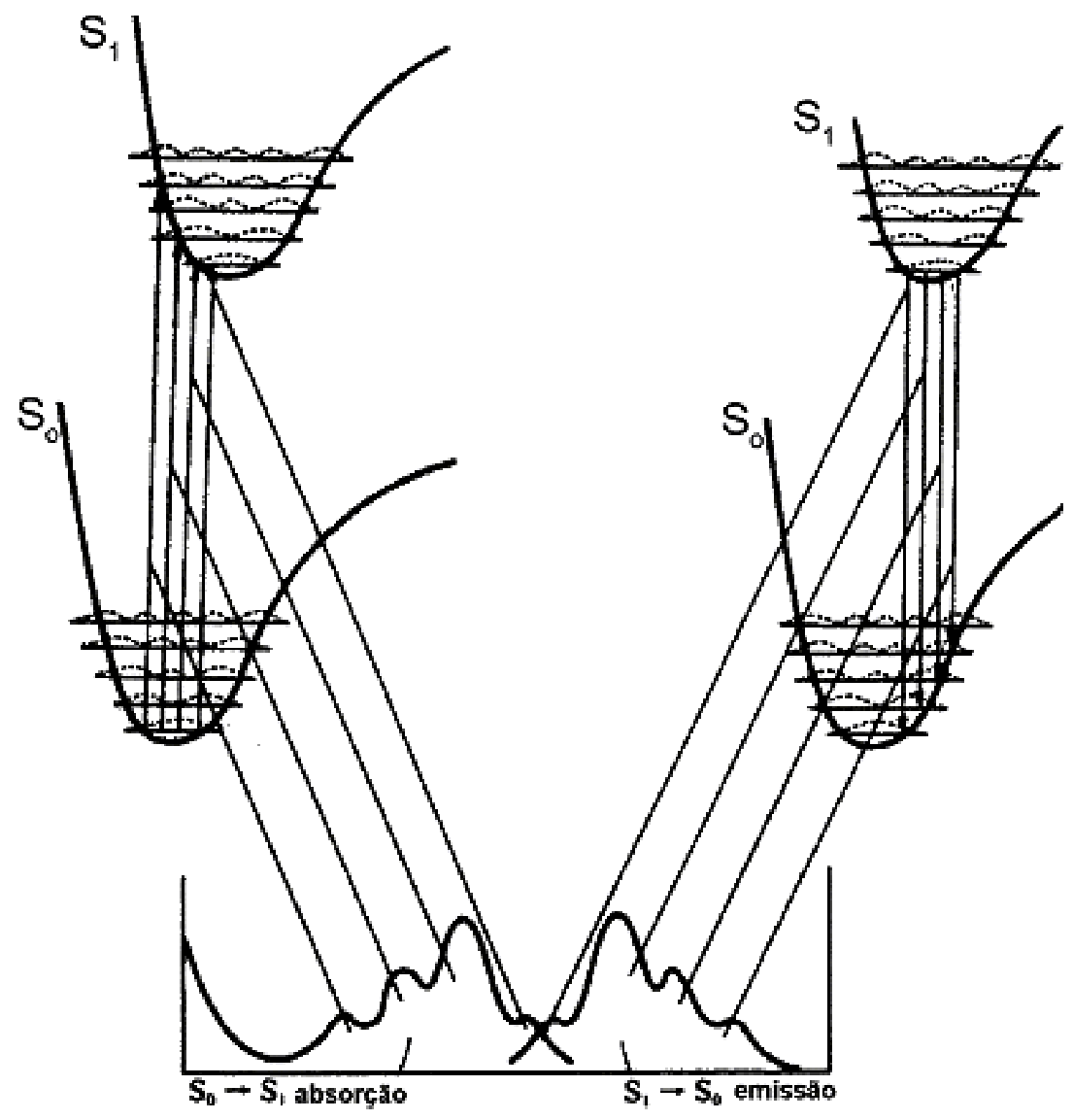

Figura 2.6: Espectro de emissão e absorção entre estados eletrônicos $\mathbf{S}_{\mathbf{0}}$ e $\mathbf{S}_{\mathbf{1}}$. 


\section{Capítulo: Preparação de dispositivos emissores de luz poliméricos}

Nesse capítulo, apresentamos os detalhes de cada etapa da preparação de um dispositivo PLED, desde o cuidado com o substrato, com a preparação e deposição do filme fino polimérico e com a evaporação dos eletrodos metálicos. A confecção de um dispositivo é essencial para o seu estudo pois para se obter bons resultados experimentais, não pode haver erro em cada uma dessas etapas.

\subsection{Construção de um PLED}

A estrutura típica de um Dispositivo Emissor de Luz Polimérico (polymer light emitting diodes - PLED) consiste em uma fina camada polimérica depositada entre um eletrodo transparente (ITO ou $\mathrm{ZnO}$ ) e um eletrodo metálico ( $\mathrm{Al}, \mathrm{Ca}, \mathrm{Mg}$, etc.). A Figura 3.1 mostra a estrutura de um PLED, onde são apresentados o substrato de vidro, o eletrodo transparente, a camada emissiva e o eletrodo metálico.

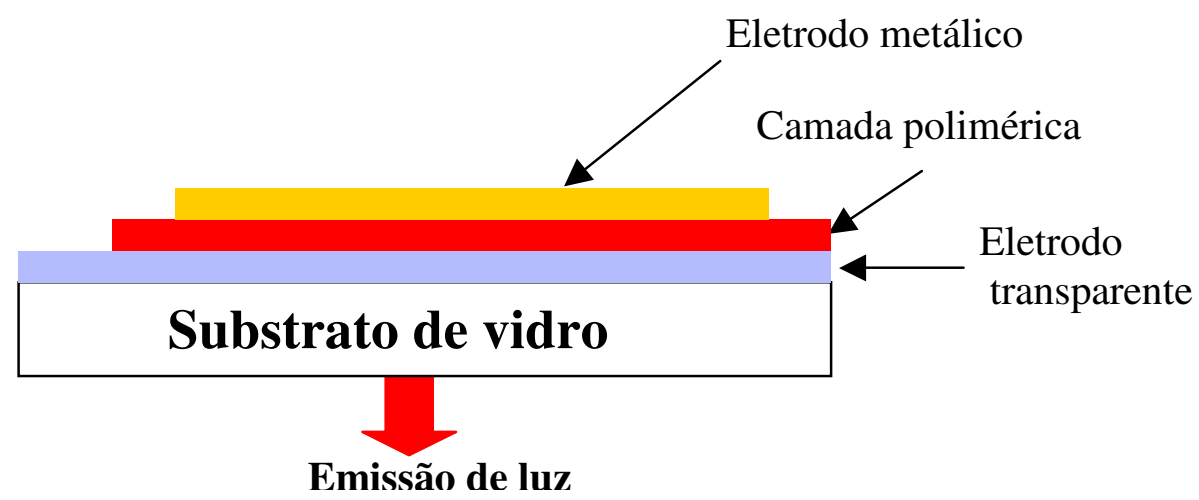

Figura 3.1: Estrutura típica de um dispositivo emissor de luz polimérico. A figura ilustra a camada polimérica entre os eletrodos metálicos e o eletrodo transparente depositados sobre um substrato de vidro. 
Ao se aplicar uma diferença de potencial entre os eletrodos, portadores de carga (elétrons e buracos) são injetados no interior do material. A interação de um par de portadores, conforme as condições locais da estrutura do material, leva à formação de um éxciton. Em havendo recombinação desse par, há emissão de luz, dando origem ao fenômeno da eletroluminescência. ${ }^{27}$.

A injeção de portadores é controlada pela escolha dos eletrodos resultado dos valores entre a função trabalho do material do eletrodo e das energias HOMO e LUMO do polímero. Para a injeção de buracos o eletrodo deve possuir alto valor para a função trabalho, enquanto para a injeção de elétrons o valor da função trabalho deve ser baixa ${ }^{26}$. O eletrodo injetor de buracos mais utilizado é o ITO (óxido de estanho e índio ou indium-tin oxide) por ser transparente no visível e possuir boa condutividade, enquanto que o eletrodo mais utilizado para injeção de elétrons é o cálcio por ter função trabalho próxima à afinidade eletrônica do PPV. ${ }^{25,7}$ A Figura 3.2 mostra o diagrama de energias entre o ITO e o $\mathrm{ZnO}$ (utilizados como injetores de buracos), o PPV e o alumínio que pode ser utilizado como injetor de elétrons.

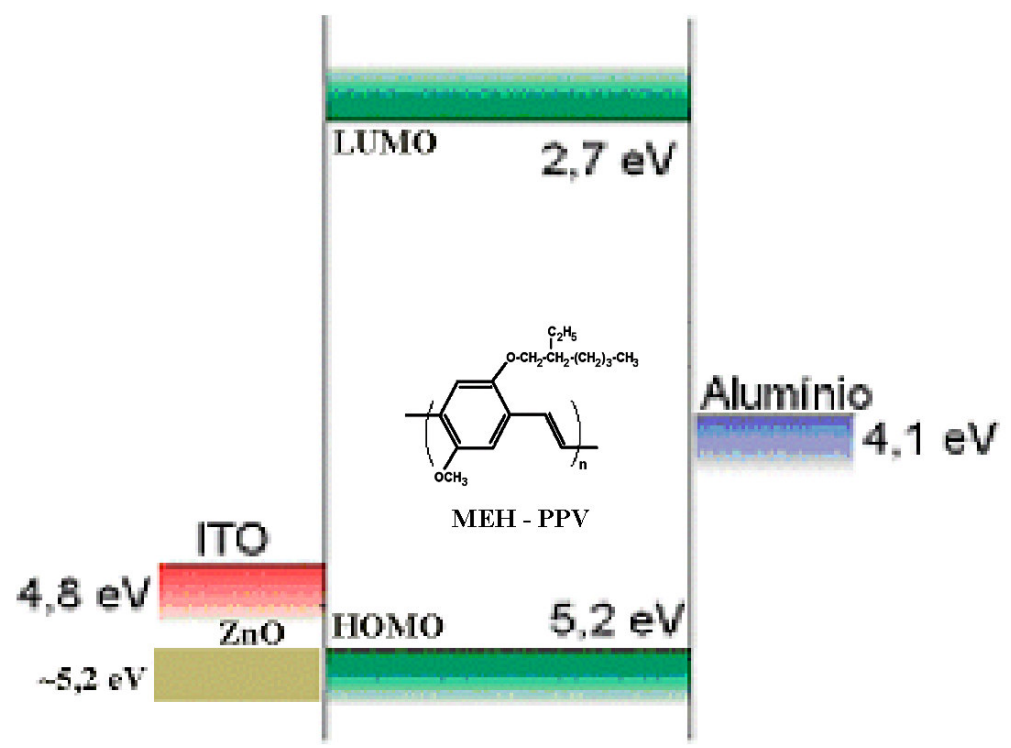

Figura 3.2: Diagrama de energias (função trabalho, HOMO - highest occupied molecular orbital e LUMO - lowest unoccupied molecular orbital) entre o ITO, ZnO, MEH-PPV e alumínio como eletrodo metálico ${ }^{7}$. 


\subsection{Confecção dos eletrodos transparentes}

Para a confecção dos eletrodos dos dispositivos emissores de luz poliméricos foram utilizadas lâminas de vidro recobertas com óxido de estanho e índio (ITO) ou com óxido de zinco $(\mathrm{ZnO})$. O valor da função trabalho do $\mathrm{ZnO}$ é próxima à do $\mathrm{ITO}$. O primeiro foi obtido comercialmente, da empresa Delta S.A, enquanto o segundo por meio de uma colaboração com o Departamento de Ciências dos Materiais da Universidade Nova de Lisboa, Portugal. O I-ZnO foi depositado pela técnica sputtering sobre substrato de vidro, com uma densidade de potência de $2,5 \mathrm{~W} / \mathrm{cm}^{2}$, em temperatura ambiente. Durante a deposição foi introduzido um fluxo de oxigênio e de nitrogênio. A pressão parcial de oxigênio foi de $2.1 \times 10^{-3} \mathrm{~Pa}$ e a pressão total foi de $1.3 \times 10^{-1} \mathrm{~Pa}$. O tempo de deposição foi de 15 minutos. Para a realização de medidas elétricas em filmes de $\mathrm{ZnO}$ não dopado, foram evaporados eletrodos de alumínio sobre o filme numa estrutura coplanar como é mostrado na Figura 3.3.

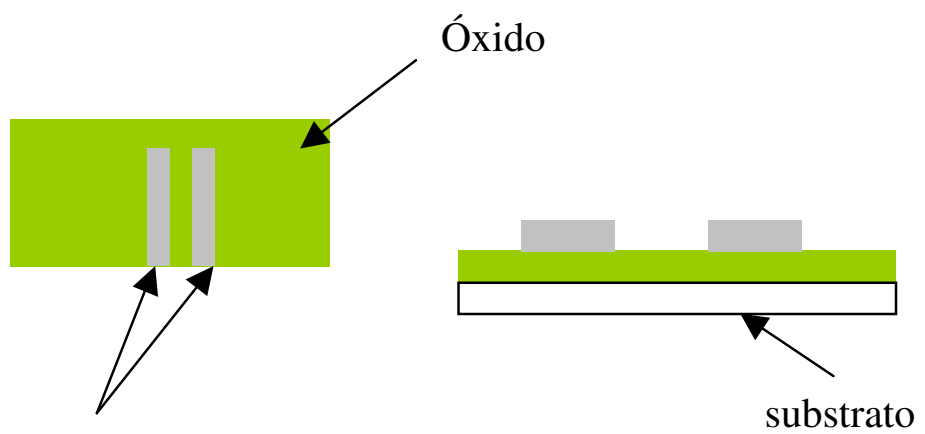

Eletrodos de alumínio

Figura 3.3: Óxido de zinco sobre substrato de quartzo ou vidro e eletrodos de alumino.(a) visão frontal (b) visão lateral

Como procedimento inicial de limpeza, as lâminas foram mergulhadas em solução de acetona e, posteriormente, de álcool isopropílico, ambos em ebulição, com o objetivo de remover umidade e impurezas adsorvidas na superfície destes óxidos. Para finalizar, as amostras foram secas com gás de nitrogênio. 
Após a limpeza inicial das amostras, foi realizado o processo de decapagem. Esse processo consiste em proteger as regiões do óxido, onde se pretende obter a geometria desejada do eletrodo, e remover a região restante com ácido clorídrico e suspensão de zinco em água. Para proteger as regiões desejadas do óxido, foram estampadas na superfície dos óxidos trilhas isolantes, as quais foram obtidas a partir da impressão a laser, em papel do tipo Glossy Paper, e transferidas para a superfície do óxido por meio de aquecimento. Para a realização desse procedimento, as trilhas foram inicialmente impressas no papel e, posteriormente, transferidas para o óxido com o auxilio de uma chapa aquecida, a $150^{\circ} \mathrm{C}$, por cerca de 2 minutos.

Em seguida, a região da superfície com óxido não protegida pela trilha isolante foi atacada quimicamente com uma pasta (suspensão) de zinco e água e ácido clorídrico 1 M. Para alcançar este objetivo, a suspensão de zinco foi depositada sobre a superfície do óxido e em seguida a lâmina foi mergulhada na solução ácida por 30 segundos. Como resultado deste processo, a reação do zinco com o ácido clorídrico, torna o óxido facilmente retirados da lâmina com a utilização de um cotonete. Em especial para o $\mathrm{ZnO}$ não foi necessário a utilização do zinco. Esse óxido foi facilmente removido da superfície do vidro utilizando-se, apenas, a imersão dos substratos na solução ácida de $\mathrm{HCl}$. Finalmente, para a retirada da tinta e possíveis resíduos depositados nas laminas, estas foram mergulhadas em acetona em ebulição até que toda a tinta fosse removida. As lâminas foram novamente secas com nitrogênio. Esse processo, denominado de decapagem do filme de óxido, é ilustrado na Figura 3.4.

Na Figura 3.4, a Etapa 1 ilustra o procedimento de transferência da tinta para a superfície do óxido. Já a etapa 2 ilustra o processo de remoção do óxido da superfície 
não protegida pela tinta com suspensão de zinco e $\mathrm{HCl}$ e, por último, a etapa 3 ilustra a retirada da tinta com acetona.

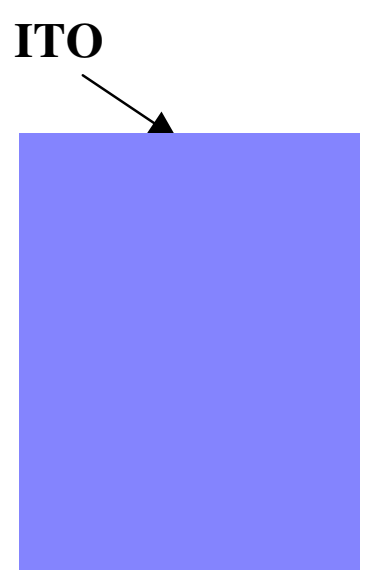

\section{Trilhas de tinta}
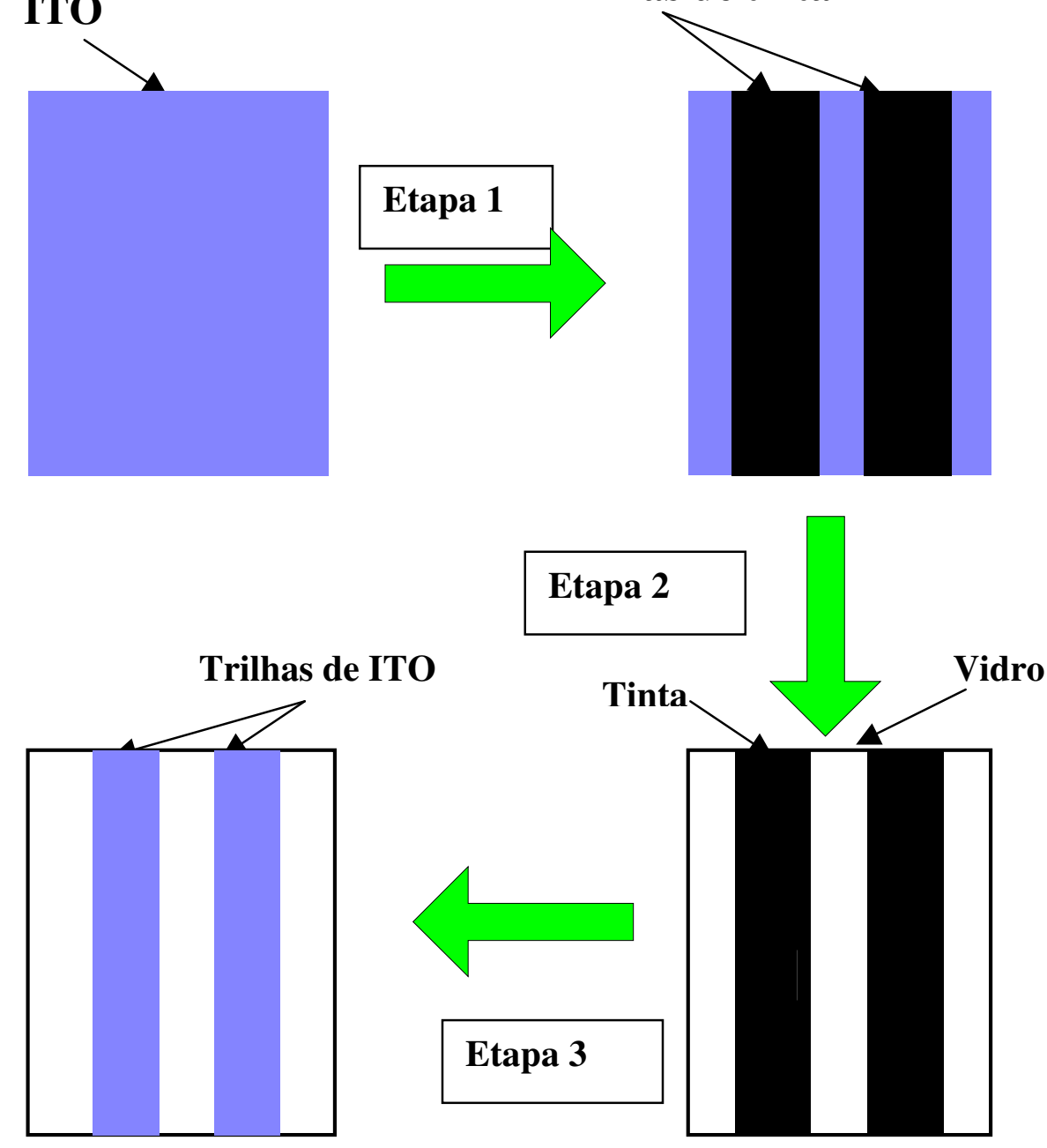

Figura 3.4: Etapas do processo de decapagem. Etapa 1: proteção das regiões de óxido com geometria desejada, no caso, trilhas. Etapa 2: retirada das regiões não protegidas com suspensão de zinco e ácido clorídrico. Etapa 3: remoção da tinta protetora com acetona em ebulição.

\subsection{Limpeza dos substratos}

A limpeza dos substratos é uma etapa muito importante pois pode interferir negativamente, caso tenha impurezas, no processo de deposição dos filmes 
poliméricos e em sua caracterização óptica pela técnica de UV-Vis. Para tanto, a limpeza destes substratos foi realizada por meio de um método padrão, que consiste em remover as impurezas adsorvidas na superfície do vidro usando-se um banho em solução básica, seguido de outro em ácida. A etapa básica consiste em imergir as lâminas em uma solução de água destilada, hidróxido de amônio $\left(\mathrm{NH}_{4} \mathrm{OH}\right)$ e peróxido de hidrogênio $\left(\mathrm{H}_{2} \mathrm{O}_{2}\right)$ em uma proporção de 5:1:1 aquecida a $75^{\circ} \mathrm{C}$ por 15 minutos. Para a etapa ácida foi utilizada uma solução de água destilada, ácido clorídrico (HCl) e peróxido de hidrogênio $\left(\mathrm{H}_{2} \mathrm{O}_{2}\right)$ em uma proporção de $5: 1: 1$, aquecida a $75^{\circ} \mathrm{C}$ por 15 minutos. Após isso, as lâminas foram aquecidas em acetona, e em seguida em álcool isopropílico ambos em ebulição, e finalmente secas com nitrogênio.

Já com os substratos vidro/ITO foi realizado um tratamento químico para aumentar a rugosidade do ITO e conseqüentemente aumentar a aderência do polímero sobre esse substrato, conforme descrito recentemente por Kin et al ${ }^{28}$. O tratamento consiste em imergir os substratos de vidro com óxido em uma solução de "águarégia" diluída (1HCl: $20 \quad \mathrm{H}_{2} \mathrm{O}: 4 \mathrm{HNO}_{3}$ ) deixando-os em ultrassom por 15 minutos e enxaguando-os bem com água destilada. Em seguida os substratos foram mergulhados em acetona e depois em álcool isopropílico, ambos em ebulição, e secas com nitrogênio.

\subsection{Preparação dos filmes}

Os métodos mais utilizados na preparação de filmes finos poliméricos são os métodos casting e spin coating. Além de eficientes na confecção de filmes finos, esses métodos são de fácil implementação e utilização. O método casting consiste em depositar a solução polimérica no substrato desejado e deixar que o solvente utilizado 
se evapore com o controle da temperatura. Desta forma, com o aumento da temperatura, o solvente irá evaporar mais rápido até que um filme polimérico fino e homogêneo seja formado. Por outro lado, o método spin coating consiste em depositar a solução polimérica no substrato, que gira tanto com uma freqüência quanto por um intervalo de tempo pré-determinados. Sob rotação, o excesso de material é expelido do substrato originando um filme fino e homogêneo. Ambos os métodos são ilustrados na Figura 3.5. 


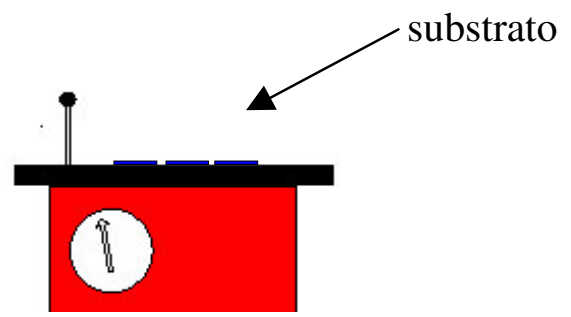

(a) Casting

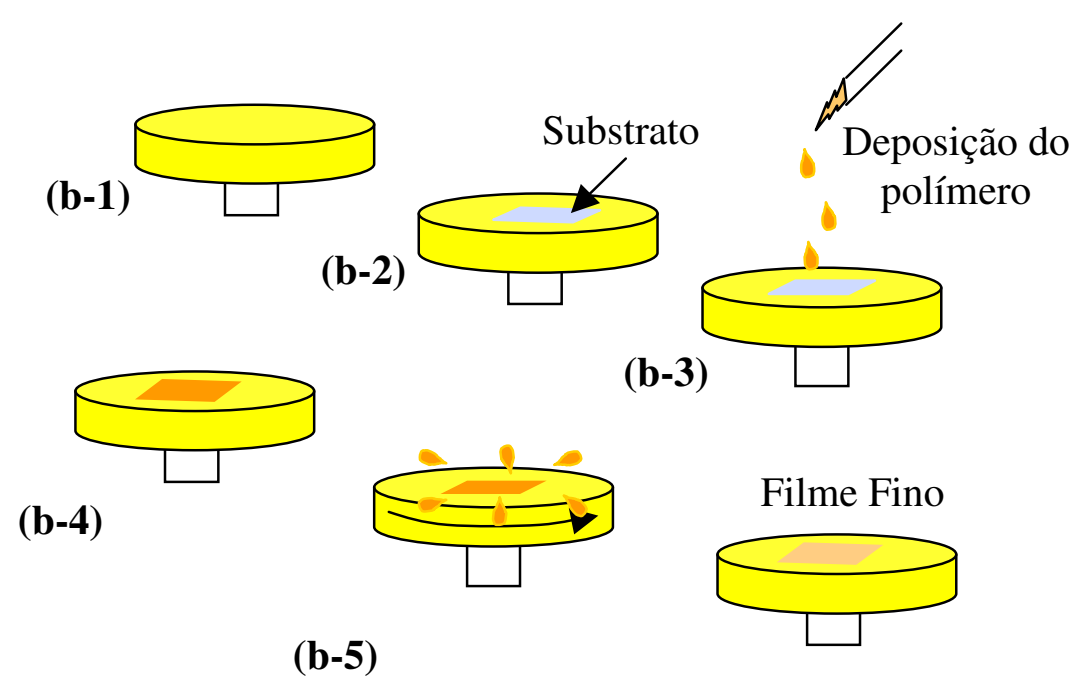

(b-6)

(b) Spin Coating

Figura 3.5: Equipamentos usados para a obtenção de filmes poliméricos pelos métodos casting e spin coating. (a) Casting (b-1) Aparato giratório (b-2) Substrato onde será depositado o polímero (b3) Deposição do polímero (b-4) Solução polimérica sobre o substrato (b-5) Aparato girando para expelir o excesso de solução (b-6) filme fino.

\subsection{Obtenção de filmes de MEH-PPV}

Para a obtenção de filmes de MEH-PPV, usados na confecção dos dispositivos, foram preparadas soluções de MEH-PPV em clorofórmio com diferentes concentrações. Foi realizado um estudo sistemático sobre o efeito da concentração e da rotação do spin coating na uniformidade dos filmes. Para baixas concentrações, menor que $5 \mathrm{mg} / \mathrm{ml}$, os filmes preparados, independente da rotação utilizada, apresentaram-se extremamente finos de modo que, ao se depositar os eletrodos 
metálicos sobre os mesmos havia uma grande incidência de curtos-circuitos. Provavelmente o filme polimérico não recobria uniformemente o óxido e, com a deposição do eletrodo metálico, este entrava em contato com o óxido, ocasionando o curto. Na tentativa de solucionar este problema, partimos para o preparo de soluções mais concentradas. Para o caso da solução de $10 \mathrm{mg} / \mathrm{ml}$, os melhores filmes foram obtidos com rotação igual a $2000 \mathrm{rpm}$, embora a incidência de curto-circuito entre o eletrodo óxido e o metálico ainda tenha sido bastante elevada. Por sua vez, as soluções de $15 \mathrm{mg} / \mathrm{ml}$ e $30 \mathrm{mg} / \mathrm{ml}$ apresentaram os melhores resultados, respectivamente com 1500 rpm e 870 rpm, além de nenhuma incidência de curto-circuito entre os eletrodos. Baseados nestes resultados optamos por padronizar o preparo dos filmes usando-se a solução com uma concentração de $15 \mathrm{mg} / \mathrm{ml}$.

\subsection{Preparação dos eletrodos metálicos}

Para a preparação dos eletrodos metálicos, foram confeccionadas máscaras mecânicas, a partir de lâminas de cobre, com geometria de trilhas semelhante as trilhas preparadas para o óxido. Para tanto, foi novamente utilizado o método de transferência de tinta de impressão de folhas Glossy, sob aquecimento, para a superfície do cobre e, posteriormente remoção da região não protegida com percloreto de ferro. Nas regiões onde a gravação não foi realizada, assim como na parte de trás da placa de cobre, foi colado fita tipo Durex, a fim de se prevenir a possível migração da solução decapante. Após a corrosão completa, as trilhas foram removidas com acetona. A Figura 3.6 ilustra o processo de construção das máscaras mecânicas. Na etapa 1 , tem-se a impressão das trilhas em papel tipo Glossy. Já, na etapa 2 a transferência para a placa de cobre. Por ultimo na etapa 3 tem-se a corrosão e retirada da tinta com acetona. 


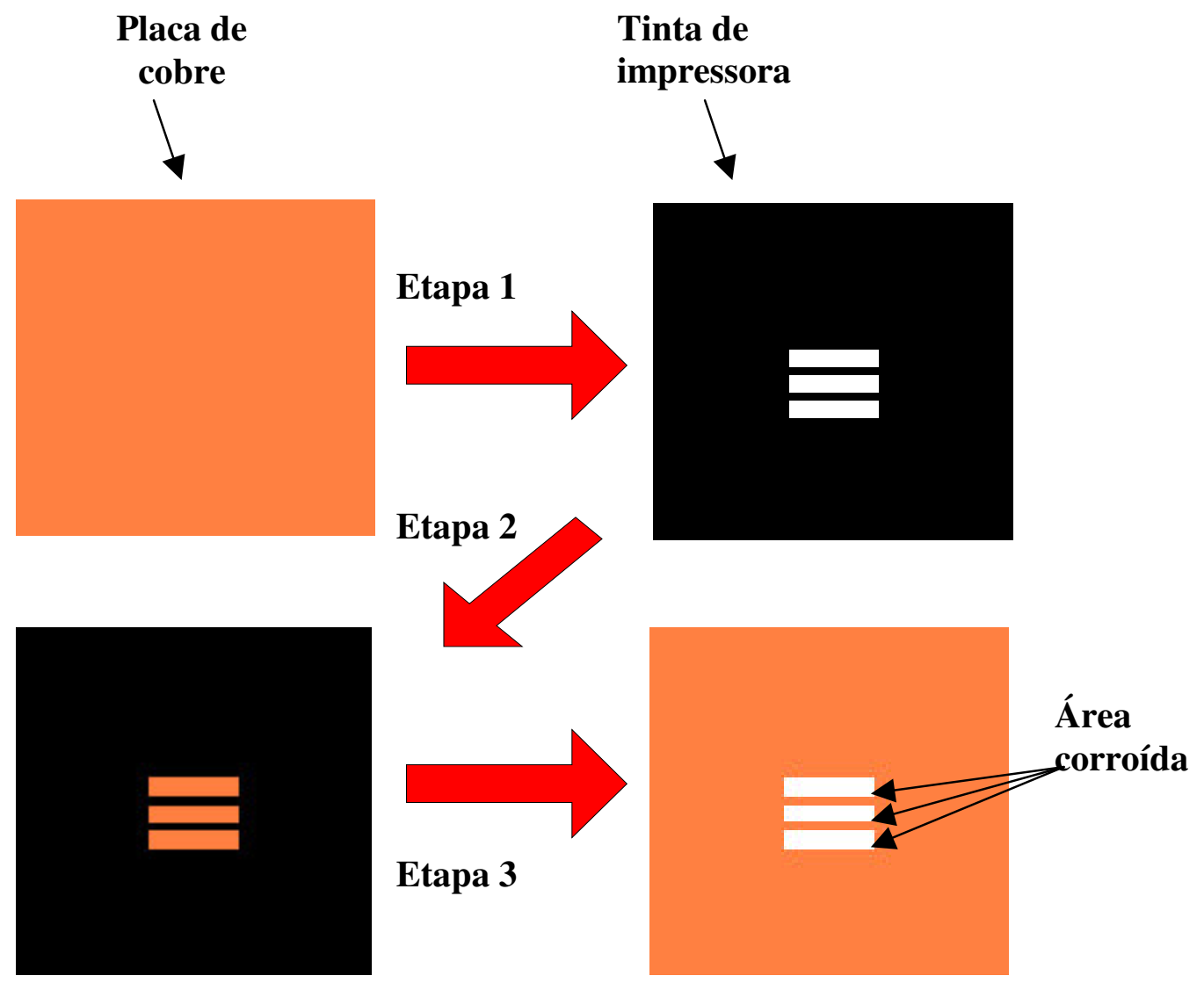

Figura 3.6: (a) Etapas do processo de construção das máscaras utilizadas na metalização. Etapa 1: impressão das trilhas em papel tipo Glossy Etapa 2: transferência para a placa de cobre. Etapa 3: corrosão e retirada da tinta com acetona.

Após o processo de metalização realizamos o último passo na construção dos dispositivos, que são os contatos elétricos e o encapsulamento. Para a conexão com os eletrodos foram utilizados contatos tipo garras, soldadas com tinta prata condutora que também serve para melhorar os contatos elétricos.

Para minimizar a degradação dos dispositivos, optamos por realizar medidas elétricas em vácuo e com controle da umidade relativa. Desse modo, para reduzir os danos causados nas amostras, sem perder a facilidade em realizar medidas elétricas, um dessecador de policarbonato foi preparado, conforme mostra a Figura 3.7. 


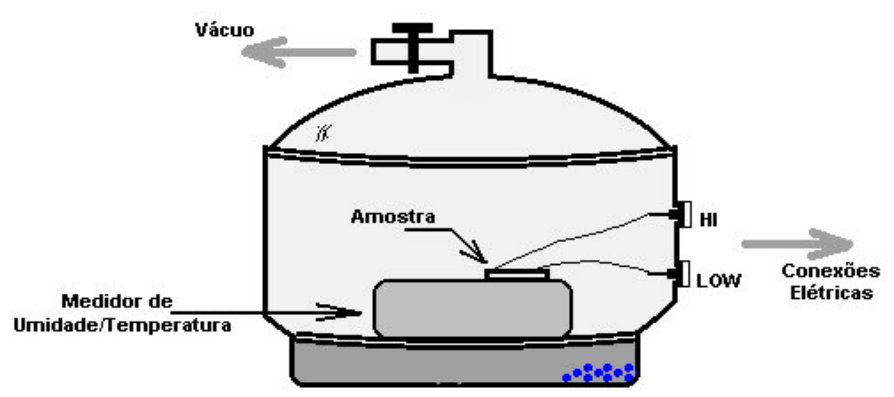

Figura 3.7: Dessecador à vácuo adaptado para a realização de medidas elétricas com controle de umidade e pressão.

Nesse dessecador, fios de cobre são soldados com tinta prata nos eletrodos de uma amostra que, em seguida, é colocada em uma base no seu interior. Os fios são conectados a plugs $\mathrm{BNC}$, adaptados na parede do dessecador, e o controle de temperatura e umidade relativa são monitorados por um medidor apropriado. As laterais do dessecador também são revestidas com adesivo preto para impedir a entrada de luz e inibir o efeito da fotocondução nesses polímeros. Uma pequena área sem adesivo foi deixada na tampa transparente do dessecador. Essa janela é coberta com um pano preto para evitar a entrada da luz de tal forma que, a emissão dos dispositivos é facilmente visualizada quando necessária. Para reduzir a quantidade de oxigênio interna, uma bomba de vácuo mecânica é acoplada ao sistema. Para garantir uma pressão constante no interior do dessecador, a bomba é mantida ligada durante todas as medidas. Como resultado, após a utilização desse equipamento, a danificação dos eletrodos metálicos na superfície dos dispositivos foi bastante reduzida. Entretanto, para correntes maiores que $2 \mathrm{~mA}$, o problema continua a existir e, por esse motivo, a corrente das amostras estudadas foi limitada em $1 \mathrm{~mA}$. 


\section{Capítulo:Equipamentos e Métodos de medidas}

Nesse capítulo apresentamos os aparatos experimentais utilizados na realização de medidas elétricas e ópticas dos dispositivos eletroluminescentes. Foram realizadas medidas de condutividade dc e ac, medidas de espectroscopia de absorção na região UV-Vis.

\subsection{Medida corrente $x$ tensão $(\mathbf{I x V})$}

Medidas de corrente vs. tensão foram realizadas numa fonte de tensão/medidor de corrente Keithley modelo 238 usado para a caracterização da condutividade dc do filme e dos dispositivos poliméricos. Este equipamento permite a variação de tensão de $-100 \mathrm{~V}$ a $100 \mathrm{~V}$ e leitura de corrente de $10^{-9}$ a $20 \mathrm{~mA}$.

\subsection{Medida de condutividade em campo alternado (AC)}

Para a realização destas medidas foi utilizado o Impedanciômetro Solartron modelo 1260 Impedance/Gain phase Analyser, que permite a aplicação de uma amplitude de tensão de 0 a $3 \mathrm{~V}$ num intervalo de freqüência de $10^{-2} \mathrm{~Hz}$ a $32 \mathrm{Mhz}$ e tensão de polarização externa de -41 a $41 \mathrm{~V}$.

\subsection{Absorção UV-vis}

Para caracterização das propriedades ópticas dos materiais utilizados como eletrodos transparentes $(\mathrm{ZnO})$, foram realizadas medidas de absorção na região do 
UV-vis foi utilizado um espectrofotômetro Hitachi, modelo U-2001, do Grupo de polímeros que permite a realização de medidas de absorção por transmitância no intervalo entre 190 e 1100nm.

\subsection{Medida com temperatura}

Com o objetivo de evitar a degradação do dispositivo, todas as medidas foram feitas sob vácuo e com umidade controlada. As medidas em temperatura ambiente foram realizadas em um dessecador com conexões elétricas apropriadas como mostra a Figura 3.7. Para as medidas em que se precisava variar a temperatura as amostras foram colocadas em um porta-amostra, em vácuo, de um criostato $\mathrm{APD}$, modelo DE202 que pode variar a temperatura de $10 \mathrm{~K}$ a $340 \mathrm{~K}\left(-260\right.$ a $\left.77^{\circ} \mathrm{C}\right)$. As conexões com o circuito externo, foram feitas através de cabos coaxiais com conectores BNC, até os instrumentos de medidas. 


\section{Mecanismos e Modelos}

\subsection{Injeção - Schottky e Fowler-Nordheim}

Para entendermos os processos de injeção de portadores de um metal em um semicondutor (ou polímero), precisamos examinar a natureza das interfaces e as barreiras energéticas formadas, quando tais materiais são colocados em contato. Nesse caso, os níveis de Fermi do metal e do semicondutor tendem a se alinham até que o equilíbrio térmico seja atingido. Em geral as funções trabalho desses materiais são diferentes, então haverá um fluxo de carga do metal para o semicondutor ou do semicondutor para o metal. No primeiro caso, a função trabalho metal é maior que a do semicondutor, então haverá um fluxo de elétrons para o metal, deixando uma região de carga positiva próxima a interface. O mesmo ocorre no segundo caso, sendo que a função trabalho do metal é menor que a do semicondutor, sendo assim, elétrons fluem para o semicondutor onde haverá um acumulo de cargas negativas. Esse acúmulo de carga próximo ao contato, formando uma região de dupla camada de carga, origina uma diferença de potencial (barreira de potencial) que é conhecida como barreira Schottky ${ }^{29}$. Essa barreira de potencial é formada pela diferença de energia entre a função trabalho do metal e a afinidade eletrônica ou potencial de ionização do semicondutor (polímero). $\mathrm{Na}$ presença desse tipo de barreira os portadores de cargas são injetados através dos mecanismos de emissão termiônica e de tunelamento.

O mecanismo de tunelamento de Fowler-Nordheim é baseado no tunelamento quântico de portadores através da barreira de potencial formada na interface metal/semicondutor (polímero). Esse mecanismo não depende da temperatura, mas 
depende fortemente do campo aplicado, e torna-se bastante evidente em altos campos e onde os efeitos térmicos de injeção de portadores são desprezíveis. A sua expressão para a densidade de corrente é da forma:

$$
\mathrm{J}_{\mathrm{FN}}=\mathrm{BE}^{2} \exp (-\mathrm{b} / \mathrm{E})
$$

Nesta equação E é o campo aplicado, $\mathrm{B}=\mathrm{q}^{3} / 16 \pi^{2} \hbar(\mathrm{q} \varphi)$ e $b=\frac{4 \sqrt{2 m^{*}}(q \varphi)^{\frac{3}{2}}}{3 q \hbar}$. Essa expressão é independente da temperatura. E $\varphi$ é a barreira de potencial.

Quando a energia térmica dos portadores de carga é da ordem ou superior a altura da barreira de potencial, o processo de emissão pode ocorrer sem campo aplicado. Isso significa que eles possuem energia suficiente para vencer a barreira de potencial, sendo emitido no semicondutor (polímero). Richardson encontrou uma equação que define a densidade de corrente e pode ser escrita como:

$$
J=A_{R} T^{2} e^{-\frac{q \phi_{B}}{k T}}
$$

Com o pré-fator $A_{R}$ definido como

$$
A_{R}=\frac{4 \pi q m k^{2}}{h^{3}}
$$

\subsection{Modelo de circuitos equivalentes}

O comportamento da impedância complexa de materiais amorfos e de dispositivos tem sido bastante estudado por circuitos equivalentes que são baseados na 
associação de elementos de circuito, como, por exemplo, resistores e capacitores. Resistores são usados para representar a resistividade dos materiais e de interfaces entre materiais distintos, enquanto capacitores podem ser utilizados para representar o armazenamento de cargas que ocorre em interfaces de distintos materiais, ou mesmo, em interfaces no interior de materiais tipo granulares. A Figura 5.1 apresenta um conjunto de configurações de diferentes formas de associar resistores e capacitores.

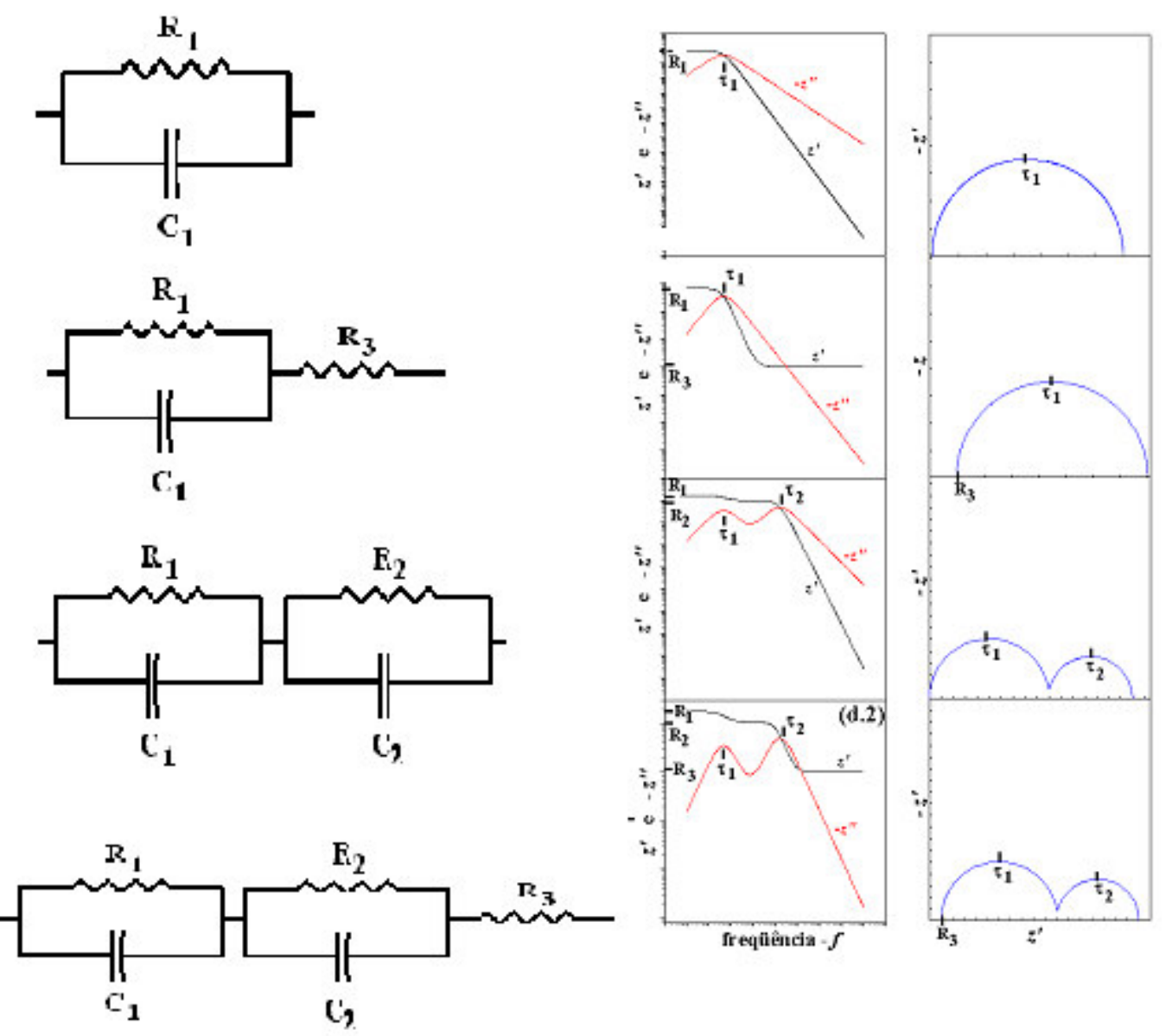

Figura 5.1: Representação do modelo de circuitos equivalentes e a representação em termos de impedância. 


\subsection{Modelo de Dyre}

Em meios desordenados, tais como materiais poliméricos, os mecanismos de condução provavelmente ocorrem como um evento de saltos (hopping) entre estados localizados. O modelo de barreiras de energias livres aleatórias (randon free energy barrier model-RFEB) ${ }^{33}$ leva em consideração a desordem do meio através de uma distribuição de barreiras de energias com valores situados entre um valor mínimo $\left(\mathrm{E}_{\mathrm{min}}\right)$ e um valor máximo $\left(\mathrm{E}_{\mathrm{má}}\right)$. Assim o portador para transpor estas barreiras leva um tempo $\tau$ (denominado tempo de espera) havendo uma freqüência de escape $\gamma=\tau^{-1}$, seguindo um processo de Arrhenius dada por $\gamma=\gamma_{0} \mathrm{e}^{-\mathrm{E} / \mathrm{kT}}$ onde $\mathrm{E}_{\min } \leq \mathrm{E} \leq \mathrm{E}_{\text {máx }}$.

Em um meio desordenado onde existe uma distribuição de energia de estados localizados (sítios de residência para os portadores) ${ }^{30}$ a função tempo de residência $\Phi(\mathrm{t})$ é obtida pela média de todos os processos possíveis de decaimento $\mathrm{Q}_{\mathrm{i}}(\mathrm{t})$ :

$$
\Phi(\mathrm{t})=\left\langle\mathrm{Q}_{\mathrm{i}}(\mathrm{t})\right\rangle
$$

Cada processo de decaimento é considerado exponencial com o tempo, com $\Phi(\mathrm{t})$ escrito como:

$$
\Phi(\mathrm{t})=\left\langle\mathrm{e}^{-\gamma_{\mathrm{i}} \mathrm{t}}\right\rangle,
$$

onde $\gamma_{\mathrm{i}}$ é ativado seguindo um processo de Ahrrhenius:

$$
\gamma_{i}=\gamma_{0} e^{-E_{i} / k T}
$$

As barreiras de energia livre $E_{i}$ são uniformemente e continuamente distribuídas entre um mínimo, $E_{\min }$, e um máximo, $E_{\max }$, respectivamente, o mais baixo e o mais alto valores de energia, e $\gamma_{o}$ é um fator de freqüência o qual depende da 
distância média $\mathrm{r}$ entre os sítios de salto (hopping sites). Então, $\Phi(\mathrm{t})$ pode ser calculada por:

$$
\Phi(t)=\frac{1}{E_{\max }-E_{\min }} \int_{E_{\min }}^{E_{\max }} e^{-\left(\gamma o e^{-E / k T}\right) t} d E
$$

que, após uma mudança de variáveis, $\gamma_{\max }=\gamma_{o} e^{-E_{\min } / k T}$ e $\gamma_{\min }=\gamma_{o} e^{-E_{\max } / k T}$, fornece:

$$
\Phi(\mathrm{t})=\frac{1}{\ln \gamma_{\max } / \gamma_{\min }} \int_{\gamma_{\min }}^{\gamma_{\max }} \mathrm{e}^{-\gamma \mathrm{t}} \mathrm{d} \gamma / \gamma
$$

Aplicando a transformada de Laplace a $\Phi(\mathrm{t})$, obtemos

$$
\begin{aligned}
& \phi^{*}(u)=(1 / u \ln \lambda) \ln \left[\left(1+u / \gamma_{\min }\right) /\left(1+u / \gamma_{\max }\right)\right] \\
& \operatorname{com} \lambda=\gamma_{\max } / \gamma_{\min } .
\end{aligned}
$$

Através da equação do transporte estocástico aplicado a uma rede

$$
\sigma(\omega)=C\left[1 / \phi^{*}(i \omega)-i \omega\right]
$$

com $\phi^{*}(i \omega)$ a transformada de Laplace de $\Phi(\mathrm{t})$, obtemos, a partir das equações (8) e (9), a equação para a condutividade de um meio sólido desordenado.

$$
\sigma(\omega)=C\left[\frac{i \omega \ln \lambda}{\ln \left(\frac{1+i \omega / \gamma_{\min }}{1+i \omega / \gamma_{\max }}\right)}-i \omega\right]
$$

sendo C um parâmetro que depende da densidade de portadores do material.

Tomando-se $\sigma_{0}=C \gamma_{\min } \ln \left(\gamma_{\max } / \gamma_{\min }\right)$, obtemos a Eq. (11) em termos de $\sigma_{0}$ : 


$$
\sigma_{D}^{*}(\omega)=\frac{\frac{\omega}{\gamma_{\min }} \sigma_{0} i}{\ln \left(\frac{\omega i}{1+\frac{\omega i}{\gamma_{\min }}}\right)}-\frac{\omega \sigma_{0} i}{\gamma_{\min } \ln \left(\frac{\gamma_{\max }}{\gamma_{\min }}\right)}
$$

Da Eq. (11), os parâmetros $\sigma_{0}, \gamma_{\min }$ e $\gamma_{\max }$ são obtidos diretamente das curvas experimentais $\sigma^{\prime}(\omega)$ e $\sigma^{\prime \prime}(\omega)$ vs. $\omega$. A Fig. 5.2 apresenta ilustrações de curvas $\sigma^{\prime}(\omega)$ vs. $\omega$ típicas de sistemas sólidos desordenados.

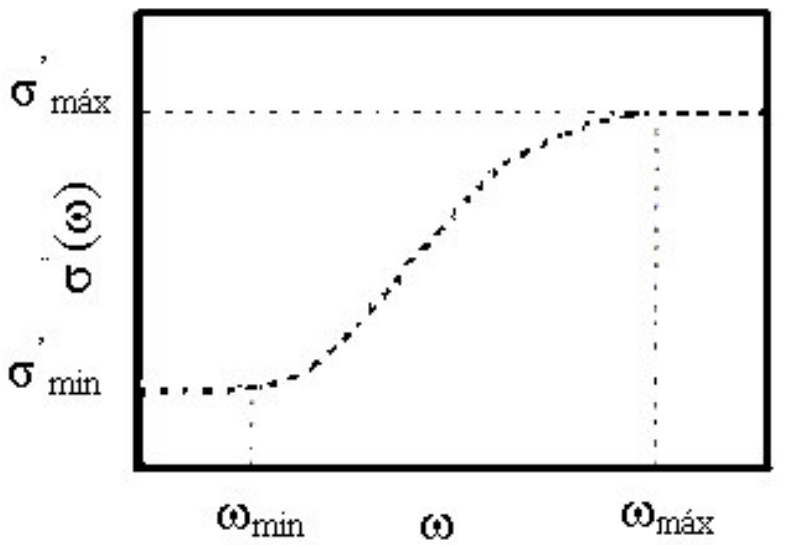

Figura 5.2: Comportamento da componente real da condutividade complexa no modelo de barreiras de energias livres aleatórias (RFEB).

Nesta figura observamos o comportamento de $\sigma^{`}(\omega)$ apresentando dois patamares, um em frequiências mais altas definindo a freqüência de escape máxima $\gamma_{\text {máx }}\left(\omega_{\operatorname{máx}}=2 \pi \gamma_{\text {máx }}\right)$ e outro em freqüência mais baixa definindo a freqüência de escape mínima $\gamma_{\min }\left(\omega_{\min }=2 \pi \gamma_{\min }\right)$ e ainda o valor de $\sigma_{0}$ que representa a condutividade em regime dc. $\mathrm{O}$ valor da freqüência $\gamma_{\text {máx }}$, em geral, é maior que o 
valor alcançado pelos equipamentos de medidas, assim a equação (11) pode ser reescrita como

$$
\sigma_{D}^{*}(\omega)=\frac{\frac{\omega i}{\gamma_{\min }} \sigma_{0}}{\ln \left(1+\frac{\omega i}{\gamma_{\text {min }}}\right)}
$$

A equação (12) representa a expressão para a condutividade de um sistema, onde o patamar apresentado em altas freqüências não pode ser obtido pelos equipamentos de medidas. 


\section{Capítulo:Resultados e discussões}

Neste capítulo apresentamos os resultados de medidas de corrente em campo constante (dc) e em campo alternado (ac) obtidos de dispositivos emissores de luz à base de MEH-PPV, óxido de zinco dopado com índio (I-ZnO) como eletrodo transparente e alumínio (Al) como eletrodo metálico. Tais medidas foram realizadas com o objetivo principal de se investigar os mecanismos de injeção de portadores de carga nas interfaces eletrodo-polímero assim como o transporte desses portadores ao longo do filme de MEH-PPV. Dispositivos usando I-ZnO ainda são pouco explorados e este estudo deverá contribuir para a avaliação da aplicabilidade destes óxidos em dispositivos emissores de luz poliméricos. Também foram realizadas e serão apresentadas, medidas de condutividade em filmes de $\mathrm{ZnO}$ não dopado, com o objetivo de investigar os mecanismos de condução nestes materiais.

\subsection{Caracterização do óxido de zinco $(\mathrm{ZnO})$}

A inclusão desse item tem como objetivo a caracterização do I-ZnO e do $\mathrm{ZnO}$ não dopado. Apresentamos as características destes óxidos através de medidas de absorção óptica (item 4.3), e valores de alguns parâmetros fornecidos por colaboradores.

Com o objetivo de investigar a transparência óptica dos filmes de $\mathrm{ZnO}$ a fim de utilizá-los como eletrodos transparentes em PLED, foram realizadas medidas de absorção UV-Vis e esta medida foi comparada com outra realizada em filme com ITO,

comumente caracterizado e estudado por diversos autores ${ }^{28,7}$ A Figura 6.1 mostra as 
curvas de absorção óptica do filme de $\mathrm{ZnO}, \mathrm{ZnO}$ dopado com índio e, para termos comparativos, do ITO.

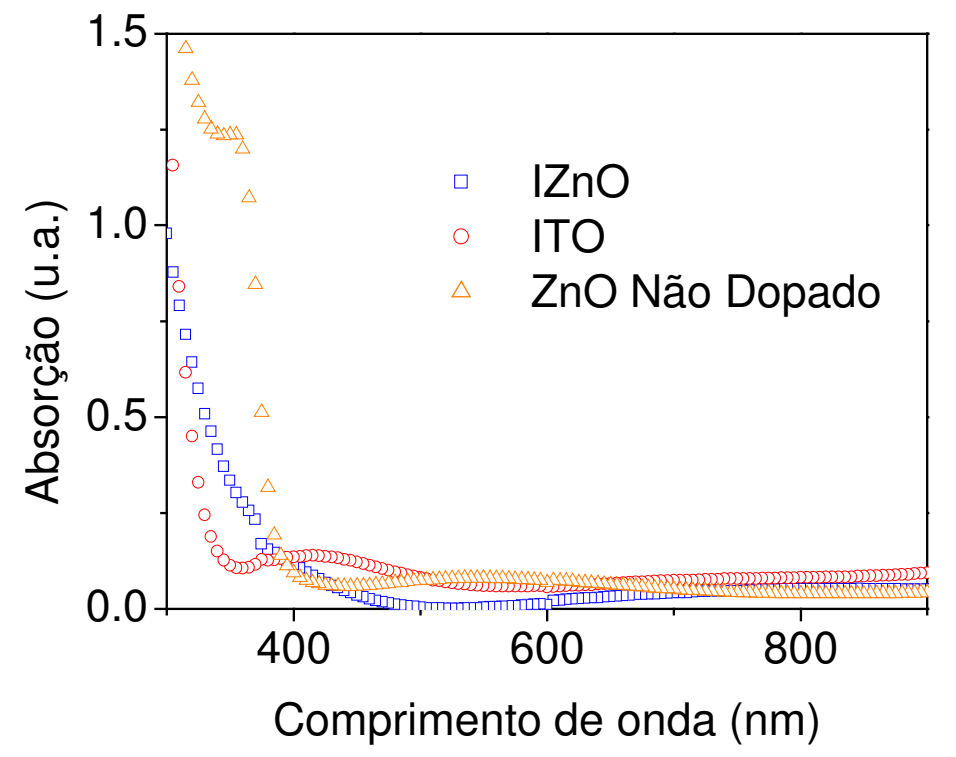

Figura 6.1: Medidas de absorção óptica em filmes de $\mathrm{IZnO}$ e $\mathrm{ZnO}$ não dopado. Para comparação, uma medida com ITO é apresentada.

Na curva apresentada na Figura 6.1 vê-se que nenhum dos óxidos apresenta qualquer absorção na região visível do espectro. Portanto, do ponto de vista óptico, o I-ZnO pode ser utilizado como eletrodo transparente em PLEDs.

Os filmes de I-ZnO têm uma espessura na ordem dos160 nm e uma resistividade na ordem dos $5.5 \times 10^{-4} \Omega . c m$. Os valores da função trabalho e gap estão em torno de $5.2 \mathrm{eV}^{21}$ e $3.3 \mathrm{eV}^{32}$, respectivamente.

\subsection{Medidas elétricas com filme de óxido de zinco $(\mathrm{ZnO})$}

$\mathrm{O} \mathrm{ZnO}$ tem recentemente chamado a atenção de pesquisadores por suas aplicações enquanto elementos ativos em dispositivos eletrônicos ${ }^{21}$. Quando dopado com índio, torna-se um condutor transparente e nosso interesse é, portanto, aplicá-lo 
em substituição ao eletrodo de ITO em PLEDs. Nesta seção vamos apresentar um estudo sobre a condutividade de filmes de $\mathrm{ZnO}$ puro crescido por deposição a vácuo (rf magneton sputtering), fornecido pelo CENIMAT da Faculdade de Ciências e Tecnologia da Universidade Nova de Lisboa, Portugal.

Resultados anteriores mostraram que sob iluminação ultra-violeta o filme de $\mathrm{ZnO}$ tem sua condutividade aumentada em até 7 ordens de grandeza, sendo esse efeito reversível pela sua exposição em atmosfera de ozônio. (Fig. 6.2)

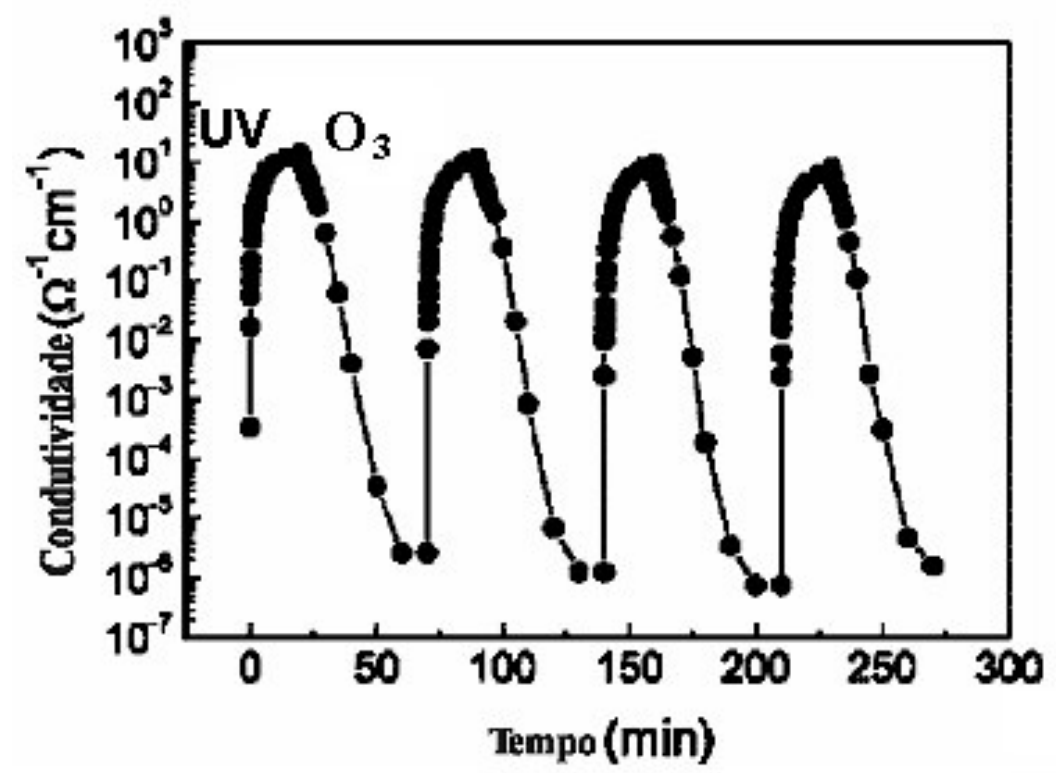

Figura 6.2: Variação da condutividade em filmes de óxido de zinco não dopado ${ }^{31}$.

Na Figura 6.3 apresentamos medidas de impedância ac de um filme de $\mathrm{ZnO}$ depositado, numa estrutura como a mostrada na Figura 3.3, capítulo 3, para três temperaturas $(300 \mathrm{~K}, 260 \mathrm{~K}$ e $220 \mathrm{~K})$.

Nessa estrutura os eletrodos são de alumínio. Observamos que quase não há variação da resistividade com a temperatura. O mesmo ocorre com a amostra depois de sofrer iluminação UV de baixa intensidade por vinte minutos Figura 6.3b. É importante ressaltar que a variação da impedância é a mesma quando os eletrodos são 
protegidos da luz, o que mostra que o efeito é oriundo de alterações que ocorrem na estrutura do $\mathrm{ZnO}$.
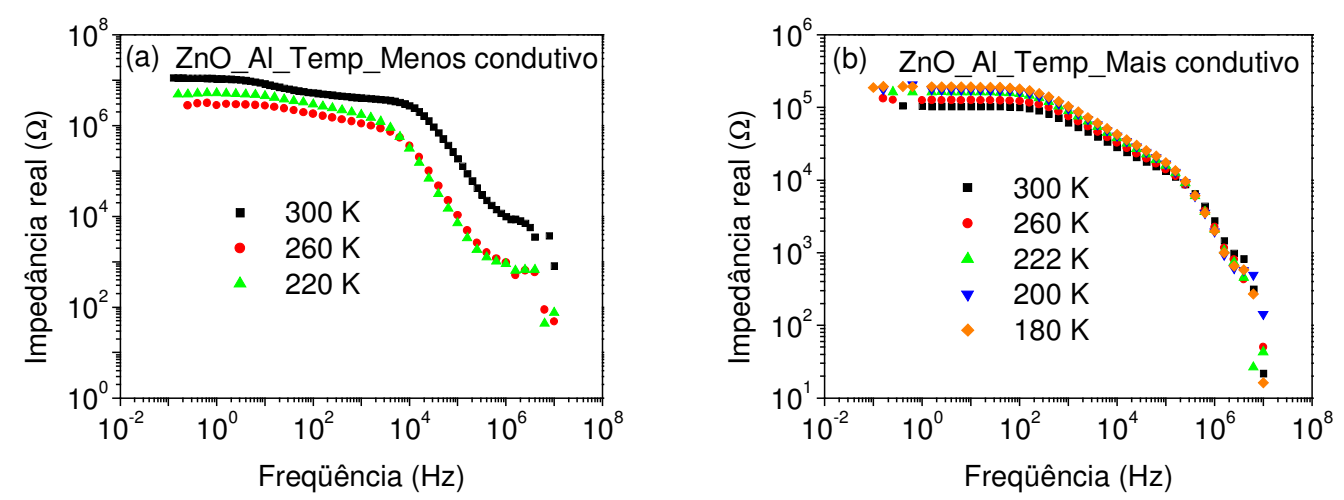

Figura 6.3: Medidas de impedância ac de um filme de $\mathrm{ZnO}$ em diferentes temperaturas (a) Filme menos condutivo e (b) Filme mais condutivo.

A Figura 6.4a mostra os resultados de medidas das componentes real - Z' $(f)$ - e imaginária - Z' $(f)$ - de um filme de ZnO tal como foi evaporado. Observamos o clássico patamar de baixa freqüência na curva de Z'(f), de valor próximo a $80 \mathrm{M} \Omega$, que se estende até um determinado valor de freqüência, denominado de freqüência crítica $\gamma_{c}$, a partir do qual a impedância decresce continuamente além da região de MHz. A curva Z' $(f)$ exibe um máximo próximo a $f_{\mathrm{c}}(100 \mathrm{~Hz})$, indicando um largo processo de relaxação. Após ser iluminada durante 20 minutos sob luz UV (380 nm), repetimos a medida e observamos que a impedância $Z^{\prime}(f)$ diminui na região de baixa freqüência, para aproximadamente $0,15 \mathrm{M} \Omega$, mas aumenta em uma ordem de grandeza na região de MHz. Isso é conseqüência, em primeiro lugar, do aumento do patamar de baixa freqüência $\left(f_{\mathrm{c}} \sim 2 \mathrm{KHz}\right)$, e da superposição de uma nova relaxação, anteriormente não detectada, com freqüência crítica próxima a $0,2 \mathrm{MHz}$, como fica evidente na curva de Z" $(f)$ (Figura 6.4b). A terceira medida, mostrada na Figura 6.4c, é feita após a exposição da amostra a um fluxo de ozônio $\left(\mathrm{O}_{3}\right)$, onde é verificada uma recuperação parcial dos valores originais de impedância. O valor de Z' $(f)$ em baixas 
freqüências é praticamente recuperado, mas não os de altas freqüências, nem o de $f_{\mathrm{c}}$. Observa-se, ainda dois picos de relaxação, porém um deles aprece em freqüência relativamente baixa $(\sim 2,5 \mathrm{~Hz})$.
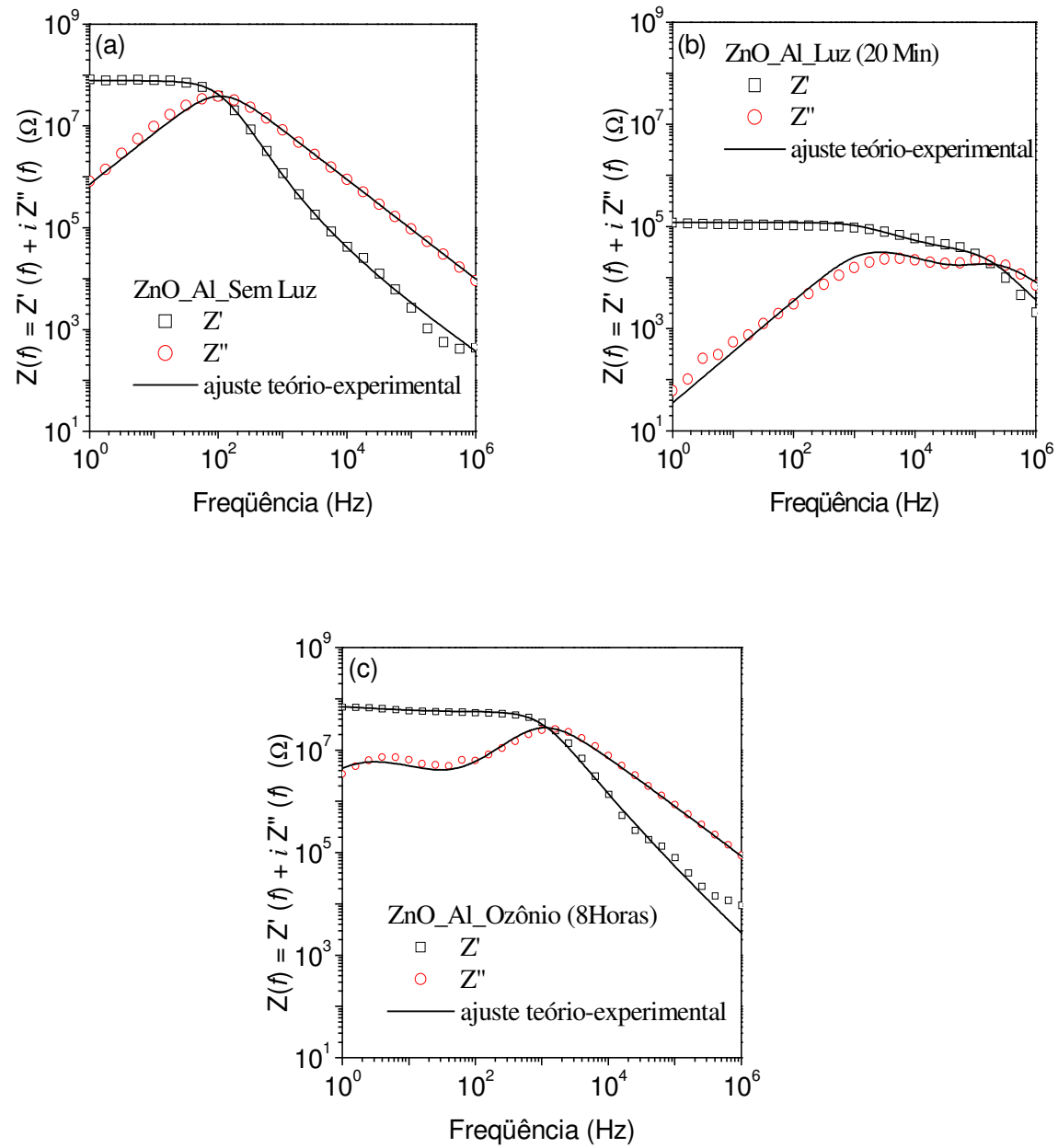

Figura 6.4 Componentes real e imaginária de medidas de impedância.(a) Antes de iluminar e (b) Após iluminar durante 20 minutos. (c) Após expor a amostra em atmosfera de Ozônio. As linhas contínuas representam os ajustes teóricos.

As curvas parametrizadas da Figura 6.5, Z" vs Z', nos mostram um efeito adicional e intrigante. Os pontos experimentais da Fig. 6.5a desenham um quase semicírculo no diagrama Z" vs Z', indicando uma só distribuição de tempos de relaxação. Já a Fig. 6.5b, da amostra iluminada, mostra a superposição de dois semi-círculos, um de raio de aproximadamente $20 \mathrm{~K} \Omega$, centrado em $20 \mathrm{~K} \Omega$, e outro de raio $35 \mathrm{~K} \Omega$ e 
centrado em $75 \mathrm{~K} \Omega$. Já a curva da Fig. 6.5c, da amostra tratada com $\mathrm{O}_{3}$, também apresenta dois semi-círculos, um de raio próximo a $30 \mathrm{M} \Omega$, centrado em $30 \mathrm{M} \Omega$, e outro de raio $8 \mathrm{M} \Omega$, centrado em $64 \mathrm{M} \Omega$. Elaboramos uma hipótese na tentativa de entender a variação das dimensões dos semi-círculos e seus deslocamentos. A partir da amostra mais condutiva, Fig. 6.5b, consideramos que o semi-círculo A, na região de frequiências mais altas, foi uma evolução do único que aparece na Fig. 6.5a; nessa figura a impedância associada ao B (de freqüências mais baixas) é muito superior à do A, o que explica o seu não aparecimento. Já, na Fig. 6.5c, a recuperação da impedância total se deu parcialmente o que permitiu observar ainda o semi-círculo A.
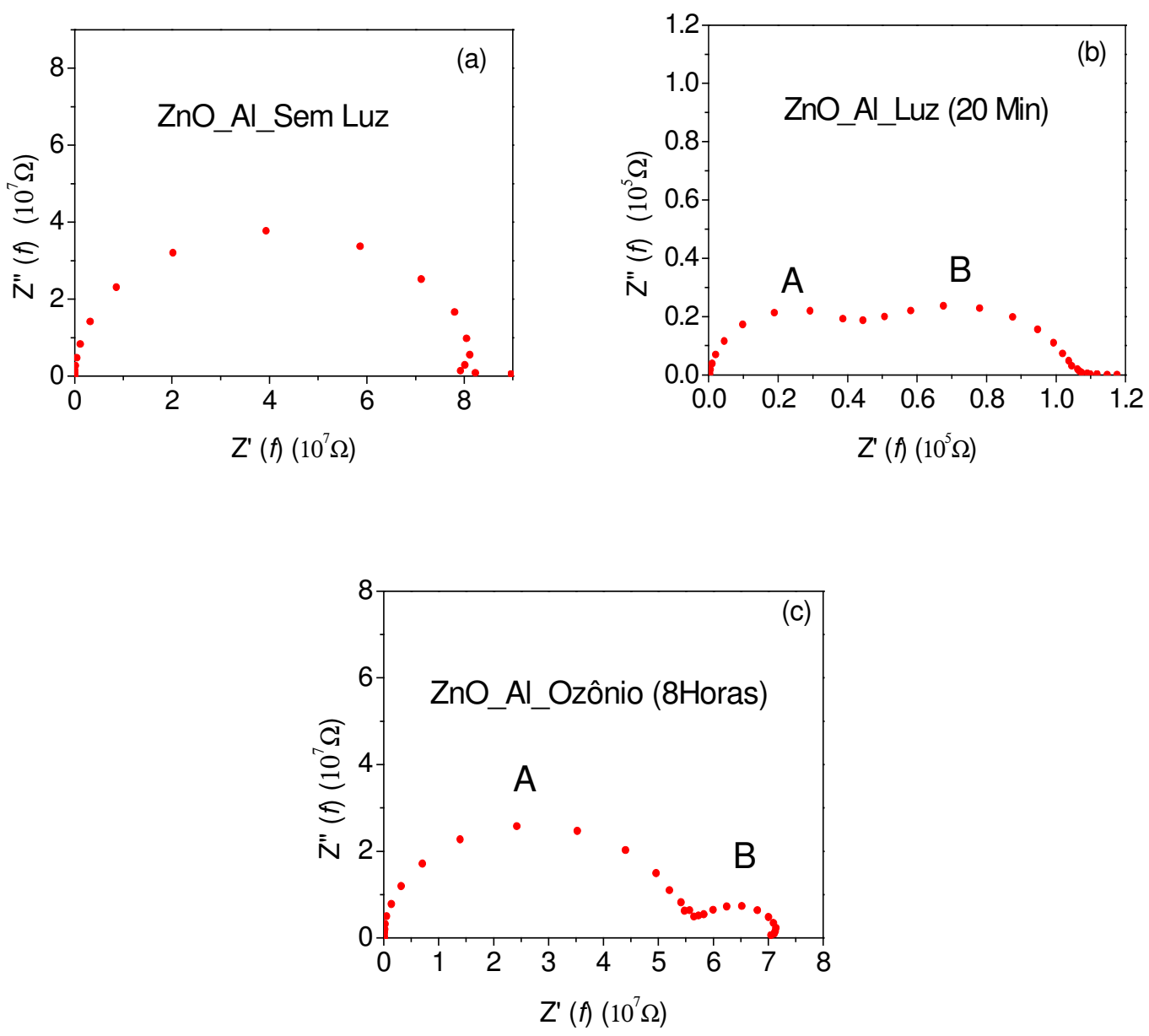

Figura 6.5: Gráficos Z” vs. Z' das medidas apresentadas na figura 6.3.(a) Antes de iluminar e (b) Após iluminar durante 20 minutos e (c) Após expor a amostra durante 8 horas em atmosfera de ozônio. 


\subsection{Medidas de corrente vs. tensão (I vs.V) de PLEDs com I-ZnO}

A obtenção de medidas de corrente vs. tensão (IxV) em dispositivos eletrônicos é importante para o estudo e a investigação de propriedades elétricas fundamentais sobre o movimento de portadores de cargas em tais sistemas. Primeiro, porque o comportamento destas curvas como função da temperatura e dos materiais utilizados como eletrodos possibilita um estudo detalhado dos mecanismos de injeção e transporte de portadores de carga envolvidos. Segundo, porque é uma técnica bastante conhecida e empregada na investigação do desempenho óptico e elétrico desses sistemas, sobretudo na avaliação de sua eficiência luminosa ${ }^{27}$.

Com base nas observações acima, medidas de corrente vs. tensão foram realizadas em dispositivos I-ZnO/MEH-PPV/Al, preparados segundo os procedimentos apresentados no capítulo $3 . \mathrm{O}$ I-ZnO é estudado aqui como óxido condutor injetor de buracos, alternativo ao ITO, por apresentar função trabalho em torno de 5,2 $\mathrm{eV}^{21}$ similar ao valor de energia referente a banda HOMO do MEH-PPV. Ele é transparente na região de emissão do MEH-PPV e possui baixa resistividade. Além disto vários trabalhos na literatura têm explorado $\mathrm{ZnO}$ em diversas aplicações, sobretudo em sensores de gases ${ }^{32}$; mas ainda há pouca aplicação desse óxido como ânodo em PLEDs. As medidas elétricas foram realizadas com controle de umidade e luz, a fim de evitar, respectivamente, a degradação da amostra e efeitos de fotocondução durante a realização das medidas. A Figura 6.6 mostra a curva $\mathrm{I} x \mathrm{~V}$ obtido com um dispositivo I-ZnO/MEH-PPV/Al, realizada a temperatura ambiente, com espessura do MEH em torno de $400 \mathrm{~nm}$ e área efetiva dos eletrodos $\sim 4 \mathrm{~mm}^{2}$. 


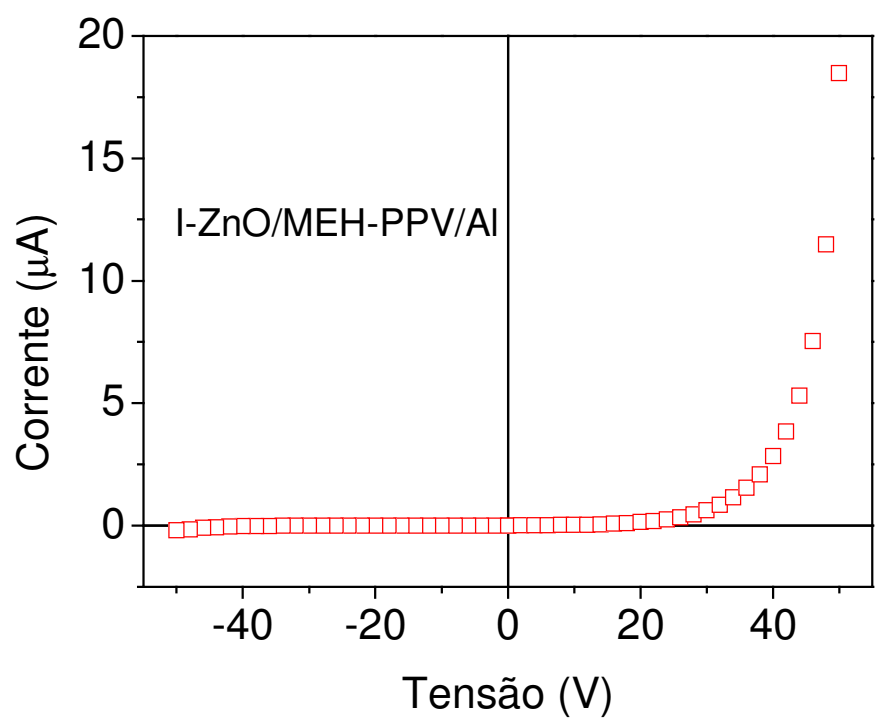

Figura 6.6: Curva densidade de corrente vs. tensão para dispositivos I-ZnO/MEH-PPV/Al. A espessura do polímero é $\sim 400 \mathrm{~nm}$ e área dos eletrodos $\sim 4 \mathrm{~mm}^{2}$. Medida realizada em temperatura ambiente sob vácuo e no escuro.

Na curva I vs. V mostrada na Figura 6.6 observamos o comportamento típico de diodos retificadores: para tensões negativas a corrente é bem inferior ao valor obtido em tensões positivas, ou seja, no modo direto (I-ZnO polarizado positivamente). Definindo-se a tensão de operação $\left(\mathrm{V}_{0}\right)$ do dispositivo como o valor da tensão em que a corrente passa a aumentar rapidamente com a tensão aplicada, obtemos $\mathrm{V}_{0} \sim$ de $25 \mathrm{~V}$. A partir da tensão de operação $\left(\mathrm{V}_{0}\right)$ a corrente apresenta um aumento no modo direto de tensão. Como a função trabalho do $\mathrm{ZnO}(5,2 \mathrm{eV})^{21}$ está próxima a HOMO do polímero $(\sim 5,0 \mathrm{eV})^{25}$, a barreira para injeção de portadores positivos é baixa, o que é uma forte indicio de que a corrente é dominada por transporte de portadores positivos. Tal observação deve-se também ao fato de existir uma elevada barreira de energia para a injeção de portadores negativos na interface Al/MEH devido ao elevado valor da função trabalho do alumínio, em torno de $4,1 \mathrm{eV}$. 
Com o objetivo de estudar o efeito da temperatura nos processos de injeção e transporte nos dispositivos, realizamos medidas de corrente $v s$. tensão numa estrutura I-ZnO/MEH-PPV/Al. A figura 6.7 mostra os resultados IxV obtidos para temperaturas entre $175 \mathrm{~K}$ a $300 \mathrm{~K}$, de $25 \mathrm{~K}$ em $25 \mathrm{~K}$, em escala linear (6.7a) e em escala monologarítimica (6.7b). As medidas foram realizadas sob vácuo usando-se o sistema descrito no item 4.1 do Capítulo 4.
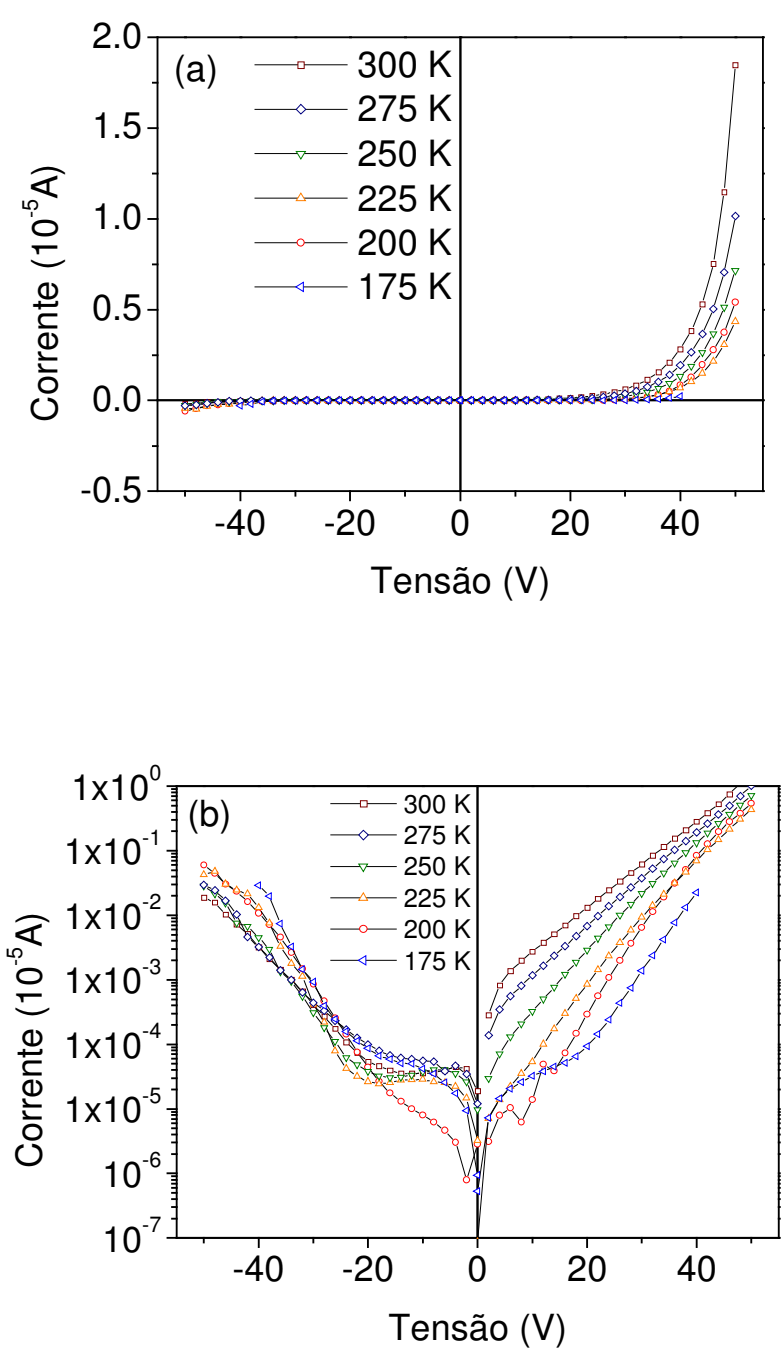

Figura 6.7: Curva IxV de um dispositivo I-ZnO/MEH-PPV/Al em diferentes temperaturas. (a) Em escala linear e (b) Em escala mono-logaritmica. 
Observamos que diminuindo a temperatura, a corrente no modo direto diminui enquanto a corrente no modo reverso apresenta pouca variação. Em baixas temperaturas a curva torna-se praticamente simétrica indicando que o mesmo processo de condução deve controlar a corrente nas duas polaridades ${ }^{5}$. Além disso, observa-se que a dependência com a temperatura é menor para valores altos da tensão direta, o que implica uma participação do efeito de injeção por tunelamento que se superpõe ao de injeção Schottky. Entretanto, a tensão limiar (threshold) $\mathrm{V}_{0}$ aumenta com a diminuição da temperatura mostrando a presença da barreira Schottky no controle de injeção, sobretudo na interface MEH-PPV/Al. A interface I-ZnO/MEH-PPV apresenta menor barreira à injeção de portadores, aproximando-se de um contato ôhmico.

\subsection{Medidas Complexas do dispositivo I-ZnO/MEH-PPV/AI}

\subsubsection{Impedância}

Nas medidas IxV, apresentadas no item 6.3, registramos a condução eletrônica, resultado da composição dos processos de injeção e de transporte. Podemos, em princípio, separar esses dois mecanismos através de medidas com campo alternado se os tempos envolvidos em cada fenômeno forem diferentes. Realizamos medidas de impedância complexa (Z* = Z' + i Z') em dispositivos I-ZnO/MEH-PPV/Al, num intervalo de freqüência de $10^{-2}$ a $10^{7} \mathrm{~Hz}$ aplicando uma tensão oscilante $\left(\mathrm{V}_{\mathrm{ac}}\right)$ de $1 \mathrm{~V}$ e uma tensão de polarização $\left(\mathrm{V}_{\text {bias }}\right)$ de 15,30 e $40 \mathrm{~V}$. A figura 6.8 mostra o resultado obtido para medida realizada em temperatura ambiente, com $\mathrm{V}_{\text {bias }}=15 \mathrm{~V}$, no escuro e sob vácuo para evitar possíveis efeitos de fotoxidação do material polimérico. 


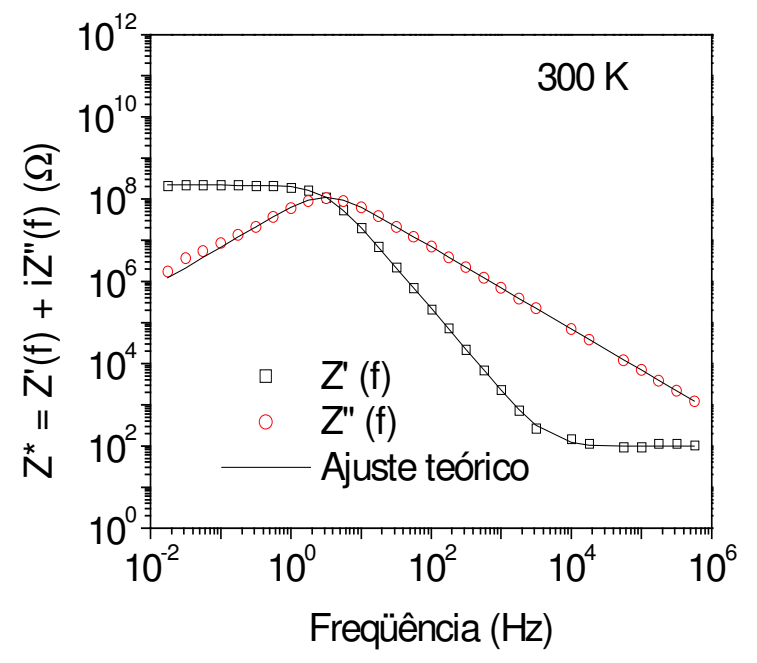

Figura 6.8: Componente real $Z^{\prime}(f)$ e imaginaria $Z^{\prime \prime}(f)$ em função da freqüência do campo elétrico oscilante do dispositivo I-ZnO/MEH-PPV/Al.

A Fig. 6.8 mostra dois patamares na curva de Z'(f); um na região de baixas freqüências e outro na região de altas freqüências. Para $300 \mathrm{~K}$, o primeiro patamar ocorre para freqüências inferiores a $1 \mathrm{~Hz}$ e o de alta para freqüências superiores a $10^{4}$ Hz. Já a componente imaginária apresenta um máximo também em torno de $1 \mathrm{~Hz}$, coincidente com a transição entre os dois patamares da componente real. A curva preenchida é o ajuste teórico, que será discutido no item 7.1.1 e os valores dos parâmetros ajustados serão mostrados e analisados no item 8.2.

A figura 6.9 apresenta resultados de curvas de impedância, real e imaginária, também com $\mathrm{V}_{\text {bias }}=15 \mathrm{~V}$, num intervalo de temperatura de 175 a $300 \mathrm{~K}$, de $25 \mathrm{~K}$ em $25 \mathrm{~K}$, realizadas num criostato como descrito no capítulo 4. 

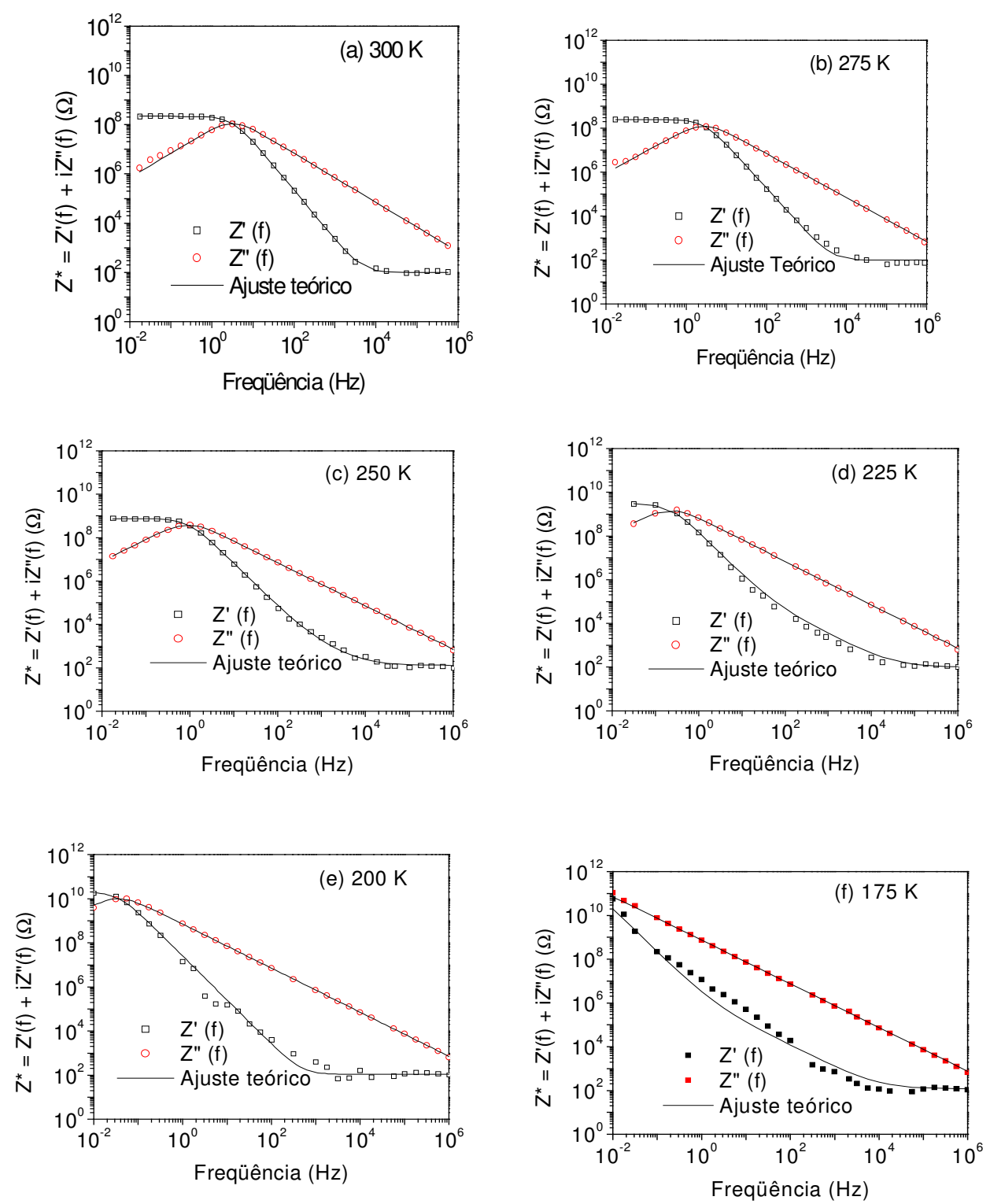

Figura 6.9: Medidas de Impedância Complexa em dispositivo I-ZnO/MEH-PPV/Al realizadas num intervalo de temperatura de 175 a $300 \mathrm{~K}$ de $25 \mathrm{em} 25 \mathrm{~K}$

Para uma melhor visualização do comportamento da Impedância com a temperatura a figura 6.10 mostra separadamente as componentes real e imaginária. 

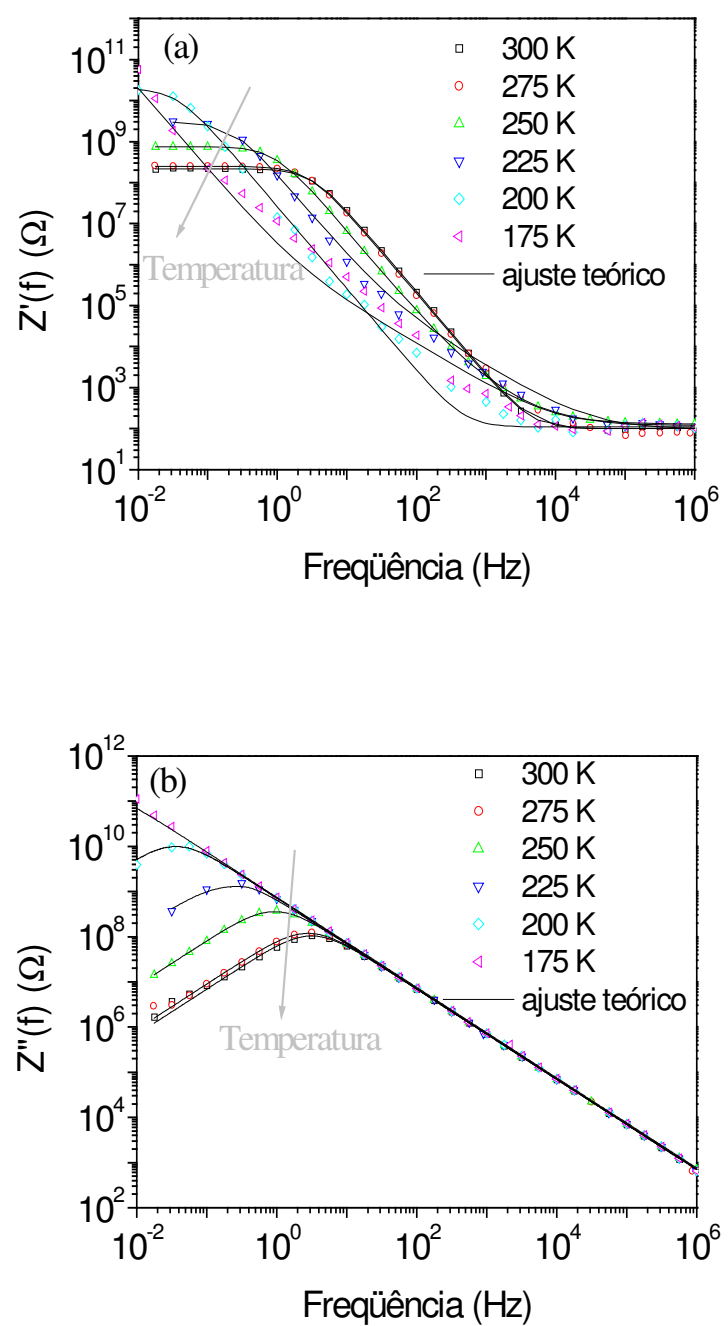

Figura 6.10 (a) Componente real (Z') e (b) Componente imaginária (Z”) de medidas de impedância complexa em um dispositivo $\mathrm{ZnO} / \mathrm{MEH}-\mathrm{PPV} / \mathrm{Al}$.

Observamos nestas curvas que o patamar da componente real Z' $(f)$ observado em baixas freqüências torna-se menos visível à medida que a temperatura diminui e a freqüência crítica $\left(f_{\mathrm{c}}\right)$ se desloca para valores cada vez menores. Sendo que em $175 \mathrm{~K}$ o patamar em Z' $(f)$ deve ocorrer abaixo de $10^{-2} \mathrm{~Hz}$, assim como o pico da relaxação em Z"(f); nesse observamos que o pico de máximo desloca-se para valores de freqüência menores à medida que a temperatura diminui. 
Os resultados de impedância complexa podem também ser analisados usandose os chamados diagramas de Argand, ou gráficos Z” vs. Z'. Na Figura 6.11 observamos a tendência de um só semi-círculo, cujo raio diminui drasticamente com o aumento da temperatura. Para $\mathrm{T}=175 \mathrm{~K}$, a impedância para baixas freqüências é muito superior a $10^{11} \Omega$; já, para $300 \mathrm{~K}$ a ordem dessa impedância essa impedância é pouco superior a $2 \times 10^{8} \Omega$. Por outro lado, a Fig. 6.11a, mostra que o valor de impedância na região de altas freqüências independe da temperatura. A extensão da região intermediária aumenta com a diminuição da temperatura; porém, sua inclinação no gráfico log-log se mantém invariável.

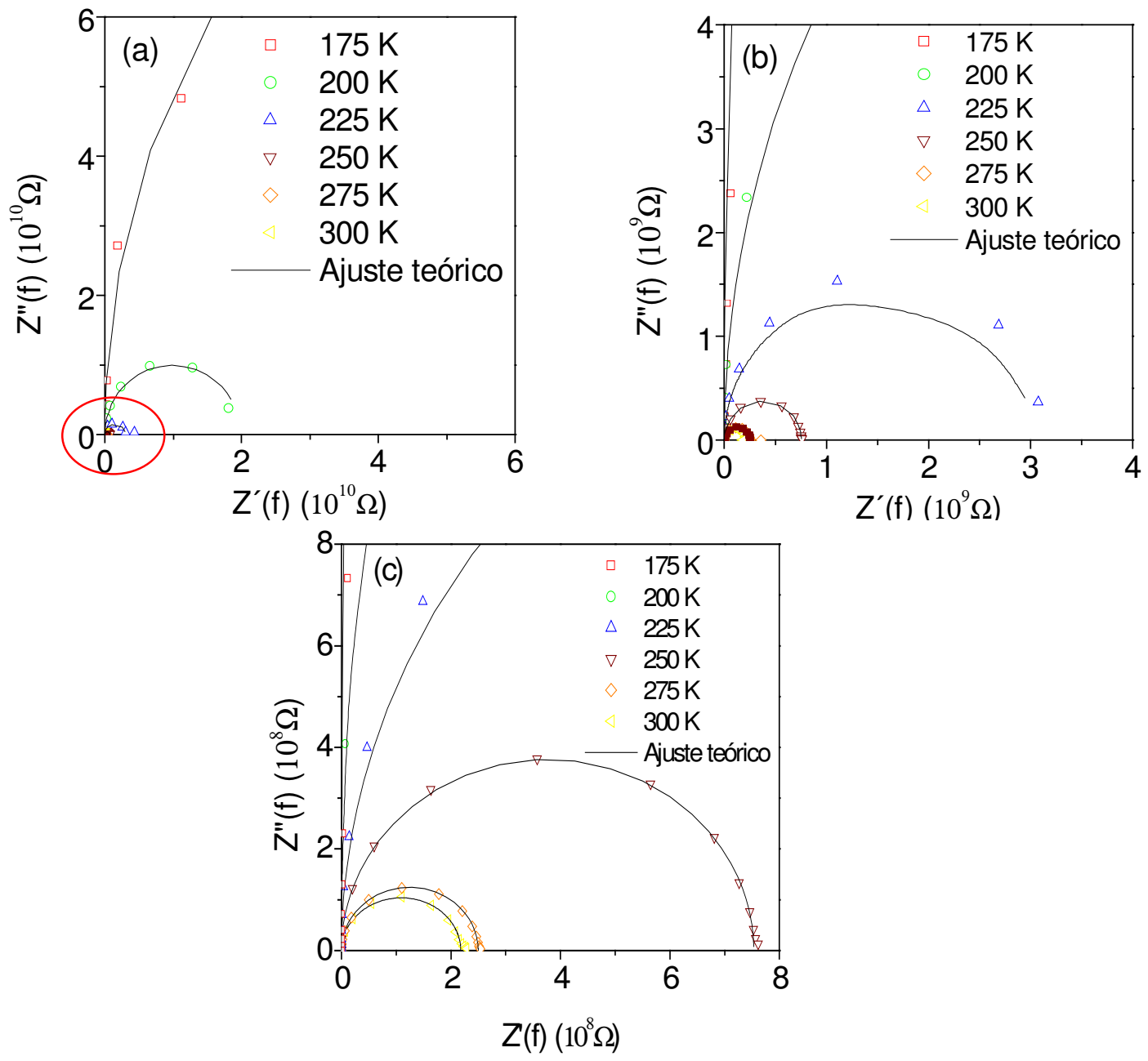

Figura 6.11: (a) Gráficos Z” vs Z'. das medidas de impedância em diferentes temperaturas. (b) e (c) Ampliação da parte circulada para melhor visualização. As linhas contínuas são os ajustes teóricos. 
Foram realizadas medidas de impedância complexa para diferentes $\mathrm{V}_{\text {bias. }}$. Essas medidas foram feitas com o intuito de estudar a contribuição da injeção de portadores nos dispositivos. A figura 6.12 apresenta os resultados de medidas de impedância realizadas para diferentes tensões de polarização a $300 \mathrm{~K}$.
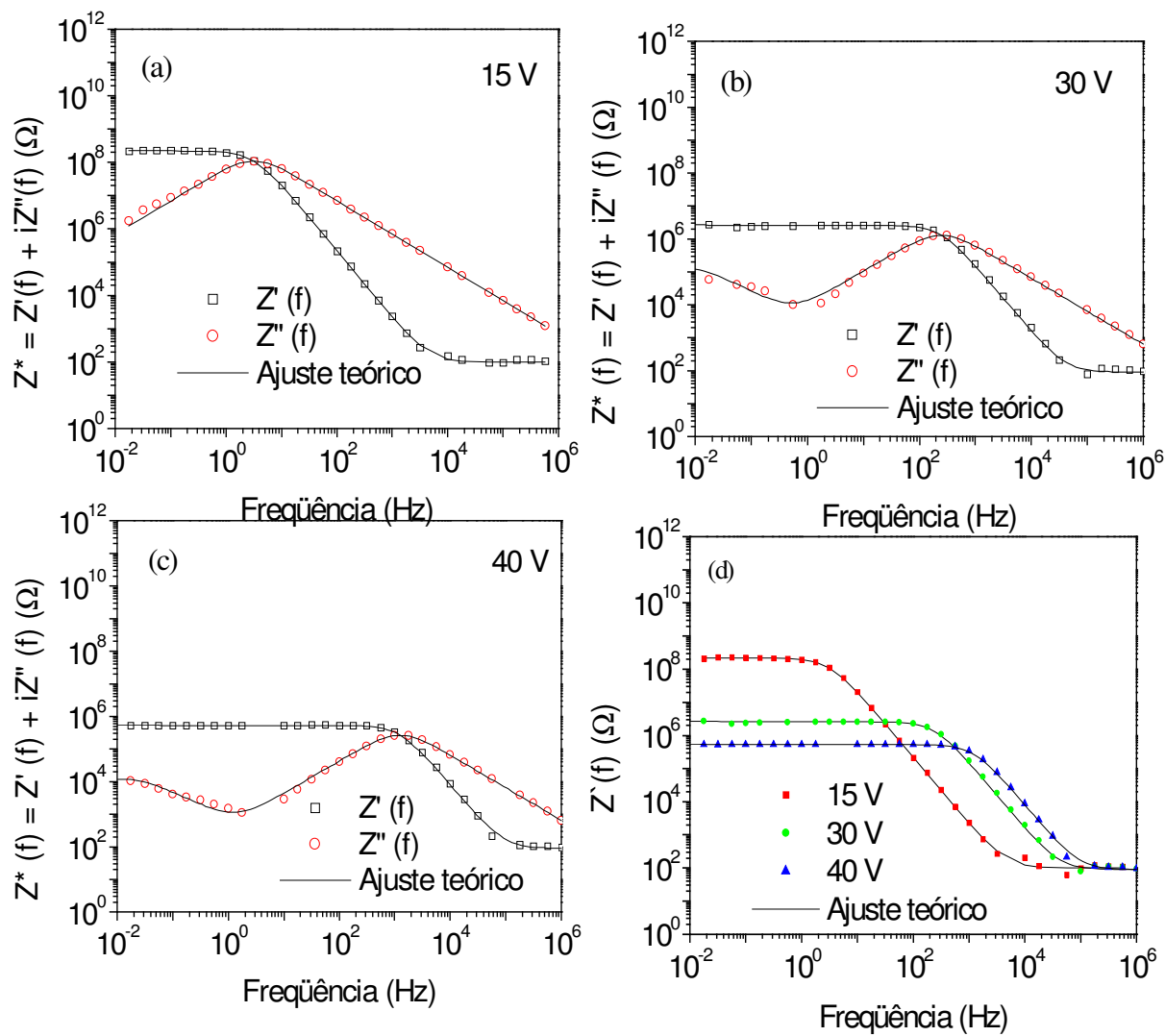

Figura 6.12: Medidas de impedância realizadas variando a tensão de polarização e mantendo a temperatura fixa em $300 \mathrm{~K}$ : (a) $\mathrm{V}_{\text {bias }}=15 \mathrm{~V}$; (b) $\mathrm{V}_{\text {bias }}=30 \mathrm{~V}$; (c) $\mathrm{V}_{\text {bias }}=40 \mathrm{~V}$; (d) Componente real da impedância em diversas tensões.

Nessa figura podemos observar que a impedância de baixas freqüências diminui com o aumento de $\mathrm{V}_{\text {bias. }} \mathrm{E}$, também, que não há variação na região de altas freqüências, assim como, a inclinação da região intermediária mantém-se inalterada. Em resumo, o efeito de $V_{\text {bias }}$ é semelhante ao da temperatura. Na expressão da injeção 
Schottky, a energia da barreira desempenha um papel primordial, assim como o da temperatura. Portanto, em baixas freqüências o valor de impedância do dispositivo, em geral, é dominado pelos efeitos de interfaces. Já, em altas freqüências, comumente, o domínio no valor da impedância é devido ao transporte no interior do material ativo no dispositivo.

\subsubsection{Condutividade}

A técnica de medida de condutividade complexa é uma importante ferramenta utilizada no estudo dos mecanismos de condução de uma variedade de materiais desordenados, incluindo os polímeros ${ }^{33,34}$. Através do estudo das componentes real e imaginária da condutividade podemos obter características importantes do mecanismo de condução no material.

Neste item apresentamos como comparação os mesmos resultados obtidos em termos de condutividade complexa $\sigma^{*}(f)=\sigma^{\prime}(f)+i \sigma^{\prime}$ ' $(f)$ em estruturas do tipo I$\mathrm{ZnO} / \mathrm{MEH}-\mathrm{PPV} / \mathrm{Al}$ como função da frequiência num intervalo de $10^{-2}$ a $10^{6} \mathrm{~Hz}$ e da temperatura num intervalo de $175 \mathrm{~K}$ a $300 \mathrm{~K}$. A figura 6.13 mostra o comportamento das componentes real e imaginária da condutividade do dispositivo em função da freqüência para diferentes temperaturas $(175 \mathrm{~K}$ a $300 \mathrm{~K})$. 

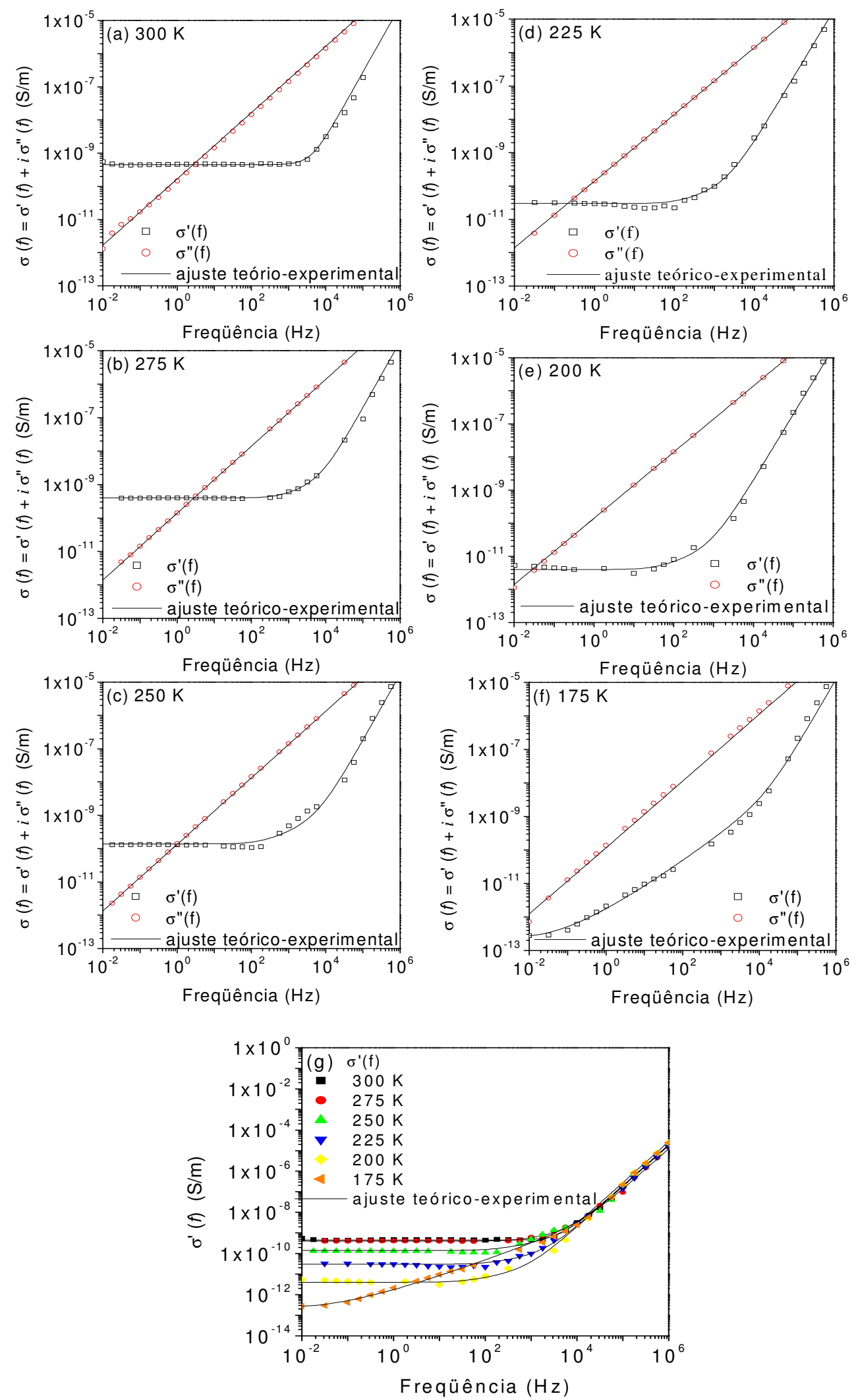

Figura 6.13: Componentes real, $\sigma^{\prime}(\mathrm{f})$, e imaginária, $\sigma^{\prime \prime}(\mathrm{f})$, obtidas de amostras $\mathrm{ZnO/MEH-}$ PPV/Al nas temperaturas (a) $300 \mathrm{~K}$, (b) $275 \mathrm{~K}$, (c) $250 \mathrm{~K}$, (d) $225 \mathrm{~K}$, (e) $200 \mathrm{~K}$ e (f) $175 \mathrm{~K}$ (g) Componente real nas diversas temperaturas. As linhas continuas (-) são os ajustes obtidos com a equação 5 do item 7.3 . 
Nessa figura observamos para a componente real da condutividade $\sigma^{\prime}(f)$ no intervalo de baixas frequiências, um patamar constante onde a condutividade independe da freqüência (regime $\mathrm{dc}, \sigma_{\mathrm{dc}}$ ), passando a depender da freqüência obedecendo a uma lei de potência para valores de frequiências mais altos. A frequiência em que ocorre esta transição é denominada de freqüência crítica $\left(f_{c}\right)$. Quanto mais alta a temperatura este patamar apresenta valores cada vez maiores, ou seja, valores mais altos da condutividade em regime dc, $\sigma_{\mathrm{dc}}$. Esse comportamento pode evidenciar um processo de injeção ativado termicamente, como já foi mostrado no modo direto de tensão da curva $\mathrm{IxV}$ da figura 6.7. Já a componente imaginária $\sigma$ "(f), apresenta uma dependência linear em todos os valores de temperaturas estudados. A título de comparação apresentamos na figura $6.13 \mathrm{~g}$. Somente as componentes reais $\sigma^{\prime}(f)$ da condutividade. Nesta figura observamos o aumento na condutividade $\sigma_{\mathrm{dc}}$ com o aumento da temperatura, enquanto a condutividade em freqüências mais altas apresenta uma fraca dependência com $\mathrm{T}$. 


\section{Capítulo:Modelos e Ajustes}

\subsection{Modelo para análise das curvas obtidas do PLED}

\subsubsection{Impedância}

Usaremos o modelo fenomenológico de circuitos equivalentes, esboçado na Fig. 7.1, para representar o dispositivo I-ZnO/MEH-PPV/Al, que associado em série um circuito RC paralelo com uma resistência. A resistência simboliza a impedância de contato e o RC o volume do MEH-PPV.

\section{$\mathbf{C}_{\mathrm{MEH}}$}

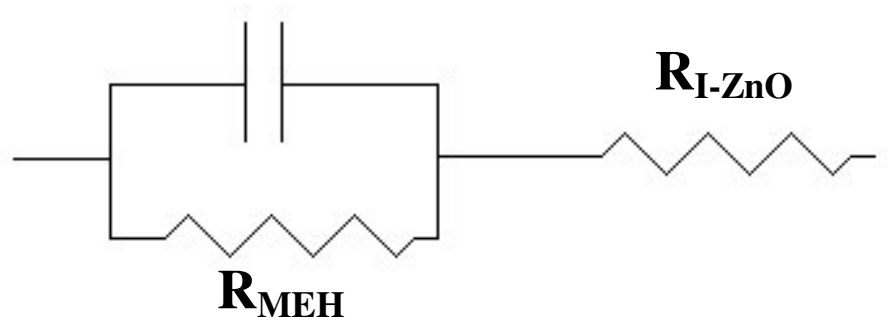

Figura 7.1: Representação do circuito equivalente utilizado para representar o sistema $\mathrm{ZnO} / \mathrm{MEH}-\mathrm{PPV} / \mathrm{Al}$

A equação equivalente para este sistema pode ser representada por:

$$
z^{*}(\mathrm{f})=z_{R}+z_{R C}^{*}(\mathrm{f})
$$

onde $z_{R}$ é a resistência do óxido de zinco dada por:

$$
z_{R}=R_{Z n O}
$$


e $z_{R C}^{*}$ (f)é a equação representando o modelo fenomenológico Cole-Cole ${ }^{35}$, que pode ser escrita como:

$$
z_{R C}^{*}(\mathrm{f}) \equiv \frac{R_{M E H}}{1+\left(\mathrm{i} 2 \pi \mathbb{f} R_{M E H} C_{M E H}\right)^{1-\alpha}} \quad 0 \leq \alpha \leq 1 .
$$

$\alpha$ é um parâmetro relacionado com a distribuição de tempos de relaxação dielétrica ${ }^{35}$. Substituindo (2) e (3) na equação (1) obtemos para a equação equivalente da impedância complexa:

$$
z^{*}(\mathrm{f})=R_{Z n O}+\frac{R_{M E H}}{1+\left(\mathrm{i} 2 \mathscr{f} R_{M E F M E H}\right)^{1-\alpha}}
$$

Através deste modelo simples de circuitos equivalentes podemos obter informações sobre características elétricas, tais como a constante dielétrica e a resistividade da camada polimérica a partir de $C_{M E H}$ e $R_{M E H}$, respectivamente. Assim sendo para a obtenção destas grandezas as seguintes equações podem ser utilizadas:

$$
\varepsilon \cong \frac{\mathrm{C}_{\mathrm{MEH}}}{\mathrm{A} \varepsilon_{0}} \ell_{\mathrm{MEH}} \quad ; \quad \rho_{M E H}=A \frac{R_{M E H}}{\ell_{\mathrm{MEH}}}
$$

onde $A$ e $\ell_{\text {MEH }}$ são a área da camada ativa e a espessura da camada polimérica respectivamente. 


\subsubsection{Condutividade}

Para a análise dos resultados das medidas de condutividade complexa obtidas de dispositivos do tipo I-ZnO/MEH-PPV/Al utilizamos o modelo de barreiras livres de energias aleatórias (modelo RFEB- Randon Free Energy Barrier Model). A Figura 7.2 apresenta uma resistência de contato com I-ZnO associada em série com o modelo para condução RFEB.

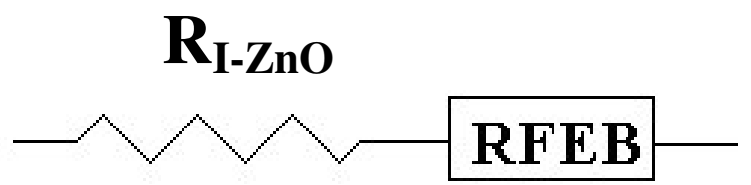

Figura 7.2: Resistência de contato do eletrodo transparente $\mathrm{ZnO}$ associada em série com o modelo microscópico de condução RFEB.

Para obtermos a equação de circuito equivalente partimos da equação para a impedância complexa

$$
z^{*}(\mathrm{f})=z_{R}+z_{R F E B}^{*}(\mathrm{f})
$$

Esta equação é composta pela impedância de contato do $\mathrm{ZnO}$ que pode ser expressa pela equação

$$
z_{R}=R \equiv \rho_{R}^{*} \frac{\ell_{Z n O}}{A}=\frac{1}{\sigma_{R}^{*}} \frac{\ell_{Z n O}}{A}
$$

onde $\rho_{R}^{*}, \sigma_{R}^{*}, \ell_{Z n O}$ e $A$ representam a resistividade, a condutividade complexa, a espessura e a área ativa respectivamente. Para o modelo RFEB a expressão para a impedância é dada por

$$
z_{R F E B}^{*}(\mathrm{f}) \equiv \rho_{R F E B}^{*} \frac{\ell_{M E H}}{A}=\frac{1}{\sigma_{R F E B}^{*}} \frac{\ell_{M E H}}{A}
$$


Sendo $\ell_{M E H}$ e $\sigma_{R F E B}^{*}$ a espessura do MEH-PPV e a condutividade complexa para o modelo RFEB. Substituindo as equações (2) e (3) na equação (1) obtemos a expressão para a impedância complexa

$$
z *(\mathrm{f})=\frac{1}{A} \frac{\sigma_{R F E B}^{*} * \ell_{Z n O}+\sigma_{R}^{*} * \ell_{M E H}}{\sigma_{R}^{*} * \sigma_{R F E B}^{*}}
$$

Assim a expressão equivalente para a condutividade complexa pode ser obtida levando em consideração a espessura do $\mathrm{ZnO}$ e do MEH-PPV

$$
\sigma_{e q .}^{*}(\mathrm{f})=\frac{\sigma_{R}^{*} * \sigma_{R F E B}^{*}}{\sigma_{R F E B}^{*} * \frac{\ell_{Z n O}}{\ell}+\sigma_{R}^{*} * \frac{\ell_{M E H}}{\ell}}
$$

A equação (5) representa a expressão para a condutividade complexa de um sistema com impedância real de contato (R), e transporte dominado pelo modelo RFEB.

\subsection{Modelo para análise das curvas obtidas do filme de $\mathrm{ZnO}$}

Para as curvas obtidas através de medidas em filme de $\mathrm{ZnO}$ não dopado também utilizamos o modelo de barreiras livres de energias aleatórias- RFEB. No modelo usado para o dispositivo foi usada resistência de contato com o óxido de zinco ( $\mathrm{ZnO}$ ) associada em série com o modelo para condução RFEB (item 5.3). Para as medidas do filme, associamos dois modelos RFEB em série, um representando o volume dos grãos e outro a interface entre grãos como mostrado na Figura 7.3. 


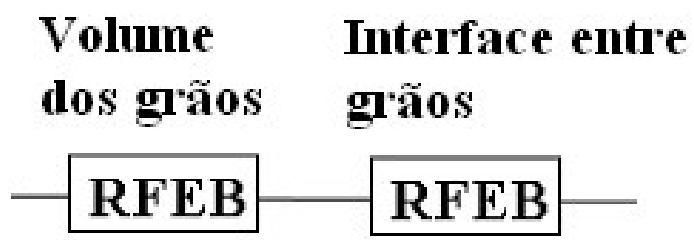

Figura 7.3: Associação em serie do modelo microscópico de condução RFEB representando o volume dos grãos e a interface entre grãos.

A analise dessas curvas foi feita em termos de Admitância Y e a expressão equivalente pode ser expressa utilizando as expressões de $\mathrm{Y}_{\text {grão }}$ e $\mathrm{Y}_{\text {int }}$ que representam a admitância do volume dos grãos e a interface entre grãos dadas por

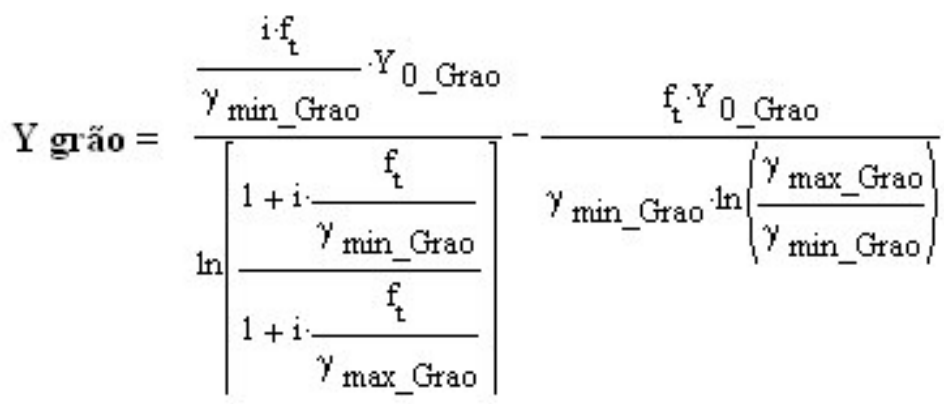

e por

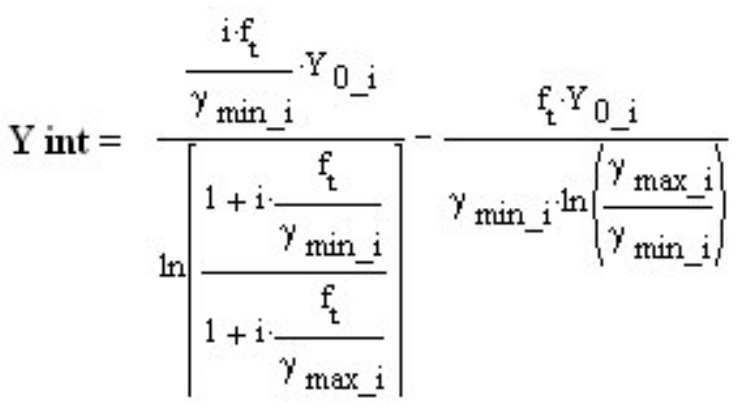

Portanto a equação equivalente pode ser escrita como:

$$
Y_{\text {eq }}=\frac{Y_{\text {grão }} \cdot Y_{\text {int }}}{Y_{\text {grão }}+Y_{\text {int }}}
$$

A equação (6) representa a expressão para a admitância complexa de um sistema com transporte dominado pelo modelo RFEB. 


\section{Discussões dos parâmetros}

\subsection{Admitância}

Imagens de microscopia de força atômica (AFM) mostraram que a estrutura dos filmes de $\mathrm{ZnO}$ depositados por sputtering é granular. As dimensões dos grãos podem variar de $100 \mathrm{~nm}$ a 2,2 $\mu \mathrm{m}$. Nesse contexto, podemos considerar duas contribuições à condutividade do filme: a devida ao interior dos grãos, e a devida a efeitos de interfaces entre eles. O material é considerado cristalino, visto os picos bem definidos que aparecem nas medidas de difração de raios- $\mathrm{X}^{31}$. O esquema abaixo mostra um esboço do modelo que propomos (Fig. 8.1). Em havendo uma distribuição de tamanhos de grãos, ainda que a dispersão não seja grande, e de formatos dos mesmos, podemos considerar, para o transporte eletrônico, o modelo de RFEB (Dyre). Com isso, definimos duas distribuições distintas de barreiras de potencial a serem vencidas durante a migração eletrônica sob campo. Essa representação é dada por dois processos RFEB em série, como mostrado na Fig.7.3.

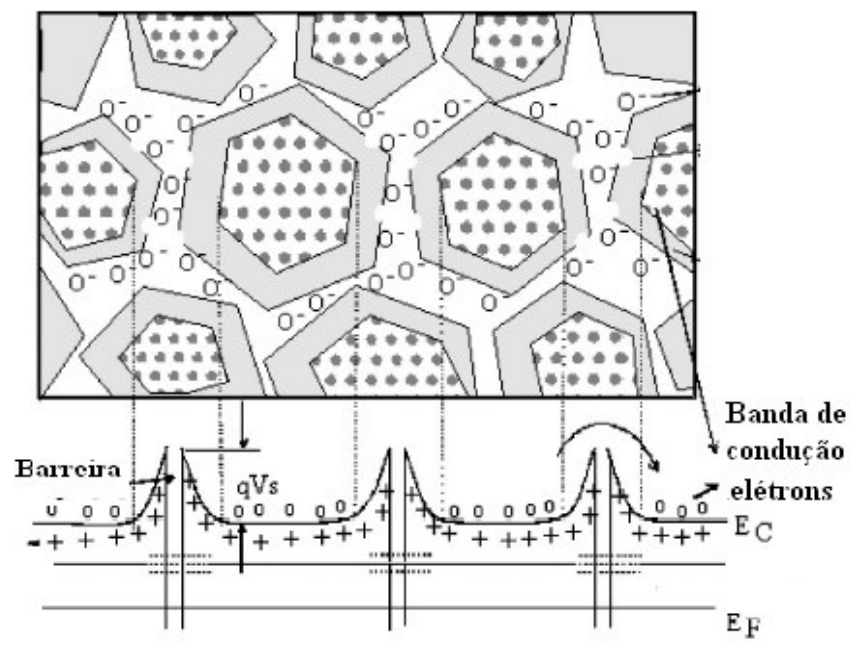

Figura 8.1: Modelo esquemático da microestrutura e correspondente bandas de energia de um óxido semicondutor. 
Os ajustes são mostrados na Fig. 8.2 e os parâmetros de ajuste estão listados na tabela 8.I. Na amostra virgem, a admitância na região de baixas freqüências foi igual a $1,3 \times 10^{-8}(\Omega)^{-1}$ (dado experimental) e $\gamma_{\min }=0,65 \mathrm{KHz}$. Nesse caso $\gamma_{\max }$ é considerado muito grande, e para termos de cálculo colocamos igual a $10^{12} \mathrm{~Hz}$ (freqüência óptica). Esse ajuste se deu praticamente com um só Dyre. As resistências de contato também foram consideradas desprezíveis. Consideramos que o processo foi todo dominado pelo efeito de interface e que a condutividade resultante dos grãos é muito superior, seguindo hipótese de que há uma concentração de íon oxigênio nas interfaces que aumenta a barreira de potencial aos elétrons ${ }^{31}$.
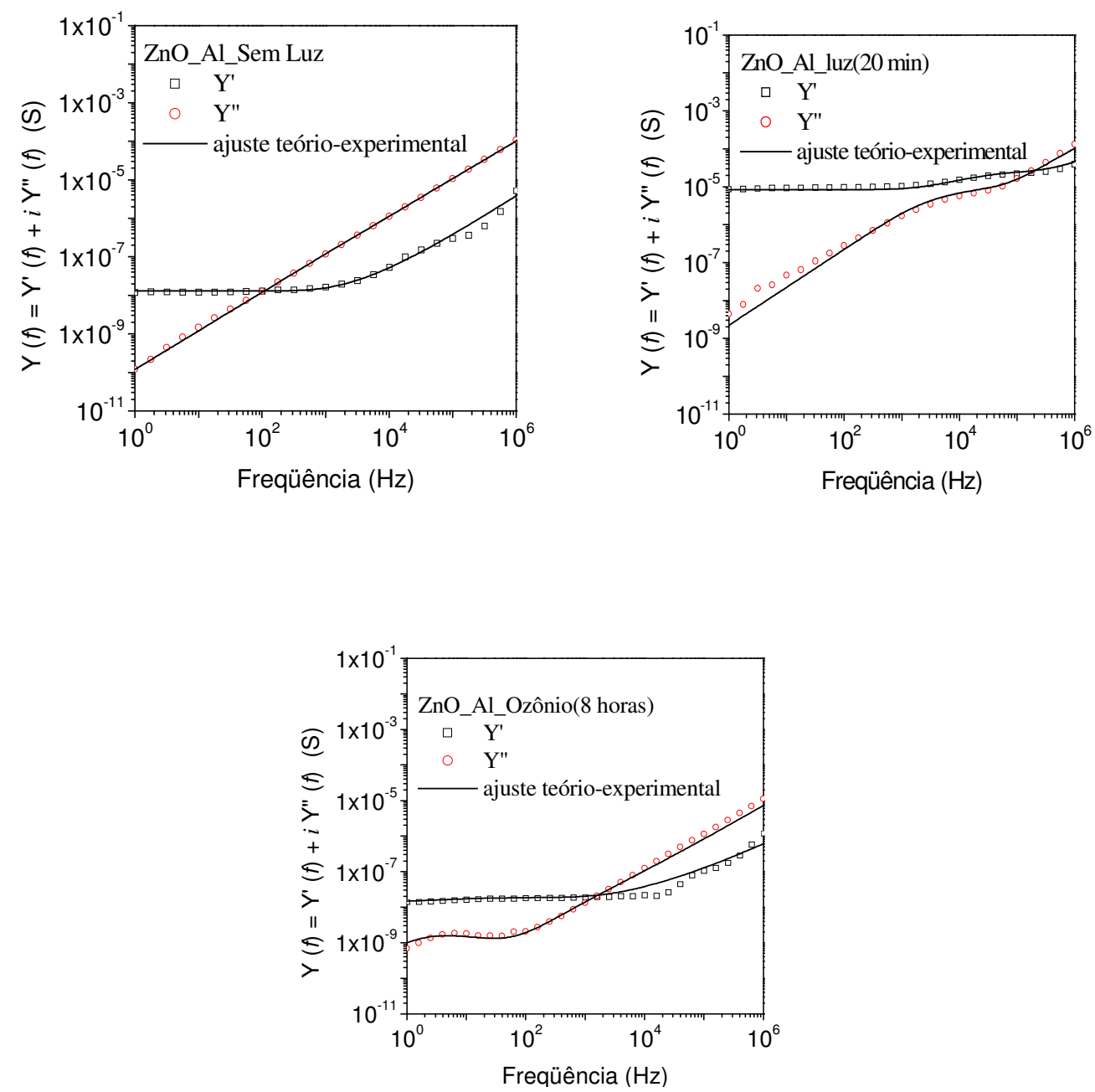
item 7.2.

Figura 8.2: Curvas de admitância apresentando os ajustes teóricos através da equação (6) do 


\begin{tabular}{|c|c|c|c|}
\hline & Sem Luz & 20 min sob luz & 8hs sob ozônio \\
\hline$Y_{\text {dc }}$ (grão) & - & $5 \times 10^{-5}$ & $1,9 \times 10^{-8}$ \\
\hline$\gamma_{\text {mín }}$ (grão) & - & $1 \times 10^{5}$ & $1,7 \times 10^{3}$ \\
\hline$\gamma_{\text {máx }}$ (grão) & - & $1 \times 10^{12}$ & $1 \times 10^{12}$ \\
\hline Kg (grão) & - & 0,5 & 0,1 \\
\hline$Y_{\mathrm{dc}}$ (interf.) & $1,3 \times 10^{-8}$ & $1 \times 10^{-5}$ & $5 \times 10^{-8}$ \\
\hline$\gamma_{\text {mín }}$ (interf.) & $6,5 \times 10^{2}$ & $9 \times 10^{2}$ & 1 \\
\hline$\gamma_{\text {máx } \text { (interf.) }}$ & $1 \times 10^{12}$ & $1 \times 10^{5}$ & $1 \times 10^{2}$ \\
\hline $\mathrm{K}_{\mathrm{i}}$ (interf.) & 2 & 5 & 2 \\
\hline
\end{tabular}

Tabela 8.I: Valores obtidos dos ajustes das curvas de medidas do filme de $\mathrm{ZnO}$ não dopado através da equação (6) do item 7.2.

Quando a amostra foi exposta à luz UV, por 20 minutos, a condutividade dc aumentou de três ordens de grandeza e o formato da curva alterou-se. Consideramos, baseado no estudo feito do artigo publicado por nossos colaboradores ${ }^{31}$, que a luz altera os estados de superfície dos grãos, e a condução do filme como um todo aumenta. $\mathrm{O}$ ajuste feito com a amostra irradiada, mostrou a presença de duas distribuições Dyre. Consideramos que o efeito da luz de alguma forma diminuiu a barreira nas interfaces e a admitância dc é, agora, a soma da resultante das interfaces com a dos grãos: a primeira valendo $10^{-5}(\Omega)^{-1}$ e a segunda $5 \times 10^{-5}(\Omega)^{-1}$. Os respectivos valores de $\gamma_{\min }$ são $0,9 \mathrm{kHz}$ e $100 \mathrm{kHz}$.

No terceiro experimento a amostra foi exposta à atmosfera de ozônio durante 8 horas, e a impedância voltou a aumentar. Nesse caso, foi observado não só o aumento de impedância, reversível, das interfaces, mas também da impedância dos grãos. Para as interfaces obtivemos $\mathrm{Y}_{\mathrm{dc}}=5 \times 10^{-8}(\Omega)^{-1}$ e $\gamma_{\min }=1 \mathrm{~Hz}$, e para os grãos $\mathrm{Y}_{\mathrm{dc}}=1,9 \mathrm{x}$ $10^{-8}(\Omega)^{-1}$ e $\gamma_{\min }=1,7 \times 10^{3} \mathrm{~Hz}$. Infelizmente, dispomos de pouca informação sobre as alterações da morfologia do $\mathrm{ZnO}$ sob $\mathrm{UV}$ e $\mathrm{O}_{3}$, mas os resultados aqui obtidos abrem perspectivas de um estudo mais apurado que correlacione a evolução dos mecanismos de condução envolvidos com as mudanças estruturais do material. No regime de alta 
freqüência, os valores de impedância sempre foram crescentes. Acreditamos que, devido à maior exposição, esse efeito é oriundo do volume dos grãos.

\subsection{Impedância}

Neste item apresentamos os ajustes dos resultados experimentais mostrados no item 6.4.1. Os ajustes feitos pela equação (4), capítulo 7. Antes de apresentar os parâmetros de ajuste, é bom destacar que o I-ZnO é bem condutivo e que a barreira na interface $\mathrm{I}-\mathrm{ZnO} / \mathrm{MEH}-\mathrm{PPV}$ é bem pequena. Ao mesmo tempo, a resistividade do MEH-PPV é considerada relativamente alta. A tabela 8.II apresenta os valores dos parâmetros obtidos através dos ajustes.

Tabela 8.II: Parâmetros obtidos com os ajustes teórico-experimentais variando temperatura e mantendo bias fixa em $15 \mathrm{~V}$ de medidas realizadas em amostra I-ZnO/MEH-PPV/Al através da equação (7.4) .

\begin{tabular}{|l|l|l|l|l|l|l|}
\hline $\begin{array}{c}\text { Temp } \\
(\mathrm{K})\end{array}$ & $\mathrm{R}_{\mathrm{ZnO}}(\Omega)$ & $\mathrm{R}_{\mathrm{MEH}}(\Omega)$ & $\mathrm{C}_{\mathrm{MEH}}(\mathrm{F})$ & $\alpha$ & $\begin{array}{c}\rho_{\mathrm{MEH}}(\mathrm{dc}) \approx \\
\mathrm{AR}_{\mathrm{MEH}} / \ell_{\mathrm{MEH}}(\Omega \mathrm{m})\end{array}$ & $\begin{array}{c}\varepsilon \approx \\
\mathrm{C}_{\mathrm{MEH}} \ell_{\mathrm{MEH}} / \mathrm{A}_{0}\end{array}$ \\
\hline 300 & 100 & $2,2 \times 10^{8}$ & $2,3 \times 10^{-10}$ & 0,001 & $5,5 \times 10^{9}$ & 2,6 \\
\hline 275 & 100 & $2,5 \times 10^{8}$ & $2,3 \times 10^{-10}$ & 0,001 & $5,8 \times 10^{9}$ & 2,8 \\
\hline 250 & 120 & $7,5 \times 10^{8}$ & $2,2 \times 10^{-10}$ & 0,001 & $1,7 \times 10^{10}$ & 2,5 \\
\hline 225 & 100 & $2,8 \times 10^{9}$ & $2,2 \times 10^{-10}$ & 0,001 & $7.0 \times 10^{10}$ & 2,5 \\
\hline 200 & 110 & $2,0 \times 10^{10}$ & $2,2 \times 10^{-10}$ & 0,001 & $5,0 \times 10^{11}$ & 2,5 \\
\hline 175 & 120 & $2,1 \times 10^{11}$ & $2,1 \times 10^{-10}$ & 0,001 & $5,2 \times 10^{12}$ & 2,4 \\
\hline
\end{tabular}

Nesta tabela, observamos que o valor da constante dielétrica permanece entre 2.5 e 3 para todos os valores de temperatura, que está dentro dos valores encontrados na literatura. Observamos também que a resistividade do MEH-PPV também está coerente com os da literatura e, sendo um semicondutor ou isolante, diminui com o aumento da temperatura. O parâmetro relacionado com a distribuição de tempos de 
relaxação $\alpha$ está muito próximo de zero, mostrando que este é um processo típico de Cole-Cole com baixa dispersão de tempos de relaxação. A resistência da interface é praticamente o do próprio $\mathrm{I}-\mathrm{ZnO}$ porque a barreira é muito pequena. Isso é corroborado pela sua independência com a temperatura.

A tabela 8.III mostra os resultados dos ajustes realizados pela equação (4), capítulo 7 , para medidas de impedância em diferentes bias $(15 \mathrm{~V}, 30 \mathrm{~V}$ e $40 \mathrm{~V})$ e mantendo fixa a temperatura em $300 \mathrm{~K}$.

Tabela 8.III: Parâmetros obtidos com os ajustes teórico-experimentais variando bias e mantendo temperatura fixa.

\begin{tabular}{|c|c|c|c|c|c|c|}
\hline $\begin{array}{c}\text { Bias } \\
(\mathrm{V})\end{array}$ & $\begin{array}{c}\mathrm{R}_{\mathrm{Zno}}: 69 \\
(\Omega)\end{array}$ & $\mathrm{R}_{\mathrm{MEH}}(\Omega)$ & $\mathrm{C}_{\mathrm{MEH}}(\mathrm{F})$ & $\alpha$ & $\begin{array}{c}\rho_{\mathrm{MEH}}(\mathrm{dc}) \approx \\
\mathrm{AR}_{\mathrm{MEH}} / \ell_{\mathrm{MEH}}(\Omega \mathrm{m})\end{array}$ & $\begin{array}{c}\varepsilon \approx \\
\mathrm{C}_{\mathrm{MEH}} \ell_{\mathrm{MEH}} / \mathrm{A}_{0}\end{array}$ \\
\hline 15 & 100 & $2,2 \times 10^{8}$ & $2,3 \times 10^{-10}$ & 0,001 & $2,2 \times 10^{9}$ & 2,6 \\
\hline 30 & 90 & $2,6 \times 10^{6}$ & $2,5 \times 10^{-10}$ & 0,001 & $2,6 \times 10^{7}$ & 2,8 \\
\hline 40 & 90 & $5,3 \times 10^{5}$ & $2,4 \times 10^{-10}$ & 0,001 & $5,3 \times 10^{6}$ & 2,7 \\
\hline
\end{tabular}

Nesta tabela observamos uma diminuição no valor da resistividade com o aumento da tensão de polarização $\mathrm{V}_{\text {bias. }}$. Isso, muito provavelmente, deve-se à dependência da condutividade do material com o campo elétrico externo, como, por exemplo, o do efeito Poole-Frenkel ${ }^{29}$. O valor da constante dielétrica entre 2,5 e 3 continua coerente, assim como a não variação da resistência de interface. 


\subsection{Condutividade}

Alternativamente, neste item apresentamos os resultados dos ajustes das curvas de medidas de condutividade complexa apresentadas na figura 6.13, através da equação (5) do item 7.1.2. Realizamos esse ajuste, pois no caso anterior, a dependência da impedância do dispositivo com a temperatura e com o campo foi, única e exclusivamente, devido às propriedades do MEH-PPV. Portanto, o modelo de Dyre enriquece o estudo do polímero, permitindo uma compreensão mais microscópica dos mecanismos envolvidos. A tabela I mostra os valores de $\sigma_{0}, \gamma_{\min }$ e a constante dielétrica do material $\varepsilon$ de medidas realizadas em um dispositivo do tipo IZnO/MEH-PPV/Al mantendo uma tensão de polarização fixa em $15 \mathrm{~V}$ e variando a temperatura da amostra.

Tabela 8.IV: Parâmetros obtidos com os ajustes teórico-experimentais, variando-se temperatura e mantendo-se tensão offset igual a $15 \mathrm{~V}$ e AC $1 \mathrm{~V}$.

\begin{tabular}{|c|c|c|c|c|}
\hline Temp $(\mathrm{K})$ & $\mathrm{R}_{\mathrm{I}-\mathrm{ZnO}} \approx \ell_{\mathrm{I}-\mathrm{ZnO}} / \mathrm{A} \sigma_{\mathrm{I}-\mathrm{ZnO}}(\Omega)$ & $\sigma_{0}(\mathrm{~S} / \mathrm{m})$ & $\gamma_{\min }(\mathrm{Hz})$ & $\varepsilon$ \\
\hline 300 & 100 & $4,5 \times 10^{-10}$ & 780 & 2,5 \\
\hline 275 & 100 & $4,0 \times 10^{-10}$ & 300 & 2,5 \\
\hline 250 & 100 & $1,4 \times 10^{-10}$ & 100 & 2,4 \\
\hline 225 & 100 & $3,0 \times 10^{-11}$ & 40 & 2,5 \\
\hline 200 & 100 & $4,0 \times 10^{-12}$ & 10 & 2,7 \\
\hline 175 & 100 & $2,5 \times 10^{-13}$ & 0,01 & 2,0 \\
\hline
\end{tabular}

Nesta tabela observamos que os parâmetros $\sigma_{0}$ e $\gamma_{\min }$ aumentam com a temperatura e a constante dielétrica $\varepsilon$ mantém um valor entre 2 e 3 para as diferentes temperaturas estudadas. A resistência do I-ZnO permanece com valor de $100 \Omega$.

Podemos construir gráficos do tipo $\ln \left(\sigma_{0}\right)$ vs. $1 / \mathrm{T}$ e $\ln \left(\gamma_{\min }\right)$ vs. 1/T para verificar se estes parâmetros seguem um processo de Arrhenius. A figura 8.3 mostra as curvas obtidas. 

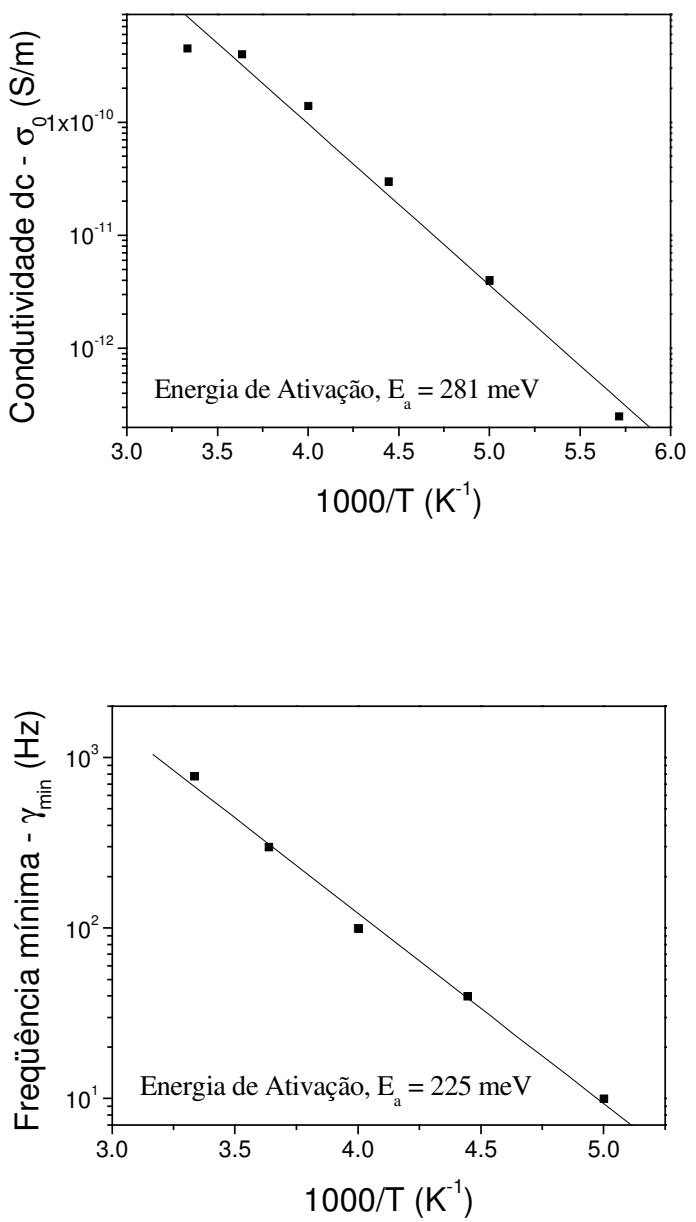

Figura 8.3: Processos ativados por Arrhenius $\sigma_{d c}=\sigma_{0} e^{-E_{a} / k T}$ e $\gamma_{\min }=\gamma_{0} \mathrm{e}^{-\mathrm{E}_{\mathrm{a}} / \mathrm{kT}} \cdot \mathrm{E}_{\mathrm{a}} \mathrm{e} \mathrm{a}$ energia de ativação térmica.

Nesta figura observamos que as duas curvas seguem o comportamento de um processo de Arrhenius com energias de ativação térmica $\left(E_{a}\right)$ com valores próximos e da ordem de meV. Estas energias representam os valores das energias máximas de salto dos portadores para a amostra.

O modelo de Dyre mostra que $\sigma_{0}$ é praticamente proporcional a $\gamma_{\min ,}$ com uma dependência adicional com $\log \left(\gamma_{\min }\right)^{-1}$. Os valores próximos de suas energias de ativação são coerentes com essa dependência. 


\section{Conclusão}

A importância dos materiais poliméricos no cenário de aplicações tecnológicas ganhou um grande impulso depois dos trabalhos de A. G. MacDiarmid, A. J. Heeger e H. Shirakawa, no final dos anos 1970s, que descobriram a condutividade eletrônica nos polímeros conjugados e as facilidades de processamento desses polímeros em forma de filmes. A partir de então, inúmeras propriedades elétricas, ópticas e eletroquímicas foram sendo descobertas, além do aparecimento de novas famílias de polímeros eletrônicos. Entre eles podemos destacar a família dos politiofenos alquilados, das polianilinas e, sobretudo, dos poli(p-fenilenos vinilenos). Esses últimos ganharam um destaque ainda maior pelo alto índice de luminescência exibido, tanto em processos fotoluminescentes quanto eletroluminescentes. $\mathrm{O}$ fenômeno da luminescência nos poli(p-fenilenos vinilenos) (PPV) não é ainda totalmente entendido, mas é muito forte a hipótese de que a recombinação de portadores em éxcitons moleculares é a origem da emissão de luz. A formação de um éxciton, e sua instabilidade, pode ser bem compreendida em cálculos de uma só macromolécula, mas filmes com diferentes estruturas morfológicas, de distintos graus de empacotamentos moleculares, jogam um papel decisivo no caráter e na distribuição dessa perturbação num filme polimérico.

A presente dissertação não atacou esses problemas mais essenciais da origem da luz emitida por um filme de polímero luminescente, mas pretendeu dar uma contribuição ao entendimento de mecanismos de injeção e transporte elétrico em diodos emissores de luz fabricados com o MEH-PPV, um derivado do PPV que emite na cor laranja-avermelhada. Tradicionalmente, o eletrodo transparente injetor de buracos nesses dispositivos é o ITO. O ITO preenche todas as características físicas 
para um bom ânodo. É transparente na região visível, deixando a luz gerada se projetar para fora do diodo; tem boa condutividade e, principalmente, uma função trabalho adequada à injeção de buracos no PPV e seus derivados. O valor de sua função trabalho, próxima a $5 \mathrm{eV}$, coincide com a do HOMO (highest occupied molecular orbital) desses polímeros. A única desvantagem do ITO fica por conta do seu alto poder de contaminação de oxigênio sobre o polímero. É bem conhecida a degradação estrutural das moléculas dos polímeros conjugados devido a processos de fotooxidação. Essa reação é conseqüência do rompimento de ligações duplas ao longo da cadeia devido à incidência de luz (sobretudo uv) deixando em seu lugar um radical livre, e na presença de $\mathrm{O}_{2}$ há a formação de um grupo carbonila. Com isso, a concentração de centros excitônicos recombinantes é diminuída e a luminescência do polímero se apaga. Em nosso trabalho substituímos o ITO por óxido de zinco dopado com índio ( $\mathrm{I}-\mathrm{ZnO})$, que tem características semelhantes à do ITO (condutividade, função trabalho e transparência) e é muito simples de ser depositado. A colaboração que o Grupo de Polímero Bernhard Gross tem com a Faculdade de Ciência e Tecnologia da Universidade Nova de Lisboa (Portugal) está sendo útil nessa substituição porque eles dominam toda a tecnologia de deposição de $\mathrm{ZnO}$, com ou sem dopantes, inclusive a tecnologia de deposição a frio, muito útil para tornar versátil a fabricação de dispositivos eletrônicos poliméricos. Essa dissertação é a primeira a investir nesse sentido e pretende abrir caminho para alternativas tecnológicas para os diodos poliméricos emissores de luz (PLEDs).

Nessa direção, iniciamos nosso trabalho estudando um pouco as propriedades elétricas de filmes finos de $\mathrm{ZnO}$ depositados sobre substratos de quartzo pela técnica de sputtering. Para isso, a ferramenta de análise foi a técnica de impedanciometria. Realizamos uma série de medidas de impedância, real e imaginária, num intervalo de 
$10^{-1} \mathrm{~Hz}$ a $10 \mathrm{MHz}$, em amostras virgens, isto é, logo depois de depositadas, e repetimos as medidas após exposição à luz UV e, em seguida, após exposição a um fluxo de ozônio $\left(\mathrm{O}_{3}\right)$. Esses experimentos foram motivados pelo fato recém-descoberto de que a condutividade do $\mathrm{ZnO}$ aumenta consideravelmente quando sofre ataque de luz uv, mas recupera sua condutividade original quando em contato com atmosfera de $\mathrm{O}_{3}$. Nossas medidas confirmaram esses fenômenos, e através da análise do modelo Random Free Energy Barrier Model, estudamos a evolução dos parâmetros elétricos do filme de $\mathrm{ZnO}$ sob essas condições experimentais. Para explicar os resultados usamos o fato de que o $\mathrm{ZnO}$ tem uma estrutura granular e colocamos dois mecanismos fundamentais de controle de transporte eletrônico: um no interior dos grãos e outro nas interfaces entre eles.

Depois, com eletrodo de I-ZnO construímos diodos de MEH-PPV, tendo alumínio como cátodo, e caracterizamos eletricamente os dispositivos através de medidas de corrente contra tensão, curvas I $v s \mathrm{~V}$, e de medidas de impedanciometria e de condutividade ac. Realizamos as medidas ac para diferentes temperaturas e aplicando-se uma tensão de polarização $\left(\mathrm{V}_{\text {bias }}\right)$ superposta à tensão ac de exploração do sinal. A evolução das curvas, tanto de impedâncias quanto de condutividades, foram coerentes, e usamos os modelos de circuitos equivalentes (Cole-Cole) para ajustar as curvas experimentais. Em seguida, ajustamos as curvas com o modelo Random Free Energy Barrier Model (RFEB) e comparamos os dois ajustes. Apesar de mais simples, e muito usado no estudo de equivalência a dispositivos, a análise do modelo Cole-Cole não dá os detalhes microscópicos fornecidos pelo modelo RFEB. Nossa análise mostrou que o domínio das características elétricas dos nossos PLEDs se deu fundamentalmente pelos mecanismos de transporte da camada ativa do MEHPPV, que se sobrepôs aos de injeção de portadores pelos eletrodos. 
Esse trabalho proporcionou meu contato com todas as técnicas de fabricação de dispositivos PLEDs, desde a síntese do polímero, passando pelas técnicas de fabricação de filmes finos, de deposição de contatos e, até sua caracterização. Também foi extremamente útil no que diz respeito ao conhecimento e domínio, experimental e teórico, da técnica de impedanciometria e dos estudos detalhados de mecanismos de injeção em interfaces metal/semicondutor. $\mathrm{O}$ mundo dos materiais poliméricos, por seu lado, me mostrou a dimensão da dificuldade de correlacionar suas propriedades físicas com a estrutura semicristalina e muito desordenada desses sistemas. No entanto, esses sistemas acabam nos surpreendendo pelos improváveis resultados, quase sempre repetitivos, e nos desafiam a mergulhar cada vez mais nesse complexo mundo amorfo, mas de enorme potencial tecnológico. Fico feliz se essa pequena contribuição mostrar que o $\mathrm{I}-\mathrm{ZnO}$, ou o $\mathrm{ZnO}$ com outro dopante, é uma boa alternativa de ânodo para os dispositivos optoeletrônicos poliméricos. 


\section{Referências}

1 CHIANG C.K.; FINGER C.R.; PARK Y.W.; HEEGER A. J.; SHIRAKAWA H.; LOUIS E. J.; GRAU S.C.; MACDIARMID A.G. Electrical conductivity in doped polyacetylene, Phys. Rev. Let. v. 39, p. 1098 (1977)

2 BURROUGHES J. H.; JONES C.A.; FRIEND R.H. New Semiconductor device physics in polymer diodes and transistors; Nature, v. 335, p. 137 (1988)

3 BURROUGHES J. H.; BRADLEY D.D.C.; BROWN A.R.; MARKS R.N.; MACKAY K.; FRIEND R.H.; BURNS P.L.; HOLMES A.B. Light-emitting diodes based on conjugated polymers; Nature, v. 347, p. 539 (1990) 6, p. 35 (1999)

${ }^{4}$ FRIEND R.H.; BURROUGHES J. H.; SHIMODA T. Polymer diodes; Phys. Word, v. 12, n.

${ }^{5}$ KARG S. et al. Electrical and optical characterization of poly(phenylene-vinylene) light emitting diodes, Synthetic Metals, v. 54 (1-3), p. 427 (1993)

6 SANTOS L.F.; BIANCHI R.F.; FARIA R.M. Electrical properties of polymeric light-emitting diodes, Journal of Non-Crystalline Solids, 338-340, p. 590 (2004)

BIANCHI, RODRIGO FERNANDO Estudo das propriedades eletrônicas $\boldsymbol{e}$ ópticas de filmes e dispositivos poliméricos. São Carlos, 2002, 140 p. Tese (Doutorado) - Instituto de Física de São Carlos, Universidade de São Paulo

8 BRAUN D.; HEEGER A. J. Visible light emission from semiconducting polymer diodes; Appl. Phys. Lett., v. 18, p. 1982 (1991)

9 PARKER I.D. Carrier tunneling and device characteristics in polymer light-emitting diodes; J. Appl. Phys., v. 75, n. 3, p. 1656 (1994)

${ }^{10}$ BASSLER H. et al. Majority carrier injection from ITO anodes into organic light-emitting diodes based upon polymer blends, Synthetic Metals, v. 68, p. 263 (1995)

11 MALLIARAS G.G.; SCOTT J.C. Charge injection and recombination at metal-organic interface Chemical Physics Letters, v. 299, p. 115 (1999)

12 MALLIARAS G.G. et al. Mobility-dependent Charge injection into an organic semiconducting Physical Review Letters, v. 86, n. 17, p. 3867 (2001)

13 ABKOWITZ M.A.; MIZES H. A.; FACCI J.S. Emission limited injection by thermally assisted tunneling into a trap-free transport polymer, Appl. Phys. Lett. v. 66, n. 10, p. 1288 (1995)

${ }^{14}$ BLOM P.W.M.; DE JONG M.J.M.; VLEGGAAR J.J.M. Electron and hole transport in poly(p-phenylene vinylene) devices; Appl. Phys. Lett. v. 68, n. 23, p. 3308 (1996) 
15 BLOM P.W.M.; DE JONG M.J.M.; VAN MUNSTER M.G. Electric-field and temperature dependence of the mobility in poly(p-phenylene vinylene), Physical Review B, v. 55, n. 2, p. R656 (1997)

${ }^{16}$ CONWELL E.M.; WU M.W. Contact injection into polymer light-emitting diodes, Appl. Phys. Lett., v. 70, n. 14, p. 1867 (1997)

17 BLOM P.W.M.; DE JONG M.J.M.; VAN MUNSTER M.G. Electric-field and temperature dependence of the mobility in poly(p-phenylene vinylene), Physical Review B, v. 55, n. 2, p. R656 (1997)

${ }^{18}$ ARKHIPOV V.I. et al Charge injection into light-emitting diodes: Theory and experiment Journal of Applied Physics, v. 84, n. 2, p. 848 (1998)

${ }^{19}$ MALLIARAS G.G.; SCOTT J.C. Charge injection and recombination at metal-organic interface Chemical Physics Letters, v. 299, p. 115 (1999)

${ }^{20}$ Osada T. el al Polymer-based light emitting devices: investigations on the role of the indiumtin oxide (ITO) electrode, Synthetic Metals, v. 96, p. 77 (1998)

${ }^{21}$ ZUGANG L. Organic thin film electroluminescent devices with ZnO:Al as the anode, J. Phys: Condens. Matter, v. 8, p. 3221 (1996)

${ }^{22}$ CDT, página da internet, em www.cdtltd.co.uk.seiko.htm

${ }^{23}$ PHILIPS, página da internet, em $\underline{w w w, p h i l i p s . c o m}$

${ }^{24}$ GREENHAM N.C.; FRIEND R.H., Semiconductor devices physics of conjugated polymers, Sol. Stat. Phys. v. 49, 1 (1995)

25 SANTOS, LUCAS FUGIKAWA Estudo de processos de transporte em dispositivos poliméricos emissores de luz. São Carlos, 2004, 182 p. Tese (Doutorado) - Instituto de Física de São Carlos, Universidade de São Paulo.

${ }^{26}$ FAHLMAN M.; SALANECK W. Surfaces and interfaces in polymer-based eletronics, Surface Science, v. 500, p. 904 (2002).

${ }^{27}$ BRUTTING W.; BERLEB S.; MUCKL A.G. Devices physics of organic light-emitting diodes based on molecular materials Organic Eletronics, v. 2, p. 1 (2001)

${ }^{28} \mathrm{KIM}$ et al. Indio-Tin oxide treatments for single and double layer polymeric light-emitting diodes: The relation between the anode physical, chemical and morphological properties and devices performances J. Applied Phys., v.84, n. 12, p. 6859 (1998)

${ }^{29}$ KAO K.C.; HWANG W. Electrical transport in solids Pergamon Press (1981)

${ }^{30}$ BIANCHI R.F., LEAL FERREIRA G.F., LEPIENSKI C.M, FARIA R.M., Alternating conductivity of polyaniline, J. Chem. Phys. 110, 9, 4602 (1999).

${ }^{31}$ MARTINS, R. et al.Zinc oxide as an ozone sensor. J. App. Phys., 96, 3, 1398-1408, 2004

${ }^{32}$ BENDER M. et al Highly sensitive ZnO ozone detectors at room temperature Jpn. J. Appl. Phys., v. 42, p. L435 (2003) 
${ }^{33}$ DYRE J.C. The random free-energy barrier model for ac conduction in disordered solids, Journal of Applied Physics, v. 64, n. 5, p. 2456 (1988)

${ }^{34}$ DYRE J.C.; SCHRODER T.B. Universality of ac conduction in disordered solids, Review of Modern Physics, v. 72, n. 3, p. 873 (2000)

${ }^{35}$ BÖTTCHER C.J.F, BORDEWIJK, Theory of electric polarization - Vol II, Elsevier Sciet. Pub. Comp., The Netherlands (1978) 